\title{
LOS MANTÍSPIDOS DE LA PENÍNSULA IBÉRICA Y BALEARES (INSECTA, NEUROPTERIDA, NEUROPTERA, MANTISPIDAE)
}

\author{
Víctor J. Monserrat \\ Departamento de Zoología y Antropología Física. Facultad de Biología. José Antonio \\ Nováis, 2, Universidad Complutense, 28040 Madrid (Spain). E-mail: artmad@bio.ucm.es \\ urn:Isid:zoobank.org:author:9D6FB187-2230-42DE-A754-20BE8A8BEB2A
}

\section{RESUMEN}

En esta revisión se recopila toda la información existente sobre las cuatro especies de mantíspidos (Insecta, Neuropterida, Neuroptera: Mantispidae) presentes en la Península lbérica y Baleares. Partiendo de los datos generales conocidos sobre esta familia y estas especies, se incluye una clave de identificación para las especies ibéricas y, en base a esta información ibérica y al nuevo material ahora estudiado, se anotan nuevos datos sobre su morfología, su biología y su distribución geográfica, fenológica y altitudinal en la zona estudiada. Se sugieren al menos dos ciclos anuales en la mayoría de las especies ibéricas. Se anotan nuevos e interesantes datos sobre la biología y el comportamiento reproductor de los imagos y sobre los estadios pre-imaginales de alguna de sus especies, discutiendo algunos previos datos conocidos. Se describe una nueva especie, Mantispa incorrupta n. sp., que parece representar la especie vicariante en el Mediterráneo occidental de Mantispa scabricollis McLachlan, 1875, especie pontomediterránea citada de Europa en las islas griegas de Lesbos, Chios y Rodas. Se propone una nueva sinonimia: Mantispa llliger en Kugelann, $1798=$ Afromantispa Snyman \& Ohl, 2012 n. syn.

$$
\text { urn:Isid:zoobank.org:pub:08343040-B6DB-4212-A810-5ED21648A9FE }
$$

Palabras clave: Insecta; Neuroptera; Mantispidae; Faunística; Biología; Morfología; Península lbérica; Baleares.

\section{ABSTRACT}

\section{The mantispid lacewings in the Iberian Peninsula and Balearic Islands (Insecta, Neuropterida,} Neuroptera, Mantispidae)

In this review all existing information on the four species of mantispids lacewings (Insecta, Neuropterida, Neuroptera: Mantispidae) present in the Iberian Peninsula and Balearic Islands is reported. Based on the known general data on this family and on these species, an identification key to the lberian species is included. On the basis of this lberian information and of the new material now studied, new data on their morphology, biology and geographical, phenological and altitudinal distribution in the study area are noted. It is suggested that there are at least two annual cycles in most of the lberian species. New and interesting data on the biology and reproductive behavior of imagoes and on the pre-imaginal stages of some species are recorded, and some previously known data are discussed. A new species, Mantispa incorrupta n. sp., is described, which seems to represent the vicariant species in the western Mediterranean of Mantispa scabricollis McLachlan, 1875, a Pontomediterranean species recorded from Europe in the Greek islands of Lesbos, Chios and Rhodes. A new synonymy: Mantispa Illiger en Kugelann, 1798 = Afromantispa Snyman \& Ohl, 2012 n. syn. is propossed.

Key words: Insecta; Neuroptera; Mantispidae; Faunistics; Biology; Morphology; Iberian Peninsula; Balearics.

Recibido/Received: 21/04/2014; Aceptado/Accepted: 3/09/2014; Publicado en línea/Published online: 11/12/2014

Cómo citar este artículo/Citation: Víctor J. Monserrat., 2014. Revisión de los mantíspidos de la Península lbérica y Baleares (Insecta, Neuropterida, Neuroptera, Mantispidae). Grael/sia, 70(2): e012. http://dx.doi.org/10.3989/graellsia.2014.v70.115.

Copyright: ( 2014 SAM y CSIC. Salvo indicación contraria, todos los contenidos de la edición electrónica de Grael/sia se distribuyen bajo licencia de uso y distribución Creative Commons Reconocimiento no Comercial 3.0. España (cc-by-nc). 


\section{Introducción}

Para información del lector, anotamos en esta introducción datos generales sobre esta familia que, por su extensión, agrupamos en diferentes apartados relacionados con su caracterización y diagnosis, su morfología, su biología y comportamiento, sus estadios preimaginales y su desarrollo, su registro fósil y su historial relacionado con su Taxonomía y Sistemática y su conocimiento en la Fauna Ibérica.

\section{CARACTERÍSTICAS Y DIAGNOSIS}

La familia Mantispidae es, sin duda, una de las más sorprendentes dentro del orden de los neurópteros, tanto por la curiosa morfología de sus imagos (Figs. 1-9), con sus características patas anteriores raptoras y su convergencia adaptativa con los mántidos (Insecta: Dictyoptera, Mantodea, Mantidae), con quienes comparten caracteres morfológicos y etológicos comunes (Bolívar, 1882; McKeown \& Mincham, 1948; Ulrich, 1965; Poivre, 1976; Aspöck et al., 1980), como por su especialización en el desarrollo de sus estadios larvarios (Figs. 20-22), pues sus larvas (Mantispinae), inicialmente terrestres y activas, buscan arañas, principalmente Lycosidae (tarántulas), en cuyos sacos ovígeros penetran y dentro de ellos se desarrollan con sorprendentes cambios morfológicos (citados en ocasiones erróneamente como hipermetamorfosis). Fueron Brauer (1852a, 1855a, 1855b, 1869), Rogenhofer (1862a, 1862b) y Poujade (1898) quienes iniciaron con sus observaciones la asociación entre las arañas (Lycosa, Dolomedes, Clubonia, Dressodes) y los mantíspidos, curiosa biología que ha sido posteriormente corroborada en muchas otras especies de esta subfamilia.

Otras especies de otras subfamilias (Symphrasinae) están mayoritariamente asociadas a himenópteros sociales y son depredadoras en colonias de abejas y avispas aculeadas (Melitoma, Polistes, Polybia, Synoeca, Megachile) a quienes a veces imitan (mimetismo batesiano polimórfico), y a veces se han obtenido o se las ha encontrado asociadas a pupas de lepidópteros, dípteros o coleópteros. Estadios larvarios de especies de otras subfamilias (Symphrasinae, Calomantispinae) parecen ser más generalistas (predando sobre isópteros, dictiópteros, dípteros, lepidópteros, noctuidos, megaquílidos, escarabeidos, etc.), o la biología de sus fases larvarias es desconocida (Drepanicinae) (información en White, 1841, 1861; Brauer, 1852a, 1855a, 1855b, 1869, 1887; Smith, 1863; Rogenhofer, 1862a, 1862b; Poujade, 1898; Berg, 1899; Main, 1931; Woglum, 1935; Woglum \& Lewis, 1935; Balduf, 1939; Linsley \& MacSwain, 1955; Werner, 1962; MacLeod, 1964; Parker \& Stange, 1965; Werner \& Butler, 1965; Peterson, 1967; Batra, 1972; Popov, 1973; Opler, 1981; Penny, 1982a, 1982b; MacLeod \& Redborg, 1982; Penny \& da Costa, 1983; Gepp, 1984, 1986; Boyden, 1983;
Redborg \& MacLeod, 1985; New, 1986; Lambkin, 1986a, 1986b; Monserrat \& Díaz-Aranda, 1989; Dejean \& Canard, 1990; Hoffman \& Brushwein, 1990, 1992; Stange \& Wang, 1998; Redborg, 1998; Hoffman, 1992, 2002; Redborg \& Redborg, 2000; New, 2003; Ohl, 2004a, 2004b, 2007a; Beck, 2005; Reynoso-Velasco, 2007; Buys, 2008; ReynosoVelasco \& Contreras-Ramos, 2008, 2009, 2010; Kral, 2013 , etc.).

Representan otro ejemplo más de las sorprendentes adaptaciones de los neurópteros a nichos específicos poco ocupados, que les ha permitido sobrevivir evitando o minimizando la competencia y la presión ejercida por nuevos grupos de insectos holometábolos más evolucionados.

Muchos de los datos existentes en esta familia, tanto en la morfología de sus imagos como en la de sus estadios preimaginales, la relacionan con otras familias de neurópteros próximas. En particular con Rhachiberothidae (con quien comparten la presencia del primer par de patas raptoras), y que junto a Berothidae, forman el grupo hermano de Mantispidae y, a su vez, las tres lo son de Dilaridae (Ghilarov, 1962; Aspöck et al., 1980; Schlüter \& Stürmer, 1984; Schlüter, 1986; Mansell, 1986; U. Aspöck, 1992; Aspöck \& Mansell, 1994; Aspöck, 1994, 1995, 2002; Aspöck \& Nemeschkal, 1998; U. Aspöck et al., 2001, 2003, 2012; Haring \& Aspöck, 2004; Engel \& Grimaldi, 2007; Aspöck \& Aspöck, 2010), no sin falta de debates, de controversias y de consenso (Tjeder, 1959, 1968; MacLeod \& Adams, 1967; Whalley, 1980, 1983; Lambkin, 1986a, 1986b; Minter, 1990; Willmann, 1990, 1994; Redborg, 1998; Grimaldi, 2000; Archibald \& Makarkin, 2004; Grimaldi \& Engel, 2005; Monserrat, 2006, 2014; Winterton et al., 2010 , etc.), compartiendo, estas familias, como decimos, muchos elementos anatómicos, morfológicos y/o biológicos.

Con unas 561 especies descritas y numerosas sinonimias propuestas, unas 420 especies actuales pertenecientes a unos 44 géneros son conocidas. $\mathrm{Su}$ sistemática está dividida en cuatro subfamilias habitualmente reconocidas, que se diferencian en caracteres del pronoto y mesonoto, número y morfología de las uñas en los tarsos anteriores, y naturalmente en su morfología alar, genital y su biología: Symphrasinae (con unas 32 especies de tres géneros del Nuevo Mundo), Drepanicinae (con unas 37 especies de cuatro géneros de Sudamérica y Australia), Calomantispinae (con unas 10 especies de dos géneros del sur de Norteamérica, Centroamérica y este de Australia) y Mantispinae (con unas 334 especies de numerosos géneros de las zonas intertropicales y templadas de todos los continentes, entre el $50^{\circ} \mathrm{N}$ y $45^{\circ} \mathrm{S}$ ) (Lambkin, 1986a, 1986b; New, 1989; Ohl, 2004a, 2007a, 2012). Todas las especies europeas (y lógicamente ibéricas) pertenecen a la subfamilia Mantispinae. 
Esta curiosa y cosmopolita familia incluye especies mayoritariamente habitantes de zonas tropicales, subtropicales, y en menor medida en zonas templadas, a veces boscosas, en ocasiones con muy escasa y aislada vegetación, a veces están presentes en medios térmicos, secos y espacios abiertos y soleados, y pocas veces en zonas eremiales, xéricas y subdesérticas (New, 1986), y están ausentes en climas fríos, aunque se han citado hasta $2.200 \mathrm{~m}$ en zonas de alta montaña (ahora citamos material recolectado a $4.600 \mathrm{~m}$ ), y en general son muy locales y normalmente poco frecuentes, aunque a veces pueden llegar a ser puntualmente abundantes (Hungerford, 1936; Lambkin, 1986a, 1986b). Con cierta frecuencia acuden a la luz (New \& Haddow, 1973; Rice, 1986; Hoffman, 2002; New, 2003; Ábrahám \& Mészáros, 2006), y aunque son insectos mayoritariamente de actividad diurna, sus ojos poseen elementos tanto a visión por superposición, como por aposición (Eggenreich \& Kral, 1990; Kral et al., 1990, 2000; Kral, 1990, 2013).

\section{MORFOLOGÍA}

Sus especies alcanzan tamaños pequeños a grandes (longitud de alas anteriores entre 3,6-35,0 mm). Son de morfología inconfundible (Figs. 1-9). Normalmente son de coloración parda, a veces críptica o disruptiva con el entorno (verdes o con manchas), o marcadamente mimética (imitando hojas), o falsamente aposemática (imitando avispas), e incluso vistosamente coloreadas o con alas fuertemente manchadas.

Dejando al margen las subfamilias no europeas, de las que sólo haremos alguna referencia cuando creamos conveniente, y circunscribiéndonos a las especies de nuestras latitudes, los adultos son insectos que alcanzan tamaños medianos (Figs. 1-9), con longitud de las alas anteriores entre 7-22 mm; en las especies ibéricas: machos / hembras de M. styriaca: 8,9-14,3 mm / 6,8-15,0 mm; M. perla: 14,0-15,0 mm / 11,2-14,0 mm; M. aphavexelte: $6,9-14,3 \mathrm{~mm} / 6,8-15,2 \mathrm{~mm}$; $M$. incorrupta n. sp.: $6,4-7,9 \mathrm{~mm} /$ 9,5-12,8 mm). Su complejo y aleatorio desarrollo larvario y los recursos disponibles durante este periodo hacen que exista una gran variabilidad en el tamaño de los adultos (incluso en una misma especie, población y/o puesta), y dentro de ello es frecuente un cierto dimorfismo sexual (Kuwayama, 1924; Lucchese, 1956; Handschin, 1959a; Poivre, 1981a), siendo habitualmente mayores las hembras (también en otros géneros, especialmente en Calomantispinae se han descrito diferencias entre los sexos en coloración, venación, tamaño del pterostigma, antenas, etc.). A pesar de esta diferencia de tamaño, que puede alcanzar hasta el doble entre unos ejemplares y otros, se suelen conservar las proporciones de los elementos externos del cuerpo, aunque pueden apreciarse algunas diferencias en la venación alar, especialmente en el número de Sectores del Radio en ciertas especies (Lambkin, 1986a, 1986b).
$\mathrm{Su}$ tegumento en general es pardo, a veces de tono amarillento y/o con manchas pardas o negruzcas sobre los escleritos (Figs. 1-9), y en general es muy poco piloso. La cabeza es pequeña, pero extremadamente móvil, porta dos grandes e iridiscentes ojos (Eggenreich \& Kral, 1990; Kral et al.1990, 2000; Kral, 1990, 2013), en M. styriaca con unos 3.500 omatidios y casi un $60 \%$ de la superficie total de una esfera, y carecen de ocelos (Figs. 1-9). Las piezas bucales poseen mandíbulas alargadas y masticadoras, muy externalizadas y adaptadas a su régimen depredador. Palpos maxilares de 5 segmentos y palpos labiales de 3 , con lígula bien desarrollada. Normalmente las antenas son cortas, mucho más cortas que las alas (más largas en algunos géneros como Mimetispa), muy móviles (y en permanente movimiento, especialmente durante la caza y el cortejo). Escapo y pedicelo bien desarrollados, y flagelo con artejos moniliformes, a veces lamelados o expandidos lateralmente, como en Nampista o Euclimacia (Ohl, 2009; Snyman et al., 2012), y frecuentemente es más largo el primero (Fig. 43). Portan abundante setación, distinta según la zona dorsal o ventral de los flagelómeros (Fig. 43), que son normalmente pardos y, en ocasiones, alternadamente pigmentados de pardo y más pálido a lo largo de su longitud (Figs. 1-9, 43). Se han citado frecuentes casos de teratologías en ellos (Poivre, 1981a, 1981b, 1982b). Pueden existir diferencias en el número de flagelómeros, incluso dentro de la misma especie, incluso población. En la subfamilia (Mantispinae) y en las especies del género Mantispa oscila entre 24-36, y en sus especies europeas oscila entre 24-29, sin que exista dimorfismo significativo (machos: 25-28; hembras: 24-29) (Lucchese, 1956, Poivre, 1978, 1981a, 1983), aunque en Mantispa incorrupta n. sp., este número parece oscilar en función del sexo y es algo menor (machos: 22; hembras: 23-26), y sólo en el género Nampista, con 37-38 flagelómeros en sus antenas, se ha citado dimorfismo sexual en la forma de los flagelómeros (Ohl, 2009).

El tórax es poco piloso. Destaca el pronoto, en general enormemente alargado y tubular, y posee dos marcadas prominencias laterales (Figs. 1-9, 23, $24,34,35,39,40,44,45)$ que han sido citadas como evidencias externas de apodemas para la insercción muscular del primer par de patas, pero sorprendentemente, nosotros hemos detectado que a ellos arriban troncos traqueales, sugiriendo que también porten los correspondientes estigmas del segmento protorácico, lo cual no dejaría de resultar peculiar y excepcional. A veces el pronoto es de aspecto granuloso y portador de pequeños tubérculos en la base de las setas (Figs. 44, 45).

El pterotórax es generalmente mucho más ancho y corto que el protórax, que es generalmente muy alargado (Figs. 1-9) (en todas las especies europeas salvo en el género Nampista). Sus patas son marchadoras, estando las anteriores muy modificadas y adaptadas 


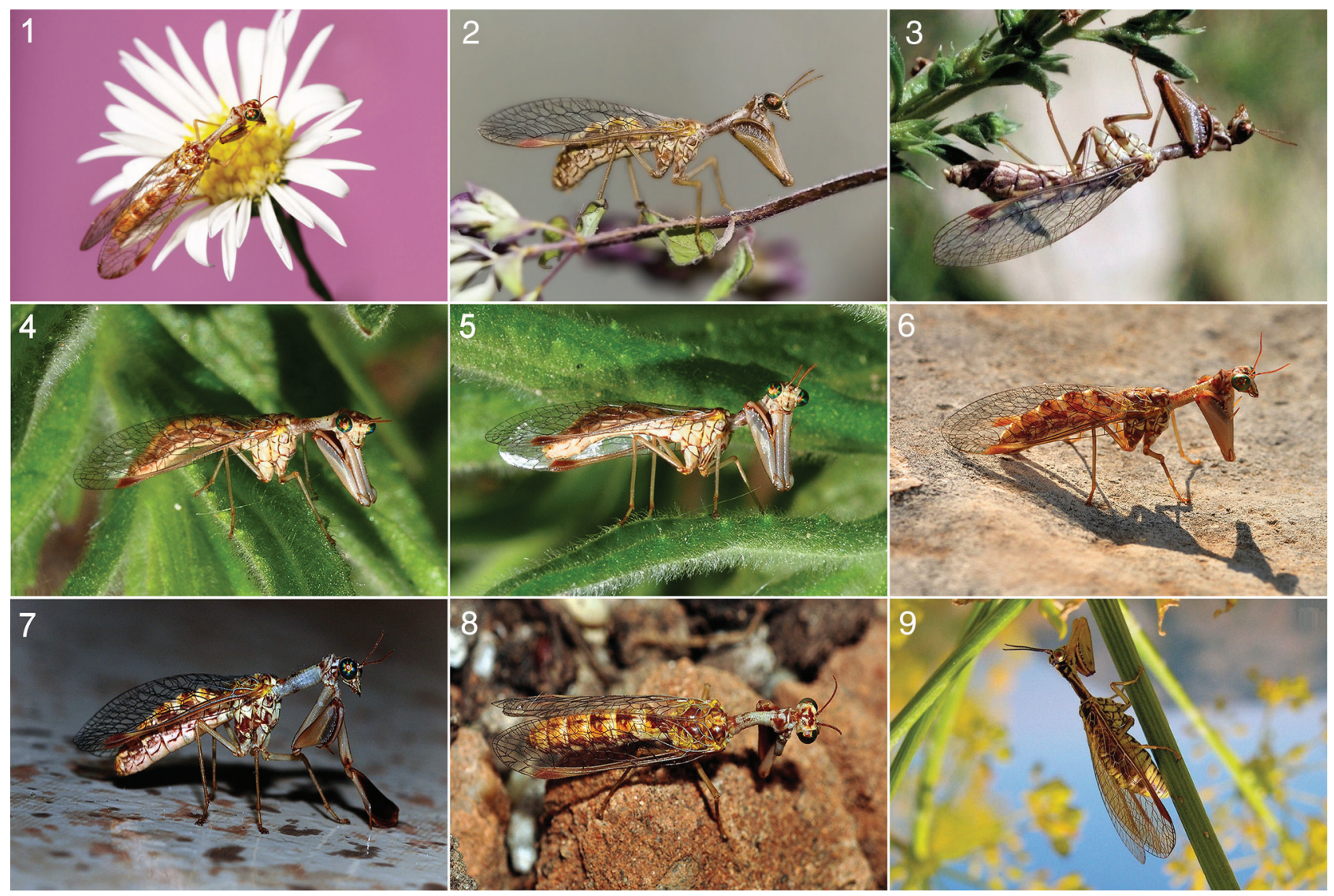

Figs. 1-9.- Aspectos de mantíspidos ibéricos en su ambiente natural: 1-8, Mantispa styriaca; 9, Mantispa perla. Foto 1 de Jorge Almeida (http://www.flickr.com/photos/superegnum/); 2 de Enrique Gil Alcubilla; 3 de Isidro Martínez; 4-8 de Francisco Rodríguez (http://faluke.blogspot.com.es/search/label/neuroptera); 9 de Marcello Romano, de Nicoli Aldini et al., 2012.

Figs. 1-9.- Habitus of Iberian mantispids in their natural habitats: 1-8, Mantispa styriaca; 9, Mantispa perla. Photo 1 by Jorge Almeida (http://www.flickr.com/photos/superegnum/); 2 by Enrique Gil Alcubilla; 3 by Isidro Martínez; 4-8, by Francisco Rodríguez (http://faluke.blogspot.com.es/search/label/neuroptera); 9 by Marcello Romano, from Nicoli Aldini et al., 2012.

a la caza y, normalmente, éstas no se emplean para la locomoción habitual (corrientemente caminan como insectos funcionalmente tetrápodos) (Figs. 1-9), y a pesar de ello, poseen excelente capacidad de agarre al sustrato, incluso sobre superficies lisas, y una enorme adaptabilidad corporal a muy diferentes posiciones, especialmente ante los movimientos de una potencial presa (Figs. 1-9). Las patas anteriores son prensiles y raptoras, extremadamente especializadas (Figs. 1-9, 25, 36, 41, 46, 47). Poseen inserción en la región anterior del protórax y tienen coxas extremadamente alargadas, fémur enormemente modificado para la caza y captura de las presas, estando aplanado lateralmente y es muy robusto, con varias fuertes espinas (generalmente tres) alternadas con otras menores sobre el margen ventral, siendo la proximal (buttoir) de mucho mayor tamaño y mesial a la tibia cuando ésta está retraída sobre el fémur, a diferencia de las restantes que quedan en posición externa (Figs. 25, 36, 41, 46, 47). Las espinas portan en su extremo receptores táctiles (órganos de Stitz) derivados de sensilas tricoideas especializadas (Poivre, 1974). Algunos géneros como Plega poseen hileras de rígidas setas en vez de espinas. En estas patas anteriores la tibia también está muy modificada, y es arqueada y opuesta a estas espinas, actuando como pinza para asir a las presas (Figs. 25, 36, 41, 45, 46, 47). Tarsos de 5 segmentos acabados en una única uña (algunos géneros como Plega poseen una espina distal en el primer tarsómero). Resto de las patas marchadoras, gráciles y alargadas (Figs. 1-9), con tarsos de 5 segmentos acabados en dos uñas curvas, simples o polidenticuladas.

Sus alas son subiguales, estrechas, alargadas, algo más largas las anteriores, y de ápices redondeados (Figs. 10, 26, 37, 42, 48). Generalmente son hialinas, iridiscentes, a veces levemente coloreadas de pardo amarillento ahumado, y siempre con pterostigma aparente y pigmentado de pardo o pardo-rojizo-rosáceo. Son portadoras de venación bastante simplificada y similar en ambas alas (Fig. 10), y tricosoros ausentes (pequeños espesamientos sobre el margen alar situados en el extremo de las bifurcaciones de las venas longitudinales) (Figs. 10, 26, 37, 42, 48). Venación escasa, con venillas costales poco numerosas y no bifurcadas. Vena C y Sc coalescentes antes del pterostigma, Sc y R casi confluyentes a través de una venilla transversal bajo el pterostigma, aunque alcanzan el margen alar separadamente (Figs. 10, 26, 37, 42, 48). 


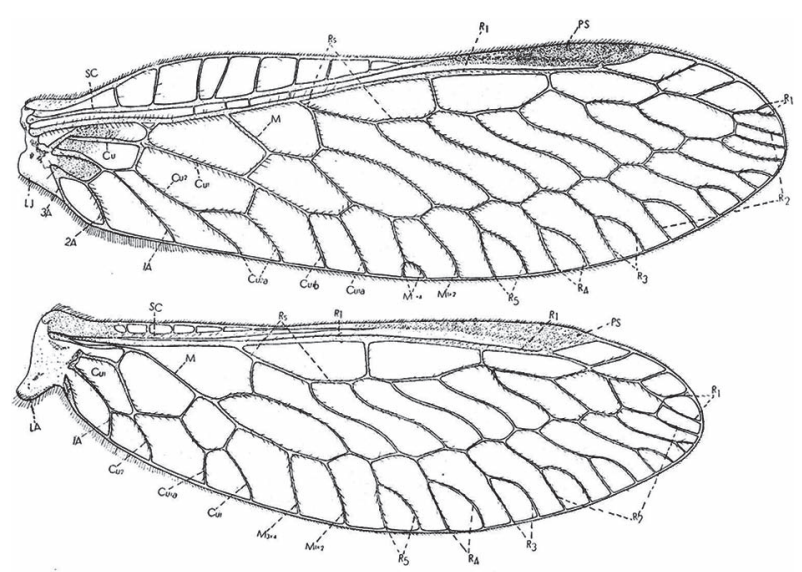

Fig. 10.- Terminología alar de Mantispa perla, de Lucchese (1956). A: anal; Cu: cubital; LA: lóbulo anal; LJ: lóbulo yugal; M: mediana; PS: pterostigma; R: radio; Rs: sector del radio; Sc: subcostal.

Fig. 10.-Wing terminology of Mantispa perla, from Lucchese (1956). A: anal; Cu: cubital; LA: anal lobe; LJ: yugal lobe; $\mathrm{M}$ : median; PS: pterostigme; $\mathrm{R}$ : radius; Rs: radial sector; Sc: subcostal.

Existen varios Sr y una única serie de venillas gradiformes está presente en ambas alas. Pterostigma alargado o triangular, y muy bien definido y coloreado. Esta coloración suele prolongarse en las venas Sc-R, que son más oscuras, y el resto de la venación es parda y la membrana hialina y muy iridiscente en ambas alas, a veces de aspecto ahumado o más oscura en su zona basal (Fig. 37). Su terminología es variable según autores (Ferris, 1940; Lambkin, 1986a, 1986b; Aspöck et al., 1980; Hoffman, 1992; Snyman et al., 2012, etc.), y anotamos en la fig. 10 la adoptada por Lucchese (1956). Habitualmente las mantienen plegadas "en tejadillo" sobre el abdomen (Figs. 1-9), y al margen del vuelo, son utilizadas como elemento de reconocimiento, apaciguamiento y atracción sexual durante el cortejo, y en situaciones de peligro, a veces saltan y se dejan caer al suelo y, a diferencia de otras familias de neurópteros, no adoptan por un breve tiempo un comportamiento de tanatosis con las alas plegadas y así disuadir o mitigar el interés del potencial depredador. Aunque son buenos voladores, sus vuelos en general son cortos y breves.

Su abdomen es algo más corto que sus alas (Figs. 1-9), posee 10 segmentos con tergos y esternos bien definidos y amplias y extensibles áreas pleurales.

La genitalia masculina y femenina es algo variable según las subfamilias y géneros, aunque es de destacar una marcada uniformidad general y, a diferencia de muchas otras familias de neurópteros, las diferencias en la genitalia masculina son en ocasiones muy sutiles y muy poco diversicadas (Figs. 27-33, 49-53), presentando incluso cierta variabilidad intraespecífica, hechos que complican la taxonomía, la diagnosis inequívoca y las identificaciones incuestionables en numerosos ejemplares y taxa. Aún menores diferencias hallamos en el caso de las hembras, cuya terminalia resulta en general sorprendentemente homogénea, ocasionalmente las hembras poseen un largo ovopositor (Plega, Symphrasinae), y ciertos elementos en la forma del margen caudal del $8^{\circ}$ esternito o en la espermateca han sido descritas para diferenciar géneros y/o especies europeas (Lucchese, 1956; Poivre, 1981a, 1982b; Aspöck \& Aspöck, 1994), pero a veces resultan muy tediosas y subjetivas o generalmente ineficaces en la definición de algunos taxa, al menos europeos (ej. Mantispa hauseri Poivre, 1982), por lo que en nuestro caso, salvo algunos elementos (Figs. 54-58) no han sido considerados. En las especies que nos competen, la genitalia masculina de las especies ibéricas se anota en las figs. 27-33, 49-51, siguiendo la terminología de Aspöck et al. (1980), y algunos elementos de la genitalia femenina se anotan en las figs. 54-58.

\section{BIOLOGÍA Y COMPORTAMIENTO}

Con respecto a su biología, comentemos que, en general, sus imagos son muy activos, ágiles, buenos voladores, pero como hemos indicado, de vuelos cortos y breves, y por ello con escasa capacidad de dispersión. Se han citado especies de actividad nocturna (Hoffman, 2002), y algunos autores los han recolectado masivamente a la luz, especialmente en zonas tropicales (Tjönneland, 1962; New \& Haddow, 1973; Bowden \& Morris, 1975; Rice, 1986) [y también nosotros, ej.: Pseudoclimaciella tropica (Westwood, 1852) en Guinea Ecuatorial], pero en nuestras latitudes, aunque citamos algunos ejemplares recolectados a la luz, es un hecho poco frecuente (ya hemos citado anteriormente su capacidad de visión tanto diurna, como nocturna).

Las especies imitadoras de himenópteros acuden con frecuencia a las flores y se agregan en ellas con marcada actividad diurna, habiéndose citado como potenciales polinizadoras (Smith, 1934; Tjeder, 1963; Batra, 1972; Opler, 1981; Redborg \& MacLeod, 1983; Boyden, 1983; New, 1986; Lambkin, 1987; Dejean \& Canard, 1990; Hoffman, 1992), y en ocasiones han sido observadas alimentándose de fluidos, exudados vegetales y nectarios florales y extraflorales (Keeler, 1978; Hoffman, 2002), y sobre flores amarillas de papilionáceas hemos hallado numerosos ejemplares de Zeugomantispa minuta (Fabricius, 1775) y Z. compellens (Walker, 1860) en Veracruz (México), y a veces son aparentemente atraidas por frutas (Parfin, 1958). En nuestra fauna han sido pocas veces halladas sobre flores (Fig. 1), aunque Nicoli Aldini et al. (2012) también citan Mantispa perla sobre flores amarillas en Italia (Fig. 9), aunque más bien las deben utilizar como plataforma de caza, de forma similar a lo observado en Mantodea o Thomisidae (Snyman et al., 2012), aunque en $M$. styriaca ha sido citada cierta "supuesta" cripsis entre su pigmentación externa y las inflorescencias de Quercus (Séméria, 1992). 
Al margen de lo anteriormente anotado, su régimen alimenticio mayoritario es depredador generalista (depredadores al acecho) de pequeños insectos voladores de tegumento no demasiado esclerificado, $y$ otros insectos no malolientes, generalmente dípteros, microlepidópteros e himenópteros no aculeados (tampoco aprecian las hormigas). A veces se han citado presas de mayor tamaño (incluidos imagos de mirmeleónidos o crisópidos: Hungerford, 1936; Poivre, 1976; Aspöck, 1999), bien voladores o de movimientos activos. Sus técnicas de caza al acecho implican una excelente visión esteroscópica (Kral, 1990; Mayer \& Kral, 1993; Kral et al., 2000; Kral, 2013) y la captura es precedida por movimientos previos de las antenas y laterales del pronoto y la cabeza para la previsión de las distancias y ángulos de ataque para acertar con mayor probabilidad de éxito (Figs. 4, 5) en el rápido movimiento de sus patas anteriores raptoras que, previos "atléticos" estiramientos, se proyectan sobre las presas a velocidades sorprendentes (Kral, 2013). Asida la presa es posteriormente devorada, y más tarde el aseo de sus patas anteriores, tarsos de las restantes y antenas es obligatorio.

A veces los imagos se encuentran próximos a zonas infestadas por homópteros o véspidos, donde pueden verse atraidas sus potenciales presas y con frecuencia muestran señales de agregación (Dejean \& Canard, 1990), y varios ejemplares pueden ser recolectados en una misma rama o árbol, quizás también por atracción sexual o agregación en zonas específicamente elegidas para efectuar las puestas (Kral, 2013).

En condiciones de laboratorio (Lucchese, 1956; Davidson, 1969; Brushwein \& Culin, 1991) no son infrecuentes los casos de canibalismo (a veces mutuo entre ambos sexos, donde las patas anteriores del contrario tienden a ser mutiladas en los primeros ataques), $\mathrm{y}$ aunque hemos recolectado ejemplares mutilados (que podrían haber perdido una de sus patas anteriores en este proceso), también lo demostramos en accidentes de caza (ver datos anotados en M. styriaca). No obstante el canibalismo parece un hecho poco probable en la naturaleza, ni siquiera en periodos de puesta donde puede existir cierta agregación de ejemplares.

$\mathrm{Su}$ longevidad como imagos parece ser mayor en hembras que en machos (quizás por eso parecen más frecuentes), y oscila entre 4-6 semanas, hasta 67 días según Hungerford (1936) para una hembra de M. interrupta, 81 días para una hembra de Zeugomantispa viridis, según Parfin (1958), e incluso 114 días en Dicromantispa uhleri, según Redborg \& MacLeod (1985), hechos que podría sugerir su posibilidad de hibernación en estado adulto, y en nuestras latitudes se han citado unos dos meses en las hembras y unos 40 días en los machos de Mantispa perla (Lucchese, 1956) y nosotros hemos observado longevidades en cautividad de $54,37,36,26,16,8$ y 8 días para hembras de $M$. styriaca. Puntualmente han sido citadas larvas de Diptera (Sarcophagidae) parásitas de sus imagos (Parfin, 1958).
Sobre su comportamiento reproductor, en nuestras latitudes el cortejo y la cópula han sido observados a primeras horas del día (de 8-9 h a 12-13 h). Como corresponde a insectos depredadores, el cortejo no es demasiado largo (15-30 minutos, hasta 60 minutos en algunos géneros tropicales: Trichoscelia Westwood, 1852), durante el cual el macho, y a una distancia prudencial, mueve intensamente las antenas y el abdomen hacia arriba-abajo, y efectúa diversos movimientos alternativos de extensión de las patas anteriores, por lo que la visión es un elemento esencial en esta fase (Redborg \& MacLeod, 1985; Kral, 2013), y sin duda las características manchas existentes en los fémures anteriores deben representar importantes elementos en el reconocimiento visual entre los ejemplares (Figs. 25, 36, 41, 46, 47). Como se ha observado en los machos de otras familias de neurópteros, se realizan movimientos con vibración de las alas para hacerse reconocer por la hembra, y no sólo vía visual, sino probablemente también auditiva/acústica, de hecho Riek (1967) describe concentraciones de microtriquias, elementos probablemente auditivos, en la base de las alas anteriores en esta familia, y así las hallamos en nuestras especies (Figs. 26, 37, 42, 48). La hembra, hasta este momento inactiva y pasiva observadora, de estar receptiva, responde con similares movimientos (Main, 1931; Hungerford, 1936; McKeown \& Mincham, 1948; Batra, 1972; Redborg \& MacLeod, 1985; Dejean \& Canard, 1990; Hoffman, 1992; Brushwein et al., 1995a; Redborg, 1998; Reynoso-Velasco \& Contreras-Ramos, 2010). También se ha citado en los machos de nuestra Mantispa styriaca, y en otras especies de éste y otros géneros, la presencia de glándulas intertergales eversibles situadas en posición variable según los géneros, bien en la región dorsal del $5^{\circ} \mathrm{y}$ $6^{\circ}$ segmento abdominal o entre los terguitos $3^{\circ}-4^{\circ} \mathrm{y}$ $4^{\circ}-5^{\circ}$, que podrían evidenciar la secreción de feromonas de apaciguamiento, reconocimiento y atracción para la hembra (Eltringham, 1932; Lucchese, 1955, 1956; Riek, 1970; Batra, 1972; Poivre, 1976, 1982a, 1982b, 1986; Dejean \& Canard, 1990; Güsten, 1996), y que el movimiento rítmico, tanto del abdomen como de las alas, contribuyen a difundir.

La cópula se efectúa inicialmente vientre contra vientre y posteriormente oponiendo los abdómenes quedando finalmente ambos sexos mirando en dirección contraria (Lucchese, 1955, 1956) (Figs. 11-13), y sin que cese su instinto de caza durante la cópula, macho incluido (según hemos observado, este instinto no cesa tampoco durante la puesta). Pocas veces se ha observado canibalismo, sino en condiciones experimentales de hacinamiento o con marcadas diferencias de tamaño entre ambos sexos. El periodo de cópula dura entre 20-30 minutos y tres horas en especies de Mantispa (McKeown \& Mincham, 1948; Lucchese, 1955, 1956; Redborg \& MacLeod, 1985; Brushwein et al., 1995a; Redborg, 1998), aunque cópulas de 40-60 minutos y de hasta $24 \mathrm{~h}$ se han citado en otros géneros 

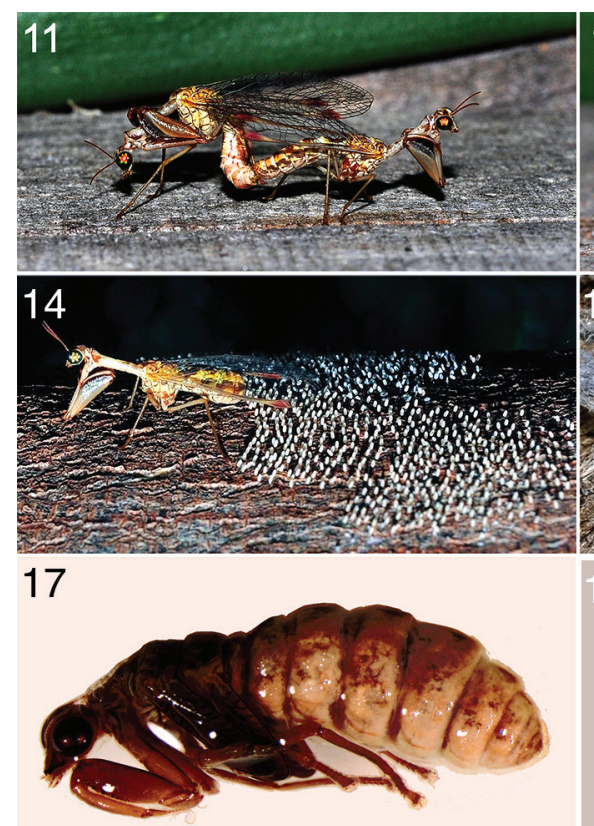
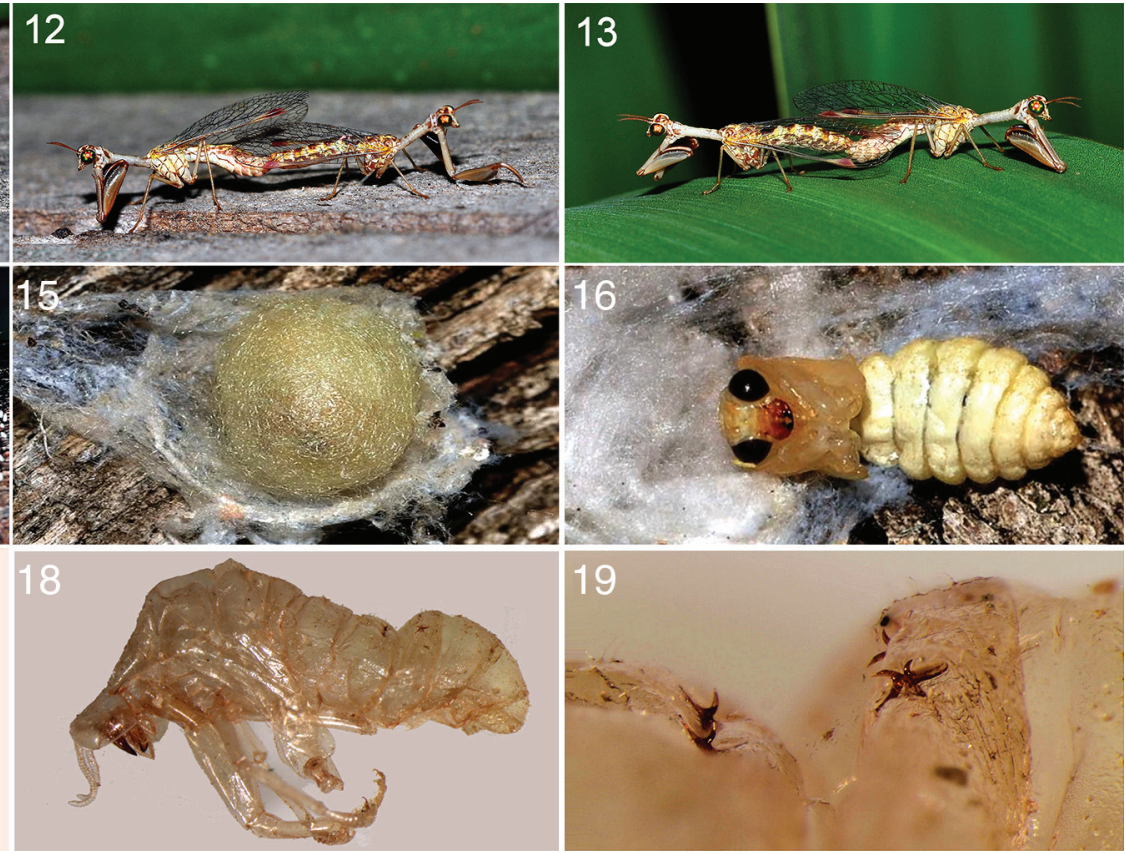

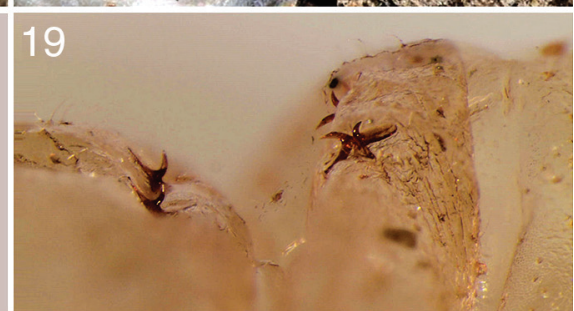

Figs. 11-19.- Aspectos del apareamiento, puesta y pupa de Mantispa styriaca. 11-13, apareamiento; 14, puesta; 15, capullo pupal; 16, prepupa; 17, pupa madura; 18, exuvia pupal; 19, dentículos abdominales de la pupa. Fotos 11-16 de Francisco Rodríguez (http://faluke.blogspot.com.es/search/label/neuroptera).

Figs. 11-19.- Aspects of mating, laying and pupa of Mantispa styriaca. 11-13, mating; 14, laying; 15, pupal cocoon; 16, prepupa; 17, mature pupa; 18, pupal exuvie; 19, pupal abdominal denticles. Photos 11-16 by Francisco Rodriguez (http://faluke.blogspot. com.es/search/label/neuroptera).

y especies (Batra, 1972; Redborg \& MacLeod, 1985; Dejean \& Canard, 1990), periodo tras el cual un espermatóforo gutiforme y blancuzco, amarillento o rosáceo queda adherido al extremo abdominal femenino (Lucchese, 1955, 1956), y que tras la separación y el obligado aseo, es inicialmente portado por la hembra y se reabsorbe, produciéndose la inseminación normalmente en las próximas 24-48 h, y desprendiéndose posteriormente los posibles restos del espermatóforo. Tras 2-5-8 días se inicia la ovoposición, generalmente a la caída del sol, aunque también hemos observado hembras de $M$. styriaca efectuando puestas durante la mañana. La transmisión del esperma debe ser suficientemente abundante a tenor de que una hembra aislada tras la cópula produce enorme cantidad de huevos fértiles durante un prolongado periodo de tiempo (Hungerford, 1936 anota para Dicromantispa interrupta 4.768 huevos depositados en 41 días).

\section{ESTADIOS PREIMAGINALES Y DESARROLLO}

En esta familia, de las 420 especies conocidas, hay referencias o han sido descritos estadios juveniles y/o huevos de especies asignadas a Mantispa styriaca, M. japonica, M. perla, M. capeneri, Leptomantispa pulchella, Campion vittatus, Dicromantispa uhleri, D. sayi, D. interrupta, D. fuscicornis, (Paramantispa decorata $)=P$. ambusta, Climaciella brunnea, $(C$. magna $)=$ Tuberonotha strenua, Zeugomantispa viridis, Trichoscelia sp., T. santareni, T. myrapetrella,
Eumantispa harmandi, Plega signata, P. banksi, P. dactylota, P. yucatanae, P. melitomae, Nolima pinal, Symphrasis sp., S. signata, S. varia y Austromantispa imbecilla (Brauer, 1852b, 1855a, 1855b, 1869, 1887; Rogenhofer, 1862a, 1862b; Poujade, 1898; Lewis, 1911; Withycombe, 1925; Kishida, 1929; Bristowe, 1932; Smith, 1934; Woglum, 1935; Woglum \& Lewis, 1935; Handschin, 1935; Hungerford, 1936, 1939; Hofmann, 1936; Kaston, 1938; Balduf, 1939; Merti, 1940; Milliron, 1940; Viets, 1941; McKeown \& Mincham, 1948; Linsley \& MacSawin, 1955; Lucchese, 1955, 1956; Parfin, 1958; Schremmer, 1959, 1983; Birabén, 1960; Peterson, 1960, 1967; Kuroko, 1961; Ghilarov, 1962; Parker \& Stange, 1965; Werner \& Butler, 1965; Davidson, 1969; Popov, 1973; George \& George, 1975; Redborg, 1979; Redborg, 1981; MacLeod \& Redborg, 1982; Penny, 1982a, 1982b; Killebrew, 1981; Gilbert \& Rayor, 1983; Rice, 1985, 1986; Redborg \& MacLeod, 1985; Monserrat \& Díaz-Aranda, 1989; Dejean \& Canard, 1990; Gepp, 1990; Minter, 1990; Rice \& Peck, 1991; Tauber, 1991; Hoffman, 1992; Hoffman \& Brushwein, 1992; Hirata et al., 1995; Hirata, 1999; Redborg \& Redborg, 2000; Hirata \& Ishii, 2001; Ohl, 2011, etc.), algunas veces, como los de M. styriaca, frecuentemente reproducidos (Stitz, 1931; Kis et al., 1970; Poivre, 1976; Şengonca, 1980; Aspöck et al., 1980; Gepp, 1984; Aspöck, 1999, etc.).

Pequeñas diferencias en la coloración general, la disposición y longitud de las setas cefálicas, de los 
palpos y mandíbulas, del tórax, patas y abdomen se han citado entre diferentes especies, dentro de una aparente marcada uniformidad, al menos en fases iniciales. Hoffman \& Brushwein (1992) aportan la terminología a utilizar y la clave de numerosas especies americanas. Ahora anotaremos algunos datos inéditos sobre la puesta y los estadios larvarios de algunas especies ibéricas.

Los huevos son pedunculados, alargados, subcilíndricos y de extremos redondeados, de unos 0,4-0,6 mm, unas 2 veces más largos que anchos (Figs. 20A-E, G, H) y pedúnculos de 1,5-2,5 mm. Son de color crema pálido a amarillento rosáceo, con micropilo bastante aparente y con aeropilos bajo él, y poseen pequeñas impresiones hexagonales-poligonales y abundantes esculturas digitiformes sobre el corion (Lucchese, 1956; Poivre, 1976; Gepp, 1990; Minter, 1990). Conforme el tiempo avanza, las pardas bandas metaméricas del embrión primero y los ocelos negros después evidencian su desarrollo (Fig. 20B-E).

Los mantíspidos son insectos típicos estrategas de la $r$ (MacLeod \& Redborg, 1982), como corresponde a animales que viven de forma parásita-parasitoide sobre otros, o predando sobre muy determinados y concretos recursos (puestas de arañas y estadios juveniles de himenópteros y coleópteros) de forma muy específica y exclusiva, hechos que les obliga a una enorme fertilidad/fecundidad, para así aumentar la probabilidad de que algún elemento consiga completar su particular desarrollo. Las hembras depositan sus puestas en varias tandas y a lo largo de varios días, generalmente sobre de las cortezas y las hojas de los árboles, a veces en el envés para proteger la puesta del sol y la lluvia (Kral, 2013), donde quedan ordenadamente adheridos sobre su pedúnculo (Lucchese, 1955, 1956) (Fig. 14). Se han citado en otras especies otras superficies más variopintas donde efectúan las puestas (postes de telégrafo, de acero, mojones kilométricos, aleros, papeles, ropa, tapias, refugios invernales de lepidópteros, e incluso sobre puestas previas). La hembra toca con su extremo abdominal el sustrato elegido, depositando parte del material fluido que segregan sus glándulas anejas que queda fijado en este extremo, y levantando el abdomen genera el pedúnculo que posteriormente se solidifica en contacto con el aire y en cuyo extremo deposita el aislado huevo (Fig. 20A-E), que queda así separado del sustrato (quizás evitando la presión de los depredadores, especialmente hormigas), de forma similar a lo acontecido en otras familias de neurópteros como Chrysopidae, Berothidae y en algunos Nymphidae, tipos de puestas en las que se ha supuesto una adaptación para evitar el canibalismo entre las larvas neonatas (Penny, 1982a), hecho que no acaba de explicarse del todo en Mantispidae (Snyman et al., 2012), dado el escaso carácter caníbal de sus larvas y su específico régimen alimentario.

Las puestas se realizan en densos grupos de hileras de huevos, paralelas o levemente arqueadas en función del arco descrito por su abdomen (Fig. 14) y ordenadamente dispuestas (Hungerford, 1936; Redborg \& MacLeod, 1985). Más o menos se efectúa la puesta de un huevo cada 4-7 segundos. A veces la puesta se realiza en un único grupo, otras veces la hembra se desplaza un trecho y son varios los grupos de huevos depositados (ver lo ahora anotado en Mantispa styriaca), y puede tardar varias horas en finalizar cada puesta. A veces se han observado puestas de Mantispa perla depositadas en las proximidades de sacos ovígeros depositados y vigilados por arañas (Lucchese, 1956).

Tras varios días $(3,5,8$, según las observaciones), nuevas puestas, generalmente de menor número de huevos, son practicadas, y se han citado en diferentes especies puestas de 614-2.976 huevos por grupo, grupos con una media de 188 huevos (aprox. 1.128 huevos), 3 grupos de entre 1.300-1.400 huevos cada uno, 5 grupos con una media de 1.558 huevos (aprox. 8.570 huevos), 23 grupos de 804 huevos como media (aprox. 18.500 huevos), 9 grupos con un total de 8.385 huevos, o puestas de 100, 250, 528, 889, 1.028, 1.800, $1.900,2.140,2.200,2.348,3.464,3.812,4.768,5.252$, $5.500,6.000,6.262,6.850,8.000,8.121,8.385$ huevos por hembra (en algunos de estos datos no se tiene certeza de puestas anteriores a su captura), con datos aún mayores estimados (Redborg \& McLeod, 1984 citan hasta más de 30.000 huevos en especies americanas), y puestas comunales de hasta 403 grupos con una estimación de un cuarto de millón de huevos (Kishida, 1929; Smith, 1934; Hoffman, 1936; Hungerford, 1936; Merti, 1940; Viets, 1941; McKeown \& Mincham, 1948; Kuroko, 1961; Davidson, 1969; Redborg \& MacLeod, 1985; Rice, 1986; Rice \& Peck, 1991; Brushwein et al., 1995a, etc.). En las especies ibéricas se ha citado una media de 800-900 huevos y hasta 1.300-4.500 huevos por hembra en Mantispa perla (Lucchese, 1955, 1956), y de 216 huevos en una hembra de M. aphavexelte, y de $282,355,889,1.216$, $1.250,1.368,1.658,3.812,5.500$ y hasta 6.000 huevos por hembra en Mantispa styriaca (Schremmer, 1959; Poivre, 1976; Monserrat \& Díaz-Aranda, 1989; Gepp, 1990, y nuevos datos ahora anotados). Naturalmente el número de huevos depositados depende del tamaño de la hembra (Lucchese, 1956; Poivre, 1976; Redborg $\&$ MacLeod, 1985), y por citar un ejemplo que lo ilustre, Redborg (1998) cita puestas de entre 614 a 2.976 huevos, según el tamaño de la hembra seleccionada. En las especies parásitas de nidos de avispas, se ha observado la penetración activa de las hembras fecundadas en su interior (Smith, 1863; Dejean \& Canard, 1990).

$\mathrm{Su}$ desarrollo es poco conocido, aunque en general es rápido, y sin duda depende de las condiciones ambientales, especialmente de la temperatura. Se han citado desarrollos de entre 15-20 días a temperatura de $23{ }^{\circ} \mathrm{C}$ para Mantispa perla (Lucchese, 1955, 1956), de 7-9 días a $27{ }^{\circ} \mathrm{C}$ y de $13-28$ días en condiciones 


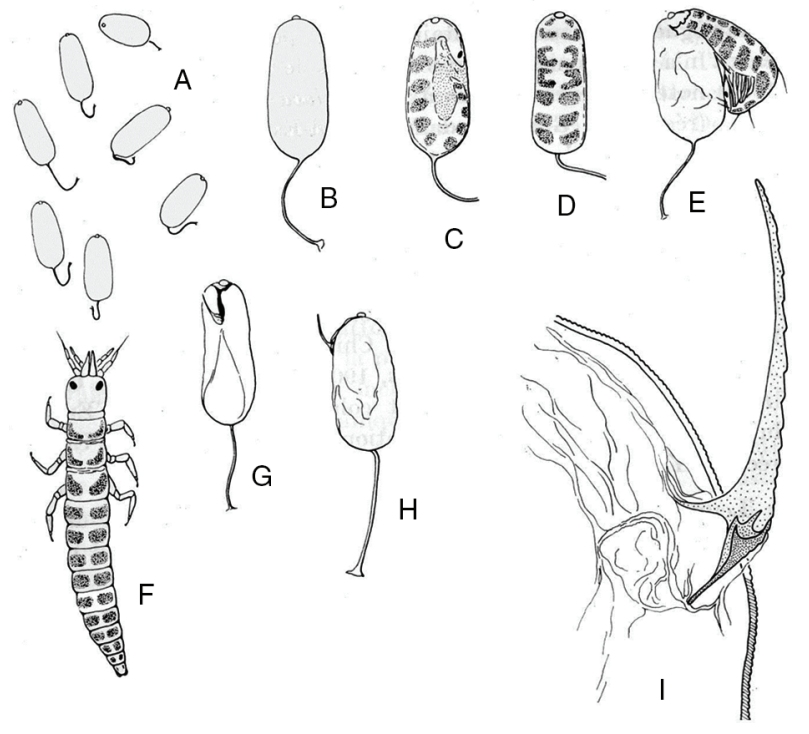

Fig. 20.- Aspectos del desarrollo embrionario en Mantispa styriaca. A, puesta; $B-E$, cambios en el aspecto externo del huevo durante el desarrollo embrionario hasta la eclosión; F, larva neonata; $\mathrm{G}-\mathrm{H}$, huevos abandonados; I, aspecto de ovirruptor. A diferentes escalas, de Poivre (1976).

Fig. 20.- Aspects of embryonic development in Mantispa styriaca. A, batch of eggs; B-E, changes in the external appearance of the egg during embryonic development until hatching; F, neonate larvae; G-H, abandoned eggs; l, ovirruptor appearance. At different scales, from Poivre (1976).

ambientales para M. japonica (Kuroko, 1961), de 28-40 días en otoño y 16-18 en verano para Campion vittatus (McKeown \& Minchan, 1948), de 10 días para Zeugomantispa viridis (Davidson, 1969), de 9-10 días a $26,5^{\circ} \mathrm{C}$ y 9-11 días para Dicromantispa sayi (Smith, 1934; Rice \& Peck, 1991), de 14-21 días (media 17,3 días para $D$. interrupta (Hoffman, 1936), de 21 días en M. styriaca (= M. pagana) (Brauer, 1869) y de 5-7 días a temperatura media de $23-29^{\circ} \mathrm{C}, 9-10$, de $12-13$ días a temperatura ambiente, de 11 días cultivados a temperatura entre $28-32{ }^{\circ} \mathrm{C}$, de 10 días a temperatura constante de $26{ }^{\circ} \mathrm{C}$, o 10 días en condiciones ambientales en M. styriaca (Monserrat \& Díaz-Aranda, 1989 y datos ahora anotados), en general algo inferiores a otros datos existentes (8-16 días según Poivre, 1976, o 21 días según Brauer, 1869) o a lo registrado en otros géneros (Climaciella, Plega, Nolima, etc.) cultivados entre $28-32{ }^{\circ} \mathrm{C}$. Parece que no soportan el frío durante esta fase embrionaria.

La ruptura del huevo se efectúa mediante una incisión longitudinal e irregular desde el polo micropilar, merced al concurso de pequeño ovirruptor denticulado (Fig. 20I) que queda adherido al corion (Figs. 20G-H) (Lucchese, 1956; Poivre, 1976). Con frecuencia se han citado eclosiones durante la noche, empleando para ello 15-20 minutos, y que las larvas neonatas permanecen un tiempo inmóviles en la base de los huevos, hasta 8-10 días en Mantispa perla y hasta dos meses en $M$. styriaca (Lucchese, 1955, 1956), antes de iniciar su dispersión, sin que exista interferencia o agresión entre las larvas así concentradas. Iniciada su actividad se dispersan con relativa facilidad, ayudándose haciendo palanca con el extremo abdominal. A veces pueden ser diseminadas por el viento (New, 1986), y se ha supuesto foresia tras el hallazgo de larvas neonatas sobre insectos voladores (Hoffman \& Hamilton, 1988).

Las larvas neonatas inicialmente son muy ágiles, veloces y activas (Figs. 20F, 21), ayudándose con el extremo abdominal para caminar con el que hacen palanca. Se dispersan desplazándose a gran velocidad buscando su futura fuente de alimentación. En este periodo de búsqueda pueden desplazarse largas distancias. En cautividad y sin alimento mantienen su actividad entre $96 \mathrm{~h}$ y un par de semanas hasta su muerte (ver nuevos datos más adelante sobre $M$. styriaca).

La sorprendente biología de estos estadios juveniles empezó a ser conocida a través de Brauer $(1852 b$, $1855 \mathrm{a}, 1855 \mathrm{~b}$ y especialmente 1869 ), e inicialmente se asociaron con arañas (Lycosidae) y sus puestas, ampliándose paulatinamente con otros tipos de presas.

No se conoce con seguridad cómo estas larvas son capaces de localizar arañas adecuadas, que éstas sean hembras, y que estén en fase de efectuar la puesta o ya la hayan fabricado o vayan a fabricar su ooteca, y aunque su alta fecundidad aumenta las probabilidades, ahora citaremos que el azar y sus curiosas adaptaciones y estrategias aumentan enormemente sus posibilidades de éxito.

Con frecuencia se han citado larvas que acceden activamente al cuerpo de las arañas y han sido observadas alojadas en las articulaciones membranosas de las patas, palpos, hileras, cámaras de los filopulmones o, en mayor medida, sobre el pedicelo de las arañas (parecen distinguir la edad-madurez de la araña, ya que se alojan en diferentes ubicaciones sobre ellas según ésta), donde no sólo practican una pasiva foresia, sino un auténtico parasitismo sobre su hospedador en esta fase, alimentándose de su hemolinfa (pueden permanecer hasta un año) a la espera de estos acontecimientos (Lucchese, 1955, 1956; Redborg, 1982; Redborg \& MacLeod, 1983, 1984; Rice, 1986; Rice \& Peck, 1991). En esta fase parásita, es probable que la larva reciba información química sobre la fisiología de la araña en relación a su sexo y su estado reproductor, e incluso exista influencia de las larvas sobre las arañas (hembras) parasitadas, ya que maduran sexualmente una muda antes que las no parasitadas, y este hecho no afecta a las arañas machos (Redborg, 1982; Redborg \& MacLeod, 1983, 1984), y también se ha observado el transvase de larvas desde arañas machos a hembras durante el apareamiento, la cópula y/o el canibalismo (Lucchese, 1955, 1956; Scheffer, 1992; O'Brien \& Redborg, 1997), pero también en ocasiones se ha observado experimentalmente poca atracción a las arañas o los sacos ovígeros ofrecidos (Monserrat \& Díaz-Aranda, 1989). 


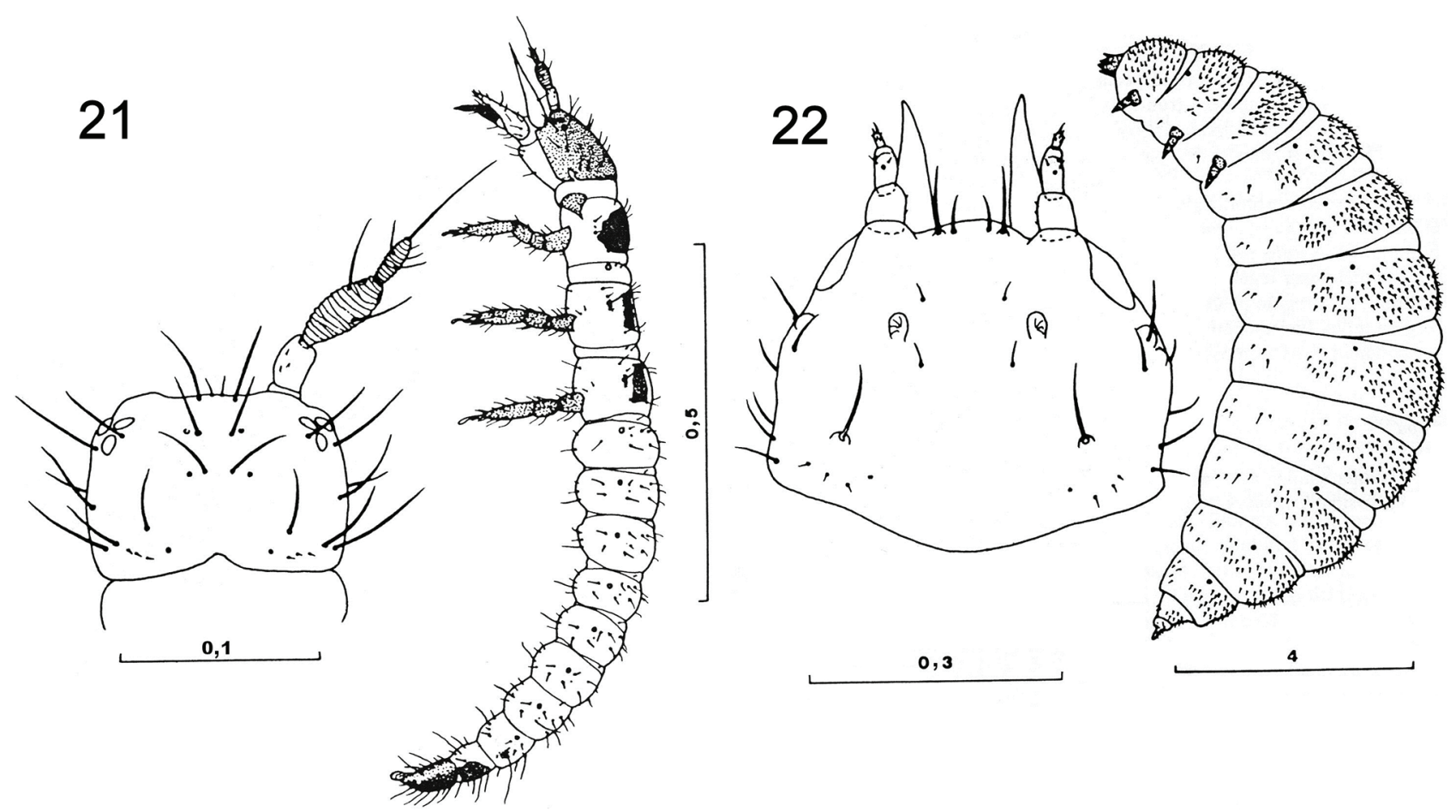

Figs. 21-22.- Larva neonata y madura de Mantispa styriaca, vista lateral, y cápsula cefálica, vista dorsal. De Monserrat \& Díaz-Aranda, 1989. Escala en $\mathrm{mm}$.

Figs. 21-22.- First and mature larva of Mantispa styriaca, lateral view, and head capsule, dorsal view. From Monserrat \& Díaz-Aranda, 1989. Scale in $\mathrm{mm}$.

En las arañas, y en función del grado de la infestación, su fisiología, su tamaño final, el tiempo de su desarrollo, el número final de las mudas en las hembras, e incluso el tamaño de su puesta y sus huevos pueden verse seriamente alterados (Redborg, 1982), e incluso algunas estrategias reproductoras han sido descritas en algunas especies de arañas (Philodromus vulgaris), como es la de producir una segunda puesta de menor tamaño, que podría ser inducida por la presencia de mantíspidos, que se habrían introducido en el primer saco ovígero depositado, liberando a esta segunda puesta de la araña de estos indeseables depredadores. No hace falta resaltar que los mantíspidos (Mantispinae) representan los más extendidos y eficaces depredadores de las arañas (Richardson, 1976; Redborg \& Redborg, 2000), y algunos estudios han demostrado infestaciones en las poblaciones de arañas de hasta el 75-78,6 \% (Rice \& Peck, 1991; Redborg, 1998; Redborg \& Redborg, 2000), similares cifras $(71 \%)$ a las halladas en el porcentage de celdillas parasitadas por mantíspidos (Plega yucatanae) en abejas centroamericanas (Parker \& Stange, 1965).

En el caso de infestación directa sobre el saco ovígero tampoco se conoce cómo penetra tan pequeña larva en la barrera de capas de seda que conforman la pared externa de los sacos ovígeros (Hoffman \& Brushwein, 1990, 1992; Hoffman, 1992; Redborg 1998), a veces de notable consistencia y con sus correspondientes estrategias ante potenciales intrusos
(Austin, 1985; Fink, 1986, 1987), aunque no queda más remedio que suponer que lo hacen mediante dos estrategias: bien de forma activa (así parece mencionar y dibujar Brauer, 1869 para nuestra Mantispa styriaca, y refieren Rogenhofer, 1862a, 1862b y Aspöck, 1994, hecho que no se corresponde con nuestras observaciones que ahora mencionaremos) y parece que las larvas que utilizan esta estrategia se sienten atraídas por la seda de los sacos ovígeros de las arañas (Redborg \& MacLeod, 1985) o bien, como anotan Redborg \& MacLeod (1983, 1984, 1985) y Redborg $(1985,1998)$, lo hacen de forma obligada desde el cuerpo de la araña durante su fabricación por ésta. Existen especies cuya estrategia, bien acceder directamente a los sacos ovígeros o bien a través de foresia previa sobre la araña, es facultativa (Redborg \& MacLeod, 1985; Redborg, 1998). A veces esta foresia es obligada (Lucchese, 1956; Redborg, 1982; Redborg \& MacLeod, 1983; Redborg \& Redborg, 2000), y así parece ocurrir en nuestras especies Mantispa perla (ver Lucchese, 1956) y Mantispa styriaca, pues Monserrat \& Díaz-Aranda (1989) obtienen hasta 6 imagos de esta especie a partir de un único saco espontáneamente infestado (a través de araña que lo generó), sin mostrar ninguna atracción (ni aparente intención de introducirse espontáneamente) en otros sacos ovígeros ofrecidos a otras larvas neonatas hermanas, de lo que se deduce que, a diferencia de lo anotado en la bibliografía (Rogenhofer, 1862a, 1862b; Brauer, 
1869 o Aspöck, 1994) es obligado el paso de la larva neonata sobre la hembra de la araña que fabricará el saco ovígero (Monserrat \& Díaz-Aranda, 1989 y material ahora citado). En ocasiones se acaba generando un auténtico parasitismo en esta fase sobre la araña, y con frecuencia han sido halladas más de una larva sobre una misma araña (Hungerford, 1939 citan hasta 15 larvas sobre un licósido, y Rice \& Peck, 1991 citan hasta 16 larvas sobre un saltícido), y sin duda se establecen relaciones de competencia entre ellas. Este comportamiento de las larvas ya está registrado desde el Eoceno Medio, en ejemplares bálticos conservados en ámbar (Ohl, 2011). En cualquier caso la araña elegida para treparla y alojarse temporalmente sobre ella, a la espera de que se produzca la puesta, ha de ser de tamaño suficientemente grande como para que la larva no entre dentro del margen de sus potenciales presas. La enorme cantidad de huevos depositados por las hembras de Mantispidae garantiza que algún ejemplar alcance su específico objetivo, y la propia actividad de las arañas en su desplazamiento sobre estas zonas con puestas "comunales" y huevos masivos favorecen su infestación (Richardson, 1976; Rice, 1985, 1986; Rice \& Peck, 1991; Redborg, 1998).

$\mathrm{Su}$ desarrollo requiere tres estadios (aunque hay erróneas observaciones clásicas de una única muda) cuya duración depende de la temperatura y del alimento disponible, siendo más largo el primer estadio. Las larvas neonatas, poseen aspecto típico campodeiforme, con antenas y patas bien desarrolladas y piezas bucales prognatas (Figs. 20F, 21) y en esta primera fase larvaria portan a cada lado de la cabeza un pequeño estemmata posterior y dos anteriores, que por su posición les da un amplio campo visual (Kral, 1989, 2013). Con diferentes métodos para lograrlo, su fin es alcanzar el interior de sacos ovígeros de arañas donde empiezan a alimentarse de los huevos que contienen. Estas tres fases larvarias presentan una morfología bastante diferente en el primer estadio respecto a los dos siguientes (incorrectamente citada como auténtica hipermetamorfosis), en los que se desarrolla una marcada fisiogastria respecto a la morfología neonata (Figs. 21-22), similar a lo observado en otras familias próximas (Dilaridae, Berothidae), pasando de activa y campodeiforme a forzosamente sésil y de tipo casi melolontiforme, cuyo más acusado crecimiento se produce en el tercer estadio. Las larvas, incorrectamente citadas en esta situación como parásitas, son realmente depredadoras selectivas de huevos de arañas (no viven a su costa perjudicándolos, sencillamente predan sobre ellos), también predan sobre pequeñas arañitas pre-neonatas o en desarrollo (ver datos ahora citados de Mantispa styriaca), y salvo que el saco contenga un mayor número de huevos necesarios para el desarrollo de la larva, pocas veces alguno sobrevive a la infestación del saco donde se desarrollaban (Rice, 1985). Para alimentarse rodean al huevo elegido y contribuyen a inmovilizarlo para proceder a su succión (consideramos que, sin duda, la dureza del corion estará sometida al proceso de la Evolución, favoreciendo la supervivencia de especies de arañas con corion más resistente a los ataques de estas larvas), y en función del color del vitelo de los huevos, las larvas van adquiriendo su coloración (blanco lechoso, crema, rosáceo, salmón, etc.) (McKeown \& Mincham, 1948; Kral, 1989; Monserrat \& Díaz-Aranda, 1989, y datos ahora anotados).

Como ocurre en las fases larvarias de otras familias de neurópteros (Chrysopidae, Berothidae, Dilaridae, Nemopteridae) en relación a colonias de insectos sociales (Weber, 1942; Principi, 1943; Tauber \& Tauber, 1968; Johnson \& Hagen, 1981; Brushwein, 1987a, 1987b; Monserrat \& Martínez, 1995; Monserrat, 1996a, 1996b, 2008, 2014), en esta familia se presume o está demostrada la emisión de allomonas en las especies parásitas de nidos de himenópteros que neutralicen la agresividad de sus individuos de la colonia (Dejean \& Canard, 1990) o, en el caso de las larvas que parasitan sacos ovígeros de arañas, que ralenticen o detengan el desarrollo embrionario de los huevos dentro de los sacos, incrementando su potencial alimento durante el tiempo requerido para su desarrollo (Redborg, 1983, y datos ahora anotados en Mantispa styriaca), hecho que se suma al daño mecánico causado por la larva sobre los huevos con tal fin. También se ha sugerido la emisión de tales sustancias en mantíspidos parásitos de avispas (Dejean \& Canard, 1990). Es probable que exista algún tipo de emisión de sustancias que impidan o eviten la competencia y la intrusión de nuevas larvas en sacos ovígeros ya ocupados, y aunque Brauer (1855a, 1869) anotaba una única larva de Mantispa styriaca por saco de huevos, hecho que se ha supuesto ser la norma, otras cifras deben barajarse respecto a esta proporción 1:1. Así Monserrat \& Díaz-Aranda (1989) obtienen hasta 6 imagos de esta especie a partir de un único saco espontáneamente infestado (vía araña que lo generó), sin mostrar atracción (ni aparente intención de introducirse espontáneamente) en otros sacos ovígeros ofrecidos a otras larvas neonatas hermanas, y en otras especies se han citado hasta 2, 3, 5, 7, 8 larvas en el interior o imagos emergidos de un mismo saco (Kishida, 1929; Smith, 1934; McKeown \& Minchan, 1948; Parfin, 1958; Gilbert \& Rayor, 1983), aun así se ha citado en la bibliografía que de producirse una variada infestación, o bien las larvas no inician su alimentación hasta que solo queda una única larva, o bien compiten y se ha constatado canibalismo.

Los recursos alimentarios existentes (número y tamaño de los huevos por ooteca) y esta competencia son las causantes de la enorme variabilidad existente en el tamaño de los imagos (Kuwayama, 1924), ya que obviamente el número de huevos disponibles durante su desarrollo va a afectar de forma significativa en el tamaño de los imagos (Redborg \& MacLeod, 1985), y esto también ocurre en las especies ibéricas, con marcadas variaciones en el tamaño de sus 
ejemplares, según anotaremos más adelante en cada especie. Experimentalmente Redborg (1998) consigue obtener imagos a partir de larvas de tercer estadio cultivadas con sólo 5 y con hasta 200 huevos de araña (Agelenopsis), que lógicamente no sólo presentaban un enorme margen de variabilidad en sus tamaños, sino que demuestran su plasticidad a la hora de explotar una amplia gama de sacos ovígeros en la naturaleza.

Mayoritariamente sus larvas han sido citadas en la bibliografía como huéspedes de Lycosidae, aunque otras familias de arañas se han ido citado en relación a las fases larvarias de los mantíspidos, sin que, en la mayoría de los casos, se hayan calibrado relaciones directas entre unos (Mantispinae) y otros (Arachnida). Parece que las especies cuyas larvas son penetradoras directas de los sacos ovígeros son algo más específicas que las especies que pasan anteriormente un periodo de tiempo sobre las arañas. Se han citado larvas sobre ejemplares de familias de arañas tanto aracnomorfas como migalomorfas, tanto sean cazadoras al acecho o a la carrera como fabricadoras de redes (telas de araña), bien de forma espontánea o inducida en condiciones experimentales (Ctenizidae, Theridiidae, Araneidae, Clubionidae, Anyphaenidae, Heteropodidae, Pisauridae, Thomisidae, Oxyopidae, Philodromidae, Scytodidae, Salticidae, Ctenidae, Gnaphosidae, Disderidae, Sicaridae, Sparassidae, Filistatidae, Oecobiidae, Dictynidae, Loxoscelidae, Pholcidae, Agelenidae, Mimetidae, Uloboridae, Tetragnatidae, Drassidae), y ahora aportamos nuevos datos sobre otra familia no citada en relación a los mantíspidos (Araneae, Lycosoidea: Zoropsidae), por lo que, aunque son más abundantes las citas sobre Lycosidae, Drassidae y Clubionidae, parecen ser bastante generalistas, y otras pueden considerarse oportunistas, ya que en algunas especies, a tenor del elevado número de especies de arañas (hasta 13 especies de 9 géneros de 5 familias) sobre las que se han hallado (New, 1986; Hoffman \& Brushwein, 1989, 1990; Hoffman, 1992), cabe pensar pues que algunas especies son marcadamente oportunistas. Más información complementaria en Brauer, 1869; Poujade, 1898; Kishida, 1929; Main, 1931; Bristowe, 1932; Smith, 1934; Handschin, 1935; Hungerford, 1936, 1939; Kaston, 1938, 1940; Milliron, 1940; Viets, 1941; McKeown \& Mincham, 1949; Parfin, 1958; Birabén, 1960; Ghilarov, 1962; Bisset \& Moran, 1967; Davidson, 1969; Askew, 1971; Valerio, 1971; Caposcale, 1971; Poivre, 1976; Tolbert, 1976; Gertsch, 1979; Killebrew, 1981; Redborg, 1981, 1982; Gilbert \& Rayor, 1983; Heiber, 1984; Downes, 1985; Rice, 1985, 1986; Redborg \& MacLeod, 1985; Roble, 1986; Fink, 1987; Lambkin, 1987; Monserrat \& DíazAranda, 1989; Hoffman \& Brushwein, 1989, 1990, 1992; Brushwein et al., 1992; O’Brien \& Redborg, 1997; Redborg \& Redborg, 2000; Ohl, 2011, etc.

Obviamente, la diferente biología, fenología y hábitat de las arañas tendrá influencia tanto en el medio donde hallemos los imagos, como en su fenología, que no dependerá exclusivamente de las condiciones abióticas y/o ambientales, como ocurre en la mayor parte de los insectos.

Se ha citado la posibilidad de hibernación en fase de adulto en algunas especies (Smith, 1934; Parfin, 1958), en estados juveniles se ha citado hibernación y agregación en las larvas nacidas en otoño (ver más adelante datos experimentales con larvas neonatas de $M$. styriaca), que reanudan su actividad entrada la siguiente primavera (Brauer, 1869; McKeown \& Mincham, 1948), y esto parece acontecer en nuestra especie Mantispa styriaca (Brauer, 1869; Main, 1931; Bristowe, 1932). En otros casos se ha citado hibernación bien sobre la araña inmadura hospedante (Redborg \& MacLeod, 1984), y así parece ocurrir en M. perla (Lucchese, 1956), o bien dentro del saco ovígero, sea como larva o como pupa (Brushwein et al., 1995b; Redborg, 1998), y todo esto hace que sea aleatorio y complejo el seguimiento fenológico de las especies en esta familia, incluso en una misma especie y dentro de una misma población y/o puesta, en función no sólo de la especie de araña que cada larva utiliza para completar su desarrollo, sino de su edad, grado de desarrollo, sexo y ciclo reproductor, amén de la fauna hospedante disponible y del hábitat y las condiciones ambientales y climatológicas donde las poblaciones se desarrollen (Redborg \& Redborg, 2000). Por ello los mantíspidos han sido citados dentro de los neurópteros como los de fenologías anuales más amplias (New, 1986), sin duda prácticamente continua en zonas tropicales o próximas (McKeown \& Mincham, 1948; Opler, 1981; New, 1986; Hoffman, 2002), y en zonas templadas con una a tres generaciones posibles, incluso cuatro han sido citadas (ver datos ahora anotados en en nuestras especies y en particular en Mantispa styriaca), con posibilidades muy diferentes dentro de una misma generación/puesta, según la suerte y circunstancias que cada ejemplar haya tenido para su desarrollo, hecho impredecible que los aleja de otras familias con fenologías más estables y vinculadas a las características ambientales del medio.

Hay pocos datos observados sobre los periodos de duración de sus estados larvarios. En nuestro género (Mantispa) y otros géneros (Campion, Climaciella) se han citado 24-5,5 días para pasar al segundo estadio, 5-2,6 días para alcanzar el tercero y 7-3,6 días en iniciar la pupación (McKeown \& Mincham, 1948; Redborg \& MacLeod, 1983). Lucchese (1956) anota para M. perla que la larva en primer estadio realizan su primera muda en 3 días, que el segundo estadio se alimenta más intensamente y muda en 4 días, al igual que el tercer estadio, que generalmente consume todos los huevos que queden dentro del saco e inicia la fase de pupación en 5 días. Nosotros aportamos más adelante datos de larvas de M. styriaca y hay datos de larvas cultivadas en laboratorio con tiempos de 15 días desde el nacimiento hasta alcanzar el $3^{\circ}$ estadio, y de sólo 
2-3 días para iniciar la pupación, y un periodo total de 20 días desde la eclosión a la pupación y de 34 días desde la eclosión a la emergencia de los imagos. Todo parece indicar pues que el periodo comprendidos entre la eclosión del huevo-inicio de alimentación y el inicio de la pupación es sorprendentemente corto, hecho que refleja su rápido desarrollo, y por poner algunos otros ejemplos Dicromantispa fuscicornis requiere 17-24 días a $24{ }^{\circ} \mathrm{C}$ (Gilbert \& Rayor, 1983), D. uhleri 10 días a $25^{\circ} \mathrm{C}$ (Redborg, 1983), igual al de $M$. styriaca a $26{ }^{\circ} \mathrm{C}$ (Monserrat \& Díaz-Aranda, 1989), o algo más (17-18 días) desde la eclosión a la pupación en ejemplares cultivados a $28-32{ }^{\circ} \mathrm{C}$ (ver datos anotados más adelante). En otros géneros (Plega, Nolima) se han citado tiempos de $15-16$ días a $25{ }^{\circ} \mathrm{C}$ (MacLeod \& Redborg, 1982). Estos cortos periodos han de tenerse en cuenta en el cálculo de posible número de generaciones anuales a lo largo de sus fenologías. En diversas especies se ha anotado el ciclo de vida completo, desde el primer estadio a la emergencia de los imagos (ej.: entre 23 y 29 días a $26^{\circ} \mathrm{C}$, y 34 días a temperatura ambiente en Mantispa styriaca, o 28 días a $25{ }^{\circ} \mathrm{C}$ en $D$. uhleri), que son periodos relativamente breves, alcanzando los dos años en otras subfamilias (Woglum, 1935; Werner \& Butler, 1965).

Se han observado periodos de un día de quiescencia inmediatamente anterior al día de la ecdisis, y como ocurre en muchos otros artrópodos, estos periodos de ecdisis pueden inducir una elevada mortalidad.

Apenas hay datos al respecto, pero completado su desarrollo, la larva madura deja de alimentarse, está menos activa e inicia la pupación confeccionando un capullo de seda que, como ocurre en fases larvarias de otras familias de neurópteros, tejen merced a secreciones de los tubos de Malpighi modificados para este menester (Bissett \& Moran, 1967) y al desarrollo de una formación terminal en el $10^{\circ}$ segmento especializado a tal fin (Fig. 22), tardando unos tres días en completarlo. A veces se ha citado pupación dentro de la exuvia de la larva madura (Kral, 2013). El capullo es esférico o levemente elíptico (Fig. 15), dependiendo su tamaño de los recursos disponibles y, consecuentemente, del tamaño que tendrá el imago (hay datos de $6 \times 5 \mathrm{~mm}$ en $M$. perla, y según nuestras observaciones de $9 \times 10 \mathrm{~mm}$ en $M$. styriaca), con una capa externa más deshilachada y esponjosa, y una interna formada por paneles independientemente tejidos y cosidos/ adheridos unos a otros (Fig. 15). Bissett \& Moran (1967) describen en detalle su fabricación. Dentro de él pasan una breve fase de prepupa $(6,7 ; 11-12$ días) (Fig. 16), antes de endurecer el tegumento y adquirir el aspecto pupal definitivo (Fig. 17).

Tampoco hay apenas datos al respecto, pero de acuerdo a lo que se ha observado y a lo que anotaremos en $M$. styriaca, tras $8-10 ; 12,8 ; 12-15 ; 19$ días, finalizada la fase de pupa (Fig. 17), y emerge el imago después de liberarse del tegumento pupal (Fig. 18), de su capullo de seda, y del saco ovígero de la araña, que deben cortar con sus mandíbulas. De forma similar a lo que acontece en Osmylidae, Berothidae, Sisyridae o Hemerobiidae, la salida del imago se ve favorecida/ facilitada por la posesión de dos pares de dentículos esclerificados y curvos sobre la región dorsal media de los segmentos 3-4 del abdomen de la pupa (Fig. 19), elementos que actúan como anclaje para liberarse de la exuvia pupal (Fig. 17), y tras varias horas en zafarse de ella y, tras retirarse un trecho, en unas especies al atardecer, en otras durante el día, en otras indistintamente, queda libre el imago, y tras expeler el fluido meconio (restos del contenido del tubo digestivo que no ha podido ser eliminado por el ano con anterioridad, debido a la falta de conexión entre el mesodeo y proctoeo, elemento que caracteriza a todos los estados juveniles de neurópteros), en una hora está listo para volar. Datos sobre pupas en diferentes especies en Lucchese (1956), Parker \& Stange (1965), Bissett \& Moran (1967), Gilbert \& Rayor (1983), Monserrat \& Díaz-Aranda (1989), etc.

En nuestra fauna hay algunas referencias sobre los estadios larvarios de alguna de sus especies, que se comentarán en cada caso (Figs. 14-22). Información general sobre la anatomía, morfología y biología de las especies de esta familia (huevos, larvas, pupas e imagos) puede recabarse en la bibliografía adjunta.

\section{Historial PALEONTOLÓGico}

Sobre su historial paleontológico, no son escasos los registros de mantíspidos fósiles (Schlüter, 1986; Grimaldi \& Engel, 2005; Engel \& Grimaldi, 2007; Wedmann \& Makarkin, 2007; Ohl, 2011), en ocasiones de ubicación discutible dentro de esta familia y, en cualquier caso, los datos son relativamente recientes [inicialmente escasos desde inicios del Jurásico (Alemania) (Ansorge \& Schlüter, 1990) y más abundantes hasta el Mioceno dominicano (Poinar, 2006)] en comparación con otras familias de neurópteros filogenéticamente próximas y de historial geológico aparentemente mucho más antiguo (Berothidae, Rhachiberothidae) (ésta también con patas anteriores raptoras). La existencia de abundantes registros desde el Jurásico-Cretácico Inferior en estas dos familias próximas, a veces asignados a Mantispidae $(\uparrow$ Retinoberotha, $\uparrow$ Paraberotha, $\uparrow$ Doratomantispa, $\uparrow$ Micromantispa, etc.), sugería para los mantíspidos una similar antigüedad en su linaje, al menos desde el Jurásico (Ansorge \& Schlüter, 1990; Ren \& Guo, 1996; Shi et al., 2014), y también de estos períodos mesozoicos han sido, a veces tentativamente, aproximados o asignados a esta familia géneros y especies como †Clavifemora rotundata del Jurásico Medio chino, $\uparrow$ Mesithone carnaria y $\uparrow$ M. monstruosa del Jurásico Tardío de Kazakhstán, $\uparrow$ Archaeodrepanicus o $\uparrow$ Dipteromantispa o † Sinomesomantispa del Cretácico Inferior chino, $\dagger$ Mantispidiptera del Cretácico de New Jersey, y otras especies como $\uparrow$ Promantispa similis del Jurásico de Karatau, y otros taxa, hoy día 
de posición más definitiva: $\uparrow$ Liassochrysa stigmatica del Jurásico alemán, † Mantispidiptera enigmatica $\mathrm{y} \uparrow$ Mantispidiptera henryi del ámbar cretácico de New Jersey y del Lïbano, $\uparrow$ Gerstaeckerella asiatica del Cretácico de Kazakstán, o $\uparrow$ Mesomantispa sibirica del Cretácico siberiano. En el Terciario parece haberse producido su mayor radiación, y existen registros más recientes e incuestionablemente fiables en su asignación familiar: $\uparrow$ Symphrasites eocenicus del Eoceno alemán, $\uparrow$ Vectispa relicta del EocenoOligoceno inglés, $\uparrow$ Feroseta prisca, $\uparrow$ Dicromantispa electromexicana y $\uparrow D$. moronei del ámbar mexicano $\mathrm{y}$ del Mioceno dominicano, $\mathrm{y} \uparrow$ Prosagittalata oligocenica $\mathrm{y} \uparrow$ Climaciella henrotayi del Oligoceno francés. Otros taxa inicialmente asignados a esta familia como $\uparrow$ Hondelagia reticulata del Liásico Superior de Alemania, ha sido sugerido como Raphidioptera, $\mathrm{y} \dagger$ Whalfera (= Fera) venatrix del ámbar báltico hallado en la costa oriental británica y de la Isla de Wight del Eoceno - Oligoceno, ha sido asignada a Rhachiberothidae. Más información en Handlirsch, 1906-1908; Cockerell, 1921; Bode, 1953; Larsson, 1978; Panfilov, 1980; Jarzembowski, 1980; Whalley, 1980, 1983; Lambkin, 1986a, 1986b; Klimaszewski \& Kevan, 1986; Nel, 1989; Makarkin, 1990a, 1996, 1999; Ansorge \& Schlüter, 1990; Willmann, 1990, 1994; Ren \& Guo, 1996; Grimaldi, 2000; Grimaldi et al., 2002; Engel, 2004; Grimaldi \& Engel, 2005; Poinar, 2006; Engel \& Grimaldi, 2007; Engel \& Grimaldi, 2007; Wedmann \& Makarkin, 2007; Winterton et al., 2010; Poinar \& Buckley, 2011; Jepson et al., 2013; Khramov, 2013; Shi et al., 2014, etc.

\section{BreVe historial SOBRe SU TAXoNomía y Sistemática}

Tras varias tentativas de ubicación taxonómica (Raphidia, Mantis) de estos particulares neurópteros (ver Oswald, 2013a) y las primeras descripciones (Poda, 1761; Scopoli, 1763, Linnaeus, 1767; Pallas, 1772, Fabricius, 1775, 1787; DeGeer, 1778; Schrank, 1781; Olivier, 1792; Illiger, 1798; Leach, 1815; Charpentier, 1825; Pictet, 1836; Guérin-Méneville, 1838, 1844; Rambur, 1842; Westwood, 1852; Brauer, 1852a, 1852b, 1867, 1868, 1887; Hagen, 1858, 1877; Westwood, 1867; McLachlan, 1867; Gerstaecker, 1884, 1885; Berg, 1899, etc.) (para los primeros autores que se interesaron por esta familia ver Aspöck, 1999 y para algunos de sus principales estudiosos ver Ohl, 2012), se fue conformando la identidad de esta familia.

Tras el primer intento monográfico (Erichson, 1839), la taxonomía y sistemática de la familia Mantispidae siguió siendo estudiada por Banks $(1912,1913)$ y más intensamente por Navás $(1909,1910,1912,1914 a$, 1914b, 1914c, 1914d, 1928, 1929a, 1929b, 1930a, 1930b, 1931, 1933, etc.), quien describió numerosas tribus, géneros y especies (según Monserrat, 1986 a: nada menos que 15 géneros, 177 especies y 5 variedades, muchas han resultado carentes de validez).
También Enderlein (1910) sentó las bases generales de la sistemática y la nomenclatura morfológica habitualmente aceptada, aunque es raro no encontrar muy diversos autores que han modificado o propuesto su propia nomenclatura, hecho que complica la terminología a emplear. Tuxen (1970) utiliza más de 4.000 términos en las estructuras genitales de los insectos, de los que unos 200 son aplicados al orden que tratamos, y Tjeder $(1954,1956,1970)$ y Acker (1960) tratan de uniformizar la terminología genital de este orden, aunque como decimos pocos autores no han propuesto o modificado sucesivamente la suya propia.

En cualquier caso, y a diferencia de otras familias de neurópteros, esta familia no es especialmente abundante en colecciones, y posee una marcada uniformidad general con leves diferencias entre géneros y especies, hechos que hacen especialmente dificultoso el abordarla de forma global, no existiendo ninguna revisión monográfica general sobre esta familia (parcialmente por Handschin, 1959b, 1959c, 1960a, 1960b, 1961, 1963) que aúne criterios, terminologías. Son muy numerosos los taxa inadecuadamente descritos, muchas veces basados en caracteres externos de un único ejemplar y sin estudiar caracteres internos/ genitales o variabilidad de los caracteres diagnósticos utilizados (especialmente frecuente a nivel intraespecífico), siendo muy necesario que numerosos taxa deban ser restudiados, redefinidos, y muchos taxa descritos en base a caracteres de coloración, venación y morfología muy variables necesitan una adecuada revisión (Kuwayama, 1924; Handschin, 1959a, 1959b, 1959c; Poivre, 1981a; Rice, 1987; Ohl, 2004a, 2004b, 2005, 2007a; Snyman et al., 2012). Sin duda, el número y posición de algunos taxa se verá modificado en el futuro, especialmente cuando se utilicen para su diagnosis los caracteres genitales adecuados, y es seguro que nuevas sinonimias serán propuestas (Tjeder, 1963).

Más recientemente Poivre (1981a, 1983, 1984a, 1984b, 1985a, 1985b, 1986, 1991) incorpora nuevos caracteres morfológicos diagnósticos (al margen de los caracteres de morfología externa y genitalia masculina ya utilizados) como son el aspecto, biometría y quetotaxia del labro, mandíbulas, maxilas, labio, palpimácula, mento, tentorio, cabeza, diámetro de los ojos, antenas, pronoto, tarsómeros, espinas del fémur anterior, orificios de glándulas, espermatecas, etc., a veces con muy leves diferencias o escasamente significativos y casi siempre tediosos de observar. En nuestras especies recomendamos que se consideren los caracteres que utilizaremos en las claves por su mayor accesibilidad, especialmente la coloración tegumentaria (especialmente de las antenas, pronoto y cara interna del fémur anterior), la morfología de las alas y del pterostigma, y de modo complementario e indudable la genitalia masculina.

Entre los autores y obras destacables citemos Miyake, 1910, 1911; Nakahara, 1912a, 1912b, 1912c; 
Stitz, 1913; Esben-Petersen, 1914, 1917a, 1917b, 1918, 1923, 1928, 1929a, 1929b; Tillyard, 1925, 1926; Smith, 1934; Handschin, 1935, 1959a, 1959b, 1959c, 1960c, 1961, 1963; Rehn, 1939a, 1939b; Kozhanchikov, 1949; Fraser, 1952, 1953; Linsley \& MacSwain, 1955; Paulian, 1957; Kuwayama, 1962; Tjeder, 1963; Parker \& Stange, 1965; Ghosh \& Sen, 1977; Poivre, 1978, 1980, 1981a, 1981b, 1981c, 1982a, 1982b, 1982d, 1983, 1984a, 1984b, 1985a, 1985b, 1986, 1991; H. Aspöck et al., 1980, 2001; Penny, 1982a, 1982b; Penny \& da Costa, 1983; Lambkin, 1986a, 1986b, 1987; Zakharenko, 1987; Hoffman, 1989, 2002; Makarkin, 1990b; Oswald \& Penny, 1991; Lambkin \& New, 1994; Aspöck, 1994; Aspöck \& Aspöck, 1994; Krivokhatsky, 1995; New, 1998; Yang \& Peng, 1998; Yang, 1999; ReynosoVelasco, 2007; Ohl, 2007a, 2007b, 2009, 2012; Reynoso-Velasco \& Contreras-Ramos, 2008, 2009, 2010; Machado \& Rafael, 2010; Snyman et al., 2012, etc., que han aportado interesantes contribuciones, y Ohl (2004a) cataloga las especies conocidas hasta la fecha, y puede obtenerse valiosa información en Oswald (2007). Para el lector interesado, en la bibliografía anotamos los trabajos más relevantes con información sobre la taxonomía y la sistemática de esta familia, y Oswald \& Penny (1991) recopilan la lista taxonómica de sus géneros, y Redborg (1998) y Ohl (2004a, 2007a) aportan interesantes datos sobre su historial y actual problemática.

Dentro de la Región Paleártica occidental son actualmente conocidas en Europa seis especies, de los géneros Mantispa (5 spp.) y Nampista (1 sp.) (H. Aspöck et al., 1980; Aspöck \& Aspöck, 1994; Aspöck, 1994, 1996; Ohl, 2009), algunas de ellas de historial taxonómico y nomenclatorial complejo y controvertido, como veremos.

Así, de las nueve especies y variedades que habían sido descritas o citadas y que eran históricamente conocidas en Europa, de ellas tres en la Península Ibérica, fueron reduciendo su número al considerarse sinónimas (Erichson, 1839; Hagen, 1858, 1866a, 1866b), y más recientemente nuevos taxa fueron introducidos en su fauna (M. mandarina) (Aspöck et al., 1980) y nuevas especies del sur de Europa se anunciaban (Poivre, 1981a) y fueron descritas (Mantispa hauseri Poivre, 1982, en base a un único ejemplar hembra), alguna variedad había sido revalidada como especie designando un neotipo (M. icterica) (Poivre, 1982d), y varias sinonimias y varios cambios nomenclatoriales y taxonómicos han sido propuestos (Zakharenko, 1987), creando una situación bastante desordenada y confusa.

Más recientemente las nueve especies descritas de Europa han sido revisadas por Aspöck \& Aspöck (1994) y Aspöck (1994), proponiendo varias sinonimias $[M$. perla Pallas, $1772=$ M. christiana Charpentier, 1825 (ya sinonimizada por Erichson, 1839); M. styriaca Poda, $1761=$ M. hauseri Poivre,
1982], designando lectotipo y paralectotipo para M.scabricollis MacLachlan, 1875, descartando alguna especie previamente citada en su fauna (M. mandarina Navás, 1914), cuestionando algunas sinonimias anteriormente propuestas por Zakharenko (1987) (M. adelungi Navás, 1912; M. lobata Navás, 1912; M. mandarina Navás, 1914; M. minuta Kozhanchikov, 1949), poniendo en sinonimia alguna especie históricamente citada en la Fauna Europea/Ibérica (M. icterica Pictet, 1865) y, por el contrario, describiendo una nueva especie en Europa ( $M$. aphavexelte), manteniendo tras estos estudios cinco especies europeas válidas y de ellas tres en la Fauna Ibérica.

En cualquier caso alguno de los criterios morfológicos utilizados para cuestionar sinonimias propuestas o para defender las diferencias entre especies conocidas y la descrita en esta contribución (Aspöck \& Aspöck, 1994; Aspöck, 1994), como son los basados en coloración tegumentaria (de ejemplares recolectados hace muchas décadas), la coloración parda o parduzca (sic) de la membrana bajo Sc, y/o el grado de esclerificación y forma de los márgenes anteriores de los terguitos $8^{\circ}$ y $9^{\circ}$ en los machos y esternitos en las hembras son, desde nuestro punto de vista, subjetivos y variables en función de la edad del individuo (o del ángulo de observación) y, por tanto, son poco sostenibles y no son demasiado convincentes, obviando estos autores (o dando menor importancia) otros caracteres de máximo interés taxonómico, como son la genitalia masculina (según estos autores idéntica entre la nueva especie descrita y alguna de las asiáticas), y algunos de sus argumentos parecen tener un cierto sesgo de defender la identidad y validez de $M$. aphavexelte que describen en base a información indirecta publicada por anteriores autores (como M. mandarina por Aspöck et al., 1980 o como M. icterica por Poivre, 1983), sin definir claramente ni dibujar su genitalia masculina y/o femenina, no sólo en esta especie, sino en todas las demás, hecho que hubiera sido deseable para zanjar definitivamente la identidad de las especies europeas quedado así incuestionablemente definidas, y en particular mantenemos serias dudas sobre la validez de $M$. aphavexelte frente a algunas especies asiáticas, en especial frente a la especie del Cáucaso $M$. adelungi, cuando otras especies europeas de este género han sido citadas en el sudeste asiático (M. styriaca, $M$. perla) y estos autores citan material de $M$. aphavexelte de Anatolia, Armenia y Mongolia (incluso probable en China). En cualquier caso, y aunque no consideramos el tema definitivamente resuelto, para no complicar aún más la situación, seguimos el criterio de Aspöck \& Aspöck (1994) y Aspöck (1994) a la espera de nuevos datos.

Tras estas dos contribuciones (Aspöck \& Aspöck, 1994; Aspöck, 1994), aparentemente la taxonomía de las especies europeas parecía estar resuelta, no así la diagnosis de las especies, su correcta descripción morfológica y genital, y la presentación de unas claves 
sobre caracteres objetivos y constantes que incluyan todas estas especies de forma inequívoca, hechos que se suman a la escasa diferencias interespecíficas existentes entre numerosas especies y la frecuente variabilidad intraespecífica, que son hechos comunes en esta familia (Kuwayama, 1924; Snyman et al., 2012).

Es quizás por todo ello por lo que tenemos serias dudas que la situación sea satisfactoria y que en algunos de los trabajos publicados se esté realmente hablando de los mismos taxa citados de una u otra forma (ej.: Şengonca, 1980; Zakharenko, 1987; Ábrahám \& Papp, 1994), hechos que se suman a la falta de concreción respecto a la diagnosis en algunos géneros en esta familia, incluido el propio e histórico género tipo Mantispa, que sin duda requiere una revisión (Snyman et al., 2012) y numerosas especies hoy día asignadas a este género probablemente no pertenezcan a él, y aunque se ha citado como estable el número de especies europeas, no parece que sea el caso en las especies paleárticas occidentales, y en esta contribución demostramos que tampoco lo era para las ibéricas, y con ellas para europeas (Lambkin, 1986a, 1986b; New, 1998; Ohl, 2007a; Snyman et al., 2012).

Es precisamente el confuso legado sobre muchos taxa pertenecientes a esta familia y lo impreciso de algunos datos y opiniones aportados por autores previos, al menos en lo que nos concierne, lo que nos ha llevado a la presente contribución en la que definimos y caracterizamos adecuadamente cada una de nuestras especies (Figs. 23-51, 54-58) y anotamos numerosos nuevos datos sobre la biología, taxonomía, morfología y distribución de las tres especies de mantíspidos que conocíamos en la Península Ibérica e Islas Baleares, y describimos una nueva especie desconocida hasta la fecha.

\section{Historial de su CONOCIMIENTo en la Fauna IbéRICA}

Tras esta introducción al tema general de los mantíspidos europeos, y centrando ya el tema exclusivamente en nuestra fauna, en nuestras latitudes son insectos de tamaño medio, normalmente poco abundantes, pero no son raros sobre vegetación arbórea, especialmente en árboles maduros y aislados (hecho ya referido por Rambur, 1842) en determinadas zonas soleadas y abiertas, y con mayor frecuencia en planifolios que acicudifolios, donde pueden resultar puntualmente abundantes, y pocas veces se han hallado sobre vegetación herbácea (Lucchese, 1956; Şengonca, 1980). Generalmente las hembras son más abundantes que los machos (McKeown \& Mincham, 1948) o lo parece porque poseen una mayor longevidad (ver más adelante fenologías del material ibérico estudiado).

Desde las primeras referencias, descripciones y citas en el s. XIX y principios del XX de mantíspidos en la Península Ibérica (Burmeister, 1839; Pictet, 1865; Bolívar, 1882; Hagen, 1866a, 1866b; Brauer, 1876;
McLachlan, 1902a, 1902b, etc.), podemos indicar que no tratamos un grupo de insectos frecuentemente citado en la bibliografía de este periodo. Más adelante destaca la obra del prolífico L. Navás (1858-1938), a quien debemos la mayoría de la información bibliográfica existente y la inmensa mayoría de las citas correspondientes a nuestra fauna, y fue él quien realizó la primera revisión de los mantíspidos incluidos en sus sinopsis de los neurópteros de España y de Cataluña, (Navás, 1924a, 1925), describiendo a lo largo de su vida multitud de taxa pertenecientes a esta familia. Su controvertida obra, muy frecuentemente cuestionada, también afecta a la taxonomía de esta familia en su conjunto [como ejemplo comentemos que Mansell (2010) menciona 764 taxa del orden Neuroptera descritos por este autor de la Región Afrotropical (especies en su mayoría) de las que el $50 \%$ ya han sido consideradas no válidas], y su obra afecta especialmente a los neurópteros de nuestra fauna [nada menos que 152 especies y 149 variedades fueron descritas por él dentro de la Fauna Ibero-Balear, que sumadas a las descritas de las Islas Canarias alcanzan un total de 239 taxa descritos en este orden de insectos en nuestra fauna (Navás, 1924a, 1925; Monserrat, 2011; Monserrat \& Triviño, 2013)]. Otros numerosos taxa por él descritos de otros continentes también han sido posteriormente sinonimizados (Penny, 1982b; Oswald \& Penny, 1991). Afortunadamente su desordenada metodología (Snyman et al., 2012) no afectó a los taxa ibéricos de esta familia.

Al margen de la cuestión meramente taxonómica, y en lo que respecta a la faunística de esta familia en la Península Ibérica, son abundantes las citas dadas por este autor en nuestra fauna (ver relación de citas de cada especie más adelante). Algunas de estas citas han podido revisarse tras el estudio del material correspondiente, dada la costumbre de Navás de repartir parte de su material en diferentes instituciones (Monserrat, 1985c, 1986a, 1988), aunque sobre el resto del material descrito o citado, debido a las penosas vicisitudes sufridas por su colección particular, y en el caso de esta familia han sido especialmente inclementes, y se ha considerado que muchos de los ejemplares de su colección personal pertenecientes a esta familia han sido destruidos (Monserrat, 1985c, 1986a, 1988).

Ya en la segunda mitad del s. XX y pricipios del presente han venido incorporándose numerosas citas, aunque son proporcionalmente escasas en relación a otras familias de neurópteros más frecuentes o más ricas en especies. Recientemente Monserrat \& Triviño (2013) anotaban la problemática existente sobre las citas y la posición taxonómica de algunas especies citadas en la Península Ibérica, anunciaban la presencia alguna nueva especie en ella que ahora describimos, y consideraban 284 registros fiables en base a material estudiado y adecuadamente revisado, así como de abundante material inédito que ahora se cita, aportando el cartografiado de las citas fiables conocidas, y destacaban que aún existen numerosas 
áreas ibero-baleares escasamente muestreadas, donde es posible su presencia (Figs. 59-62).

Enlazando con lo anteriormente citado para la fauna europea en general, según estos autores (Monserrat \& Triviño, 2013), aparentemente estaban bien definidas las tres especies que eran conocidas de la zona considerada (Mantispa styriaca, Perlamantispa perla, Perlamantispa icterica). La reciente inclusión en la zona de estudio de Mantispa mandarina Navás, 1914 primero, y de Mantispa lobata Navás, 1912 y Mantispa aphavexelte Aspöck \& Aspöck, 1994 después, al margen de otras especies europeas descritas (Aspöck et al., 1980; Poivre, 1982a, 1982b; Zakharenko, 1987; H. Aspöck, 1992; U. Aspock, 1994, 1996; Aspöck \& Aspöck, 1994) había creado una situación taxonómica compleja y confusa, y no había podido ser aún asumida ni revisada por nosotros, especialmente teniendo en cuenta ciertos trabajos previos (Poivre, 1981a, 1981b, 1982a, 1982b, 1983, 1984a) y el haber detectado la constancia de novedades dentro del nuevo material inédito de la Fauna Ibero-Balear (Monserrat \& Triviño, 2013), datos que sinceramente necesitábamos ordenar y repasar detenidamente, y afrontar la revisión de esta familia en nuestra fauna, motivo de la presente contribución.

Por todo lo anotado, con respecto a las citas y referencias existentes en la bibliografía relacionada con la zona tratada, y quizás salvo $M$. styriaca, que parece bien definida en autores previos (ver Navás, 1924a, 1925), sólo han de considerarse las dadas más recientemente por autores solventes que utilizan la genitalia para la identificación de las diferentes especies, y no deben considerarse del todo fiables las citas anteriores, ni pueden darse por válidas sin problema de considerarlas dudosas o erróneas. Aún así, y para recopilar toda la información existente, anotamos las citas bibliográficas existentes hasta esa fecha de estas especies en la Península Ibérica y Baleares, que han sido citada en ellas bajo diferentes sinonimias o combinaciones nomenclatoriales.

Aportamos ahora la revisión y, en su caso corrección, de abundante material anteriormente citado, de nuevo material inédito, y anotamos nuevos datos sobre su bastante desconocida biología, con nuevos datos inéditos sobre las plantas soporte, comportamiento reproductor, fenología y distribución geográfica y altitudinal en nuestra fauna, así como el cartografiado de los datos conocidos fiables (Figs. 59-62), aunque lógicamente no se descarta que puedan aparecer nuevos registros en otras áreas diferentes a las ahora anotadas.

Estas curiosas y llamativas especies (Figs. 1-9) están amenazadas en Centro-Europa, donde en numerosas áreas no han sido vistas hace muchas décadas (Aspöck, 1994), o están relegadas en aislados refugios y protegidos enclaves, y por ello suelen formar parte de las Listas Rojas de especies de neurópteros amenazados o en peligro de extinción (Gepp, 1981,
1983; Devetak, 1992a; Duelli, 1994; Hölzel, 1999; Jedlička, 2001; Pröse \& Gruppe, 2003; Zelený, 2005). También son actualmente objeto de atención en Internet (McEwen \& Oswald, 1998; Röhricht, 2002), y especialmente lo son en multitud de foros que recientemente han aparecido, y por la misma razón aducida para las citas bibliográficas de estas especies, estos registros podrían considerarse (siempre que los datos aportados en estas webs sean los correctos), y así lo hemos en tenido en cuenta en algunos casos al anotar parte del nuevo material ahora citado. En cualquier caso, actualizar, revisar y contribuir a su mayor conocimiento de esta poco conocida familia en la Península Ibérica es pues uno de los objetivos del presente artículo.

\section{Material y métodos}

Para la realización de esta revisión recopilamos y partimos de toda la información existente en la bibliografía referente a los mantíspidos ibérico-baleares, datos que se exponen en cada una de las especies tratadas, recopilando, cronológicamente ordenadas, todas las referencias bibliográficas existentes, a partir de las cuales se puede recabar toda la información existente sobre cada una de ellas. Anotamos los autores de estas citas, su fecha de publicación y la/s pági$\mathrm{na} / \mathrm{s}$ donde se aporta información sobre su biología (bio), descripción original (d), distribución geográfica (dis), fenología (fen), huevo (h), inclusión en claves (key), larva (1), aparezca en un listado (list), morfología del imago (mf), pupa (p), simple referencia (rf), o taxonomía (tx).

En principio, y por las diferencias morfológicas existentes entre la mayoría de las diferentes especies que tratamos, cabría suponer que las identificaciones dadas por los autores pretéritos son acertadas, sin embargo esta recopilación compilada es meramente informativa y no siempre implica la total asunción de sus contenidos. Por todo ello, para evitar la utilización de datos poco fiables citados en la bibliografía y correr el riesgo de asumir como ciertos datos basados en identificaciones erróneas o incorrectas, mezclando información de unas y otras especies, y habida cuenta del abundante material ahora estudiado, para la realización del estudio comparativo de la biología, fenología y distribución altitudinal y fenológica de las especies ibéricas, sólo se ha tenido en cuenta el material revisado y estudiado por nosotros, y puntualmente algún dato aportado por autores recientes de reconocida solvencia.

En lo que respecta al material estudiado, se ha contado con el material que hemos recolectado en los cuarenta últimos años en diferentes puntos de la Península Ibérica, el nuevo material inédito por nosotros recolectado, así como aquel otro perteneciente a ciertas instituciones y museos que nos han permitido el estudio de sus colecciones o que nos han proporcionado 
información sobre el tema que nos ocupa y cuyas siglas se anotan a continuación:

JB Colección Jan Bosselaers, (Beerse, Bélgica). MB Museu de Ciències Naturals (Barcelona, España).

MG Museo Civico di Storia Naturale "G. Doria" (Génova, Italia).

MNCNM Museo Nacional de Ciencias Naturales (Madrid, España).

MNHN Muséum National d'Histoire Naturelle (París, Francia).

NHM The Natural History Museum (Londres, Reino Unido).

VM Colección del autor (Madrid, España).

Para la exposición del material estudiado, los datos se exponen alfabética- y cronológicamente ordenados, indicándose en función de los datos de captura disponibles y por este orden el país, provincia y localidad de captura, coordenadas UTM o geográficas, altitud en msnm, fecha de captura, número de $\widehat{\partial} \widehat{\partial}$, de $ㅇ+$, o de estadios juveniles estudiados, planta sobre la que los ejemplares han sido capturados (por economía de espacio, se ha apocopando su género cuando ya ha sido utilizado) y recolector (por igual motivo, únicamente se indica el recolector cuando no ha sido el autor de esta contribución). En esta relación del material estudiado se señalan con un asterisco (*) aquellos ejemplares elegidos para realizar las figuras o fotografías de la morfología externa (me*), de sus alas (a*), su genitalia masculina $\left(\widehat{\delta}^{*}\right)$ o femenina $\left({ }^{*}\right)$ o su pupa $\left(\mathrm{p}^{*}\right)$. Cuando ha sido necesario, también se anota, como material complementario de comparación, otro material no ibérico.

Para todas las especies se comentan los datos más destacables sobre su morfología externa, segmentos genitales, biología, fases larvarias (en su caso) y distribución fenológica, altitudinal, y geográfica en la zona, así como, en algún caso, un apartado de discusión, donde se anotan los datos que hemos considerado necesario comentar. Para las fenologías de cada especie, no han sido considerados los ejemplares obtenidos ex ovo y cultivados artificialmente en condiciones no naturales.

Aunque existen datos en la morfología externa que ayudan a la identificación de las especies ibéricas de esta familia, y así los utilizamos en las claves, el estudio de la genitalia es necesario para la segura y correcta identificación de los ejemplares inmaduros o escasamente pigmentados. Para ello se procedió a la separación de los últimos cuatro segmentos del abdomen mediante disección. Si el material estaba conservado en seco se ha hidratado previamente durante 24 horas por inmersión en agua, y posteriormente se han aclarado estos últimos segmentos con hidróxido potásico al $10 \%$ templado para acceder a las estructuras genitales. Para las hembras se recomienda una leve tinción con negro de clorazol $(1 \%)$, o bien eosina, hematoxilina o mercuriocromo. Una vez realizado este proceso hemos introducido la genitalia en glicerina dentro de un portaobjetos excavado para su observación mediante un estereo-microscopio ZEISS ${ }^{\circledR}$ STEMI-SV8 con cámara clara de dibujo incorporada. Las fotografías de realizaron con un estereo-microscopio Olympus ${ }^{\circledR}$ SZX7, con cámara Olympus ${ }^{\circledR}$ S-C-30 integrada, utilizando para su proceso el software analySIS getIT. Los dibujos se realizaron a mano alzada con cámara clara y se retocaron utilizando el programa de diseño Corel Paint Shop Pro Photo XI.

Para la realización de los mapas de distribución de las especies (Figs. 59-62) se ha utilizado el programa de diseño vectorial Corel Draw 10, y, como hemos anotado, sólo se ha tenido en cuenta el material estudiado y/o revisado por nosotros, y puntualmente también todas aquellas citas bibliográficas existentes y que nos han parecido incuestionablemente solventes en función de los autores que las han dado.

Sobre la taxonomía, sistemática y morfología general (Figs. 23-58) se sigue la terminología habitualmente usada para esta familia (Aspöck et al., 1980), si bien la terminología de la venación alar en esta familia es objeto de diversas interpretaciones (Ferris, 1940; Lambkin, 1986a, 1986b; Hoffman, 1992; Machado \& Rafael, 2010; Snyman et al., 2012, etc.), habiendo adoptado la de Lucchese (1956) (Fig. 10). Para la distribución general de las especies paleárticas occidentales y/o europeas de la familia se recomienda la recopilada por H. Aspöck et al. (2001).

\section{Resultados}

\section{Los Mantíspidos de la Península Ibérica}

TAXonomía (sólo se consideran los taxa que afectan a la fauna considerada):

Mantispidae Leach en Brewster, 1815: 139

Mantispinae Leach en Brewster, 1815: 139

Género tipo por monotipia: Mantispa Illiger en Kugelann, 1798: 499.

Género Mantispa Illiger en Kugelann, 1798: 499

Especie tipo por monotipia: Mantis pagana Fabricius, 1775: 278 = Raphidia styriaca Poda, 1761: 101. Mantis pagana Fabricius, 1775 ha sido considerada sinonimia de Raphidia styriaca Poda, 1761 = Mantispa styriaca (Poda, 1761) por Aspöck et al., 1980: 182.

= Perlamantispa Handschin, 1960a: 191

Especie tipo por designación original: Mantispa perla (Pallas, 1772) = Mantis perla Pallas, 1772: 14.

= Afromantispa Snyman \& Ohl, 2012 en Snyman et al., 2012: 74 n. syn.

Especie tipo por designación original: Afromantispa tenella (Erichson, 1839) $=$ Mantispa tenella $($ Erichson, 1839: 169).

Con cierta controversia de opiniones, se ha sugerido que Perlamantispa Handschin, 1960 podría ser sinónimo de Mantispa (H. Aspöck et al., 1980, 2001; 
Zakharenko, 1987), aunque otros autores mantienen su validez (Poivre, 1982b, 1982d, 1983, 1986). Mayoritariamente fue descrito en base a caracteres de escaso valor taxonómico. Desde nuestro punto de vista ambos géneros (Mantispa y Perlamantispa) comparten la mayor parte de los caracteres que pueden considerarse de interés, sean externos y especialmente las estructuras genitales (Figs. 23-42), y sólo han sido citadas diferencias sutiles y poco equiparables (a nivel de género) con lo que ocurre en los géneros de otras familias de neurópteros y que serían irrelevantes a nivel genérico en muchas otras familias de este orden. Por ello el género Perlamantispa Handschin, 1960 no ha sido considerado.

Recientemente Snyman et al. (2012) lo consideran sinónimo de Sagittalata Handschin, 1959c: 215 [(Especie tipo por designación original: Mantispilla hilaris Navás, 1925: 573 (como "Sagittalata hilaris (Navás 1924) sic")], hecho que no compartimos. Los caracteres diagnósticos utilizados por estos autores para Mantispa y Sagittalata/Perlamantispa vuelven a ser muy sutiles y superficiales: presencia-ausencia de mancha alargada sobre las coxas [presentes tanto en $M$. perla como en $M$. styriaca, las especies tipo de ambos géneros (Figs. 25, 36)], pterostigma más o menos alargado $[M$. incorrupta $\mathbf{n}$. sp. presenta pterostigmas más triangulares y semejantes a $M$. styriaca, pero es de morfología externa (especialmente el pronoto) y alar muy diferente (Figs. 23-26, 44-48), protórax con o sin setas [todas las especies europeas asignables a cualquiera de estos géneros las poseen (Figs. 23, 24, 34, 35, 39, 40, 44, 45)], con o sin surcos transversales [presentes tanto en $M$. perla como en $M$. aphavexelte (Figs. 34, 35, 39, 40)], etc., se nos antojan caracteres que no parecen ser demasiado "contundentes" a nivel genéro y, en cualquier caso, son caracteres que no serían aceptables en la diagnosis genérica en otras familias de neurópteros, especialmente cuando sus estructuras genitales son de idéntico tipo y organización (Figs. 27-33, 49-58), y ciertos caracteres utilizados por estos autores: ectoprocto más o menos hinchado, o mediuncus visible en vista dorsal es compartido por todas estas especies (Figs. 27-33, 48-53). A pesar de estas nuevas manifestaciones, seguimos sin tener argumentos para poder considerar válido el género Perlamantispa.

Tampoco podemos considerar ni la validez del género Afromantispa, ni la imprecisa referencia a España que Snyman et al. (2012) hacen sobre la distribución del género Afromantispa por ellos creado: "Distribution. Widespread throughout Africa. A few species have been collected in the Palaearctic Region sharing borders with Africa such as Spain and the Arabian Peninsula" (es casi seguro que se están refiriendo a la nueva especie que en esta contribución describimos: Mantispa incorrupta n. sp.). Sobre la validez del género Afromantispa volvemos a no estar de acuerdo con estos autores, pues se nos antojan caracteres que no parecen ser demasiado "contundentes" a nivel genéro y que se comparten con especies de otros géneros, por lo que no pueden considerarse diagnósticos a nivel genérico. Estos autores basan la creación del género Afromantispa en tres caracteres que discutimos: 1) Antenas bicolores: [son varias las especies afrotropicales o neotropicales con antenas bicolores, y Mantispa zonaria Navás, 1925, Dicromantispa interrupta (Say, 1825) o Mantispa incorrupta n. sp. son buenos ejemplos (Fig. 43, Poivre, 1980, 1982a, 1982b)]. 2) Protórax granulado con tubérculos en la base de las setas del pronoto: (este caracter aparece en otras especies del género Mantispa: $M$. nana Erichson, 1839, M. tenella Erichson, 1839, M. scabricollis McLachlan, 1875, M. zonaria Navás, 1925 o M. incorrupta n. sp.) (Figs. 44-45, Aspöck et al., 1980; Poivre, 1980, 1982a, 1982b). 3) venilla entre Cua y Cup+Aa en las alas posteriores atenuada o ausente: (carácter presente en otras especies como Mantispa aphavexelte, Figs. 42, 48, Aspöck et al., 1980). En cualquier caso, son caracteres muy superficiales que no serían aceptables en la diagnosis genérica en otras familias de neurópteros, especialmente cuando sus estructuras genitales son de idéntico tipo y organización (Figs. 49-58).

\section{Especies consideradas}

Citamos las especies consideradas con sus sinonimias habitualmente reconocidas y las diferentes combinaciones nomenclatoriales con las que han sido citadas en la Fauna Ibérica y Balear.

\section{Mantispa styriaca (Poda, 1761) \\ Raphidia styriaca Poda, 1761 \\ Raphidia mantispa Linnaeus, 1767 \\ Mantis pagana Fabricius, 1775 \\ Mantispa pagana (Fabricius, 1775) \\ Mantis pusilla Schrank, 1781 (nec Pallas, 1772) \\ Mantispa styriaca pagana Fabricius, 1775 \\ Mantispa hauseri Poivre, 1982 \\ Mantispa kononenkoi Makarkin, 1985}

Mantispa perla (Pallas, 1772)

Mantis perla Pallas, 1772

Mantispa christiana Charpentier, 1825

Mantispa victorii Guerin, 1845

Perlamantispa perla (Pallas, 1772)

Mantispa perla icterica Pictet, 1865 (part.)

Perlamantispa perla icterica (Pictet, 1865) (part.)

\footnotetext{
Mantispa aphavexelte Aspöck \& Aspöck, 1994

Mantispa perla icterica Pictet, 1865 (autores, nec Pictet, 1865, part.)

Perlamantispa perla icterica (Pictet, 1865) (autores, nec Pictet, 1865, part.)

Mantispa icterica Pictet, 1865 (autores, nec Pictet, 1865, part) Perlamantispa icterica (Pictet, 1865) (autores, nec Pictet, 1865, part.)

Perlamantispa aphavexelte (Aspöck \& Aspöck, 1994)
}

\section{Mantispa incorrupta $\mathbf{n}$. sp.}


Especies directa- o indirectamente citadas en la Fauna Ibérica y Balear y que, según nuestro punto de vista, su estatus no se encuentra definitivamente resuelto ni consensuado:

Mantispa lobata (autores, nec Navás, 1912)

Mantispa perla lobata (autores, nec Navás, 1912)

Mantispa adelungi (autores, nec Navás, 1912)

Mantispa perla adelungi (autores, nec Navás, 1912)

Mantispa mandarina (autores, nec Navás, 1914)

\section{Clave de especies}

Los caracteres de morfología externa elegidos son sencillos y de fácil acceso, y normalmente son constantes en los ejemplares maduros. No se han utilizado algunos caracteres empleados a veces en la identificación de alguna de las especies (Poivre, 1983; Séméria, 1984; Aspöck \& Aspöck, 1994) por considerarlos variables, a veces engorrosos y de difícil acceso o de apreciación subjetiva. En caso de dudas debe recurrirse a la genitalia masculina.

1 Pterostigma de las alas abruptamente dilatado y triangular (Fig. 26). Manchas del pronoto y de las patas anteriores según figs. 23-25. Genitalia masculina según figs. 27-29..... Mantispa styriaca

- Pterostigma de las alas progresivamente dilatado y alargado (Figs. 37, 42, 48). Manchas del pronoto y de las patas anteriores diferentes, según figs. 34-36, 39-41, 44-47. Genitalia masculina según figs. 30-33, 49-51 ....... 2

2 Alas anteriores con espacio entre Sc y $\mathrm{R}$ antes del pterostigma prácticamente inexistente y más oscuro que el resto, similar al del pterostigma (Fig. 48). Pterostigma de las alas bicolor, más pálido en el centro (Fig. 48). Antenas con un grupo de flagelómeros centrales mucho más pálidos que los restantes (Fig. 43). Base de las setas en el pronoto situadas sobre pequeños tubérculos (Figs. 44, 45). Pronoto más de cuatro veces tan largo que su parte anterior más ancha (Figs. 44, 45). Manchas del pronoto y de las patas anteriores según figs. 44-47. Genitalia masculina según figs. 49-51

Mantispa incorrupta n. sp.

- $\quad$ Alas anteriores con espacio entre Sc y R antes del pterostigma presente, bien delimitado y todo él de similar color que el pterostigma (Figs. 37, 42). Pterostigma de las alas de un único color (Figs. 38, 42). Antenas con todos los flagelómeros pardos. Pronoto menos de tres veces tan largo que su parte anterior más ancha y sus setas sin pequeños tubérculos en su base (Figs. 34, 35, 39, 40). Manchas del pronoto y de las patas anteriores según figs. 34-36, 39-41. Genitalia masculina según figs. 30-33 .................. 3

3 Protórax algo más largo que el pterotórax (Figs. 9, 38), pronoto con manchas muy contrastadas según Figs. 34, 35, 38, su porción anterior más ancha es casi la mitad de su longitud total (Figs. 34, 35). Alas con membrana ahumada de pardo amarillenta, las anteriores más pigmentadas en la zona basal (Figs. 37). Cara interna de los fémures anteriores pardos muy oscuro (Fig. 36). Genitalia masculina según figs. 32, 33 ...

.. Mantispa perla

- Protórax mucho más largo que el pterotórax (Figs. 39, 40), pronoto con manchas tenues según figs. 39,40 , su porción anterior más ancha es casi un tercio de su longitud total (Figs. 39, 40). Alas con membrana de casi hialina a levemente ahumada de pardo amarillenta, pero las anteriores no más pigmentadas en la zona basal (Figs. 42). Cara interna de los fémures anteriores pardos con una gran mancha pálida (Figs. 41). Genitalia masculina según figs. 30,31 .

Mantispa aphavexelte

\section{Mantispa styriaca (Poda, 1761)}

Hagen, 1866a: 291 (mf, rf); Brauer, 1876: 290 (rf); Navás, 1900: 94 (bio, dis); McLachlan, 1902a: 33 (dis); Navás, 1905a: 18 (dis), 1905c: 38 (rf), 1908: 133 (dis, mf), 1913: 87 (dis), 1914e: 190 (dis), 1916: 155 (bio, dis); Bohigas \& Sanchez, 1917: 318 (dis); Navás, 1919a: 202 (24) (bio, dis), 1919b: 38 (dis), 43 (dis), 1921a: 152 (dis), 1921b: 65 (dis), 1922: 9 (bio, dis); 1923: 168 (bio, dis), 1924a: 255 (dis, key, mf), 1925: 129 (key, mf); Principi, 1952: 9 (dis); Auber, 1958: 11 (rf); Handschin, 1959a: 110 (dis), 114 (rf); Monserrat, 1977: 16 (list), 65 (key, rf), 1978b: 173 (bio, dis); Zakharenko, 1987: 622 (rf); Monserrat, 1979b: 414 (bio, dis); Aspöck et al., 1980: 52 (key), 183 (bio, fen, mf, rf, tx); Şengonca, 1980: 469 (rf); Poivre, 1982d: 667 (dis); Monserrat, 1982: 73 (bio, dis), 1984a: 177 (bio, dis), 1984b: 98 (bio, dis), 1984d: 33 (bio, dis), 1984c: 161 (bio, dis), 1985b: 88 (bio, dis), 1986b: 100 (dis); Díaz-Aranda et al., 1986: 1136 (bio, dis); Monserrat, 1987a: 137 (bio, dis), 1987b: 263 (mf, rf); Díaz-Aranda \& Monserrat, 1988a: 116 (bio, dis), 1988b: 221 (bio, dis), 1988c: 218 (bio, dis); Monserrat \& Díaz-Aranda, 1989: 191 (bio, dis, h, 1, p); Marín \& Monserrat, 1990: 223 (bio, dis), 1991: 181 (bio, dis); Monserrat et al., 1994: 45 (bio, dis); Marín, 1994: 260, 288, 294 (bio, dis); Aspöck, 1994: 226 (rf); Marín \& Monserrat, 1995a: 39 (bio, dis), 1995b: 114 (bio, dis); Monserrat, 1996c: 13 (list), 2005: 75 (bio, dis); H. Aspöck et al., 2001: 202 (rf); Ocharan et al., 2012: 423 (bio, dis); Monserrat, 2013: 289 (bio, dis); Monserrat \& Triviño, 2013: 15 (list), 23 (rf), 49 (dis).

Mantispa pagana Fabricius, 1775

Burmeister, 1839: 967 (rf); Pictet, 1865: 58 (rf); Monserrat \& Triviño, 2013: 15 (list).

Mantispa styriaca pagana Fabricius, 1775

Monserrat \& Triviño, 2013: 15 (list).

\section{Material estudiado:}

ESPAÑA: Álava, Musitu, 800 m, 30TWN43, 28.V.2005, 1우, I. Zabalegui (VM), Padul, 700 m, 30TWN0438, 5.VII.2005, 19, S. Pagola (VM), Ribera, 750-800 m, 30TVN8144, 12.VII.2005, $1 \widehat{\jmath}, 1 q$ sobre Pinus sylvestris, S. Pagola (VM). Albacete, El Bonillo, 26.VI.1990, $1 \overbrace{}^{\lambda}$ sobre Juniperus thurifera, F. Marín (VM), 13.VII.1991, 1 q sobre J. thurifera, F. Marín (VM), Fuensanta, 19.VIII.1990, 1 q sobre Quercus rotundifolia, F. Marín (VM). Alicante, Benidorm, 17.VII.1982, $10^{\hat{O}}$ sobre $P$. halepensis (VM), Cocentaina, 18.VII.1982, 19, 4.VIII.1982, 1 q todas sobre Q. ilex (VM), Teulada, 17.VII.1982, 1 + sobre P. halepensis (VM). Almería, Adra, Trebolar, Almería, 30SVF97, 566 m, 3.VIII.2010, 10, 1우, F. Rodríguez (Figs. 11-13), Bédar, La Serena, 15.VII.2007, $1 \hat{\jmath}, 20$ 우 sobre Prunus dulcis (VM), 20.VII.2007, $1 \delta^{\hat{\jmath}}$ a la luz (VM), Enix, 20.VII.1988, $3 \widehat{\partial} \widehat{\partial}, 1$ 우 sobre $Q$. rotundifolia (VM), 19.VI.1990, 2 우 sobre Q. rotundifolia (VM), Enix, Sierra de Gador, 30SWF38, 26.V.2010, $1 \delta^{\lambda}$ sobre Dittrichia viscosa, F. Rodríguez (Figs. 4, 5), 19.VI.1990, 2 우 sobre Q. rotundifolia, F. Rodríguez, Lucainena de las Torres, 14.VII.1994, 19 sobre Olea europea, L. M. Díaz-Aranda (VM), Níjar, 8.VII.1996, $1{ }^{\lambda}$ sobre Ceratonia siliqua, 7.V.2011, $1 \delta^{\Uparrow}$ sobre C. siliqua (VM), Rambla de Chirivel, 28.VI.1983, 1 ㅇ sobre Q. ilex (VM), Rambla de Tabernas, 11.VII.1985, 7ठోð, 3 우 a la luz (VM), VIII.1985, 5우, 1 pupa ex ovo* (p*) (VM), Rambla Honda, 30.V.1989, 1 우 sobre C. siliqua, A. Baz (VM), 1 + sobre Tamarix gallica, A. Baz (VM), Rambla Río Aguas, 30.IV.2007, $1 \widehat{O}^{\lambda}$ sobre O. europaea (VM), Río Claro, 27.VI.1983, $1 \delta^{\hat{\jmath}}$ sobre P. halepensis (VM), Sierra de Gador, 26.V.2010, 1§, F. Rodríguez (Figs. 4, 5). 
Asturias, Cangas del Tineo, s.f., $3 \circ$ 옹 E. Florez (MNCNM), Puente de Los Fierros, s.f., 1+, Dantin (MNCNM). Badajoz, Burguillos del Cerro, 14.VII.2001, 1 + sobre Q. rotundifolia (VM), Fregenal de la Sierra, 19.VI.2012, 1 ㅇ (VM). Baleares, Mallorca, Capdepera, 30.V.1908, 1ð̃, L. Navás (MB), Puerto de Pollensa, 17.IV.1975, 1§, J. \& F. Murphy (NHM). Barcelona, Calella, VI.1971, 19, Z. Bouček (NHM), Gualba, 9.IX.1934, 1 ej., L. Navás (MB), Las Planas, VIII.1964, 1ㅇ, Jordá (MB), Rubí, VII.1925, 1ð̊, L. Navás (MNCNM). Cáceres, Alcuéscar, s.f., $10 \hat{~}$

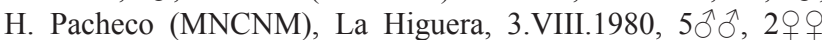
sobre $Q$. rotundifolia (VM), Mesas de Ibor, 3.VIII.1980, 1 ㅇ sobre Q. ilex (VM), Oliva de Plasencia, 1.VII.1980, 1万* (a*) sobre Q. ilex (VM), Puerto de la Cobacha, 19.V.1977, $1{ }^{\Uparrow}$ sobre Q. suber (VM), Salvatierra de Santiago, 26.VII.1980, $1 \delta^{\Uparrow}$ sobre Q. ilex (VM), Tejada de Tiétar, 2.VIII.1980, 1 q sobre Q. pyrenaica (VM), Venta de Calleja, 3.VIII.1980, $1{ }^{\Uparrow}$ sobre Q. suber (VM). Cádiz, Alcalá de los Gazules, 2.VI.1990, 1 ô sobre Q. suber, L. M. Díaz Aranda (VM), Pinsapar de Grazalema, 22.VII.2012, $1 \delta^{\lambda}\left({ }^{*}\right)$, 2 †* ( $\left.{ }^{*}\right)$ sobre $Q$. rotundifolia (VM), Sierra del Niño, 21.VIII.1981, $10^{\lambda}$, A. Vives (VM), Venta del Retín, 22.V.1977, $1 \delta^{\lambda}$ sobre O. europea (VM), 27.V.1987, 1 ㅇ sobre O. europea (VM), 9.VI.1988, 19 sobre Eucaliptus globulus, L. M. Díaz-Aranda (VM), 19.VII.1988, 1 + ex ovo (VM). Ciudad Real, Alcoba, Parque Nacional de Cabañeros, 1.VII.2007, 1今̂, 2 우 sobre Q. suber (VM), 1 + sobre Q. rotundifolia (VM), 4.VIII.2007, $1 \delta^{\lambda}$ ex ovo (VM), 29.VII.2014, 1 + sobre $Q$. rotundifolia, F. Acevedo (VM). Córdoba, Villanueva, s.f., $6 \hat{\jmath}, 4+q$, G.Ceballos (MNCNM). Gerona, Fitor, "Can Juanola", N 41 ${ }^{\circ} 54^{\prime} 08^{\prime}$ E

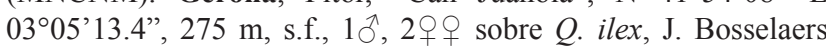
(JB), Mont Ras, "Pedrera La Morena", N 4154'55" E 0308'29", 100 m, 15.VII.2010, 1今̄, J. Bosselaers (JB). Granada, Albondón, 3649'91" N 3¹2'89'O, 898 m, 5.VII.2010, 10, 1ㅇ, sobre Q. rotundifolia (VM), Dúdar, 10.VII.2004, 1 9 , A.Tinaut (VM), El Dornajo, 3707'52.22”N 3'26'57.43”O, $1.750 \mathrm{~m}, 11$.VII.2010,

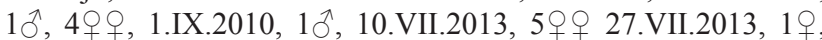
18.VII.2014, 2우, todos sobre Q. rotundifolia (VM), Güejar, 30.VII.2009, $2 \hat{\jmath} \hat{\sigma}, 1$ + sobre $Q$. rotundifolia (VM), Granada, 22.VI.1901, 1 ej., Walsingham (NHM), Haza de Lino, $36^{\circ} 48^{\prime} 51.84$ 'N 3018'29.01'”, $1.280 \mathrm{~m}, 24$.VI.2009, 1 ○े sobre $Q$. suber (VM), La Herradura, Punta de la Mona, 28.VII.2009, 1 우 a la luz (VM), La Taha, Pitres, 23.VII.2010, 1 + sobre Q. rotundifolia (VM), Otivar, 1.VI.1986, 1 đ sobre C. siliqua (VM), Puerto de la Cortichuela, $1.900 \mathrm{~m}, 3 . \mathrm{VII} .1986,1$ ㅇ sobre $Q$. ilex (VM), Puerto de los Alazores, 1.VI.1986, 19 sobre Amigdalus communis, $1 \hat{\circ}$ sobre $Q$. ilex (VM), 1.VII.1986, 3 우 sobre $Q$. ilex, 1 우 sobre A. communis (VM), Vélez de Benaudalla, 5.V.2011, 10 sobre Eucaliptus sp. (VM), Venta del Baúl, 3.VI.1986, $1+$ sobre Q. ilex (VM), Venta del Chaleco, 2.VII.1986, 1 ㅇ (VM). Guadalajara, Arbeteta, 6.VII.1984, 1 우 sobre $Q$. ilex, L. M. Díaz-

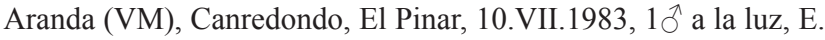
de Castro (VM), Luzón, 5.VII.1984, $1 \delta^{\Uparrow}$ (me*) sobre J. thurifera, L. M. Díaz-Aranda (VM), Valdeaveruelo, 13.VIII.1984, 1 ㅇ sobre Q. ilex, L. M. Díaz-Aranda (VM). Guipúzcoa, Marquina, s.f., 1 , leg.? (MNHNM). Huesca, Barbastro, 23.VII.1918, 1ㅇ, L. Navás (MNHN), 20.VIII.1982, 10, 1 ㅇ sobre Q. rotundifolia (VM), Puyarruego, 5.VIII.2011, 1q, E. Gil Alcubilla (Fig. 2), Santa María/La Peña (Las Peñas de Riglos), 17.VII.2010, $1 \widehat{\jmath}^{\lambda}$ en un que-

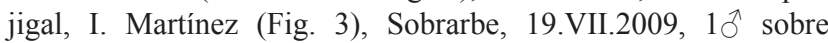
P. pinaster (VM). Jaén, Cañada Morales, 4.VII.1986, 2 오 sobre Q. rotundifolia (VM), Cazorla, Camino Agracea, 23-27.VII.1991, 1ठ, 31.VII.1991, 1 đิ a la luz, J. L. Yela (VM), Nava de San Pedro, 31.VIII.1962, 1ठ̃, V. Llorente (VM), Roblehondo, 13.VII.1991, $1 \delta$ a la luz, J. L. Yela (VM), Tiscar, 10.VIII.1988, $3 \hat{\jmath} \hat{\jmath}$ sobre

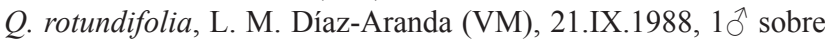
Q. rotundifolia, L. M. Díaz-Aranda (VM), Torre del Vinagre,
20.IX.1988, $1 ð$ sobre P. pinaster, 1 ㅇ sobre $Q$. rotundifolia, L. M.

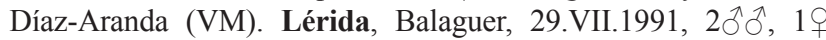
sobre $Q$. rotundifolia (VM), Carmeniú, 1.680 m, 15.VII.2009, 1 Љ sobre $Q$. rotundifolia (VM), El Torms, 21.VIII.1965, 2우, Ribes (MB), Lladurs, 2.VIII.1991, 1 ㅇ sobre Q. robur (VM), Moncortés, 4.VIII.1918, 1ðَ, L. Navás (MB), Montfalco, 20.VI.1991, 1 ㅇ sobre Q. rotundifolia (VM), 2.VIII.1991, 1今̄, 2 우 오 sobre Q. rotundifolia (VM), Ponts, 20.VI.1991, $1 \uparrow$ sobre Q. faginea (VM). Madrid, Beacos (¿Braojos?), 2.IX.1934, 1, M. Pujol (MNCNM), El Escorial, s.f., 19, Lauffer (MNCNM), El Escorial, Pinares Llanos, 2.VII.1922, 1ㅇ, G. Ceballos (MNCNM), Los Molinos, 31.VIII.1989, 1 + sobre una pared de cemento, R. Outerelo (VM), Torrelodones, 25.VIII.1989, 10, A. Vives (MNCNM), Torres de la Alameda, 27.VIII.1984, 2 우 sobre Q. faginea, A. Baz (VM), Villa del Prado, El Encinar del Alberche, 28.VIII.1991, 19, 20.VIII.1992, 1ठ, ambos sobre Q. rotundifolia, M. V. Peniado (VM). Murcia, Casa de la Carrasca, 15.VII.1982, 10* (a*) sobre Q. ilex (VM), Casa de la Rosa, 4.VII.1982, 1 ㅇ sobre Q. ilex (VM), 15.VII.1982, 7우 sobre $Q$. ilex (VM), 1.VIII.1982, $1 \delta^{\Uparrow}$ sobre Q. ilex (VM), Casas de San Pedro, 8.VI.1994, 10, 1 오 sobre O. europaea, L. M. Díaz-Aranda (VM), Puerto de la Cadena, 11.VII.1982, 1 + sobre $P$. halepensis (VM), Sierra Espuña, 26.VIII.1951, 1ㅇ, leg.? (VM). Navarra, Lerga, 27.VI.2012, $1 \delta^{\Uparrow}$ sobre $Q$. rotundifolia (VM), Torre Isabel, 18.VI.1954, 19, leg.? (VM). Orense, Orille, 3.IX.1977, 1 ㅇ sobre Q. pyrenaica (VM). Salamanca, Beleña, 2.VIII.1980, 3 우 sobre Q. ilex (VM), Ciudad Rodrigo, 15.VII.1983, 10ิ, C. Urones (VM), Dehesa de Esteban Isidro, 18.VII.1977, 1 sobre Q. ilex, F. Cabezas (VM), El Maillo,

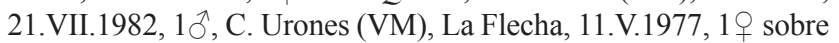
P. halepensis (VM), Membribe, 12.VII.1977, 1 ㅇ sobre Q. ilex

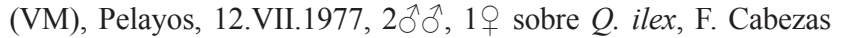
(VM), Sotoserrano, 29.VIII.1982, 19, C. Urones (VM), Valduciel,

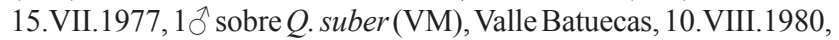
1 ㅇ a la luz (VM). Segovia, Valsaín, 8.VII.2007, 1 pupa en saco ovígero (VM). Soria, Valdemaluque, 15.VII.1989, $1 \delta^{\lambda}, 1+$ sobre J. thurifera, F. Marín (VM). Tarragona, Salou, 11.VI.1973, 1§,, Z.Bouček (NHM). Teruel, Albarracín, s.f., 1 ej., leg.? (NHM), Albarracín, Fuente de la Señora, 14.VII.1990, 10 ô sobre $P$. pinaster (VM), Mora de Rubielos, 19.VI.1987, $1 \delta^{\Uparrow}$ sobre Q. rotundifolia (VM), Orihuela del Tremedal, 5.VIII.1987, 1 + sobre $Q$. pyrenaica (VM). Toledo, El Borril, 26.V.2011, 1 + sobre Q. rotundifolia, Gálvez (VM), 9.VII.2011, 1 ㅇ sobre Q. rotundifolia, V. Triviño (VM), Sierra Higuera, Pelahustán, 24.IX.1983, 1 + a la luz en encinar, A. Vives (VM), Urda, Retén de incendios, 2.VI.2011, 1ð^, 4 우우 sobre $Q$. rotundifolia, V. Triviño (VM). Valencia, La Yesa, 14.VII.1991, 1ठิ sobre J. thurifera, F. Marín (VM). Zamora, Valparaiso, 15.VII.1977, 1 + sobre Q. faginea (VM). Zaragoza, Retuerta de Pina, Pina de Ebro, 30TYL29, 400 m, 10.VIII.1993,

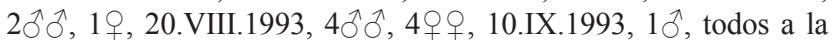
luz, J. Blasco (VM), Salvatierra de Escá, 8.VII.1994, 1 q sobre P. sylvestris, F. Marín (VM). PORTUGAL: Algarve, Loule,

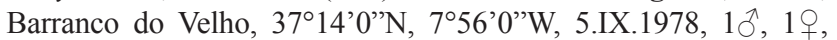
Passos de Carvalho (NHM), Serra de Monchique, 10.IX.1978, 1 đo, Passos de Carvalho (NHM). Castelo Branco, Almaceda, 7.IX.2007, 1 o, J. Almeida (Fig. 1). Como material complementario de comparación, se ha estudiado otro material no ibérico: FRANCIA: Corsica-Pineto, Bastia, 2.VIII.1978, 50̂̉, 10 우, Sette (MG). ITALIA: Liguria Occidentale, Savona, Pian Giaschi, 3.IX.1983, 1ㅇ, S. Zunino (MG). Veneto, Verona, Torri del Benaco, VII.1979, $3 \hat{\jmath} \widehat{\jmath}, 2+$ 우, Beretta (MG), Vicenza, Arzignano, VII.1966, 1 , Zanella (MG). MARRUECOS: Atlas Medio occidental, Col de Tanout-ou-Fillali, $32^{\circ} 40^{\prime} \mathrm{N}, 5^{\circ} 27^{\prime} \mathrm{W}$ (30STB6918), $2.000 \mathrm{~m}$, 25.V.1987, 1 옹 sobre $Q$. rotundifolia, V. J. Monserrat (VM). Rif Occidental, Chefchaouen, Bab Taza, 28.VIII.1983, 2 우 sobre Q. suber, V. J. Monserrat (VM). 
Especie ampliamente conocida de Europa, extendida al norte de África (Marruecos) y oeste/centro asiático (Anatolia, Armenia, Irán, Turkmenistán, Mongolia y Fernost).

Es la especie europea más frecuente y la mejor conocida dentro de la familia. La combinación de caracteres de su morfología alar, con su característico pterostigma triangular (Fig. 26) y la pigmentación del pronoto (Figs. 23, 24), con su puntuación oscura en su mitad basal, y de la cara interna del fémur (Fig. 25), completamente parda oscura, casi negra, la hacen inconfundible. No obstante hay una gran variabilidad en la intensidad de su pigmentación tegumentaria, según la madurez de los ejemplares; en los más melánicos destacan manchas pardas por todo el tórax, frecuentemente las patas medias y posteriores portan sobre sus fémures una línea parda longituninal sobre toda su cara ventral (Fig. 25).

$\mathrm{Su}$ morfología alar, con su pterostigma triangular, algo más pálido en su zona basal (Fig. 26) es característica. La envergadura alar también es extremadamente variable. En la bibliografía hay datos de alas anteriores entre 7-17 mm. En los ejemplares ibéricos que hemos medido, la longitud de las alas anteriores / posteriores oscila en los machos: 8,9-14,3 mm / 8,0$13,0 \mathrm{~mm}$; en las hembras: $6,8-15,0 \mathrm{~mm} / 5,8-14,0 \mathrm{~mm}$, duplicando (a veces casi triplicando) su tamaño según los ejemplares.

En el abdomen sus esternitos suelen portar una línea contínua central de color pardo oscuro, las pleuras son irregularmente oscuras y los terguitos portan una muy variable mancha oscura central, a veces con ocelos pálidos laterales y con una expansión triangular sobre la línea media anterior (Figs. 1-8). La terminalia y genitalia masculina se anota en las figs. 27-29, y parte de la femenina en la fig. 55.

Es la especie más frecuente en nuestra fauna. Excelente información sobre esta especie en Handschin (1959a). Datos sobre su morfología y genitalia pueden recabarse en Poivre (1981a).

Coincidiendo con lo anotado por Aspöck et al. (1980) o Ábrahám \& Papp (1994), en la península ocupa medios fuertemente soleados, evitando zonas boscosas y umbrías (por ello en Europa se ha citado que muestra preferencias por zonas con viñedos). Es característica de eriales y solanas sobre fanerófitos aislados y dispersos, sobre los que es fácil hallarla en los meses de verano. Ha sido mayoritariamente recolectada sobre ejemplares maduros y aislados de encinas: Quercus rotundifolia-Q. ilex (109 ejemplares de los 161 ejemplares estudiados con información sobre su recolecta sobre diferentes plantas), sin que parezca
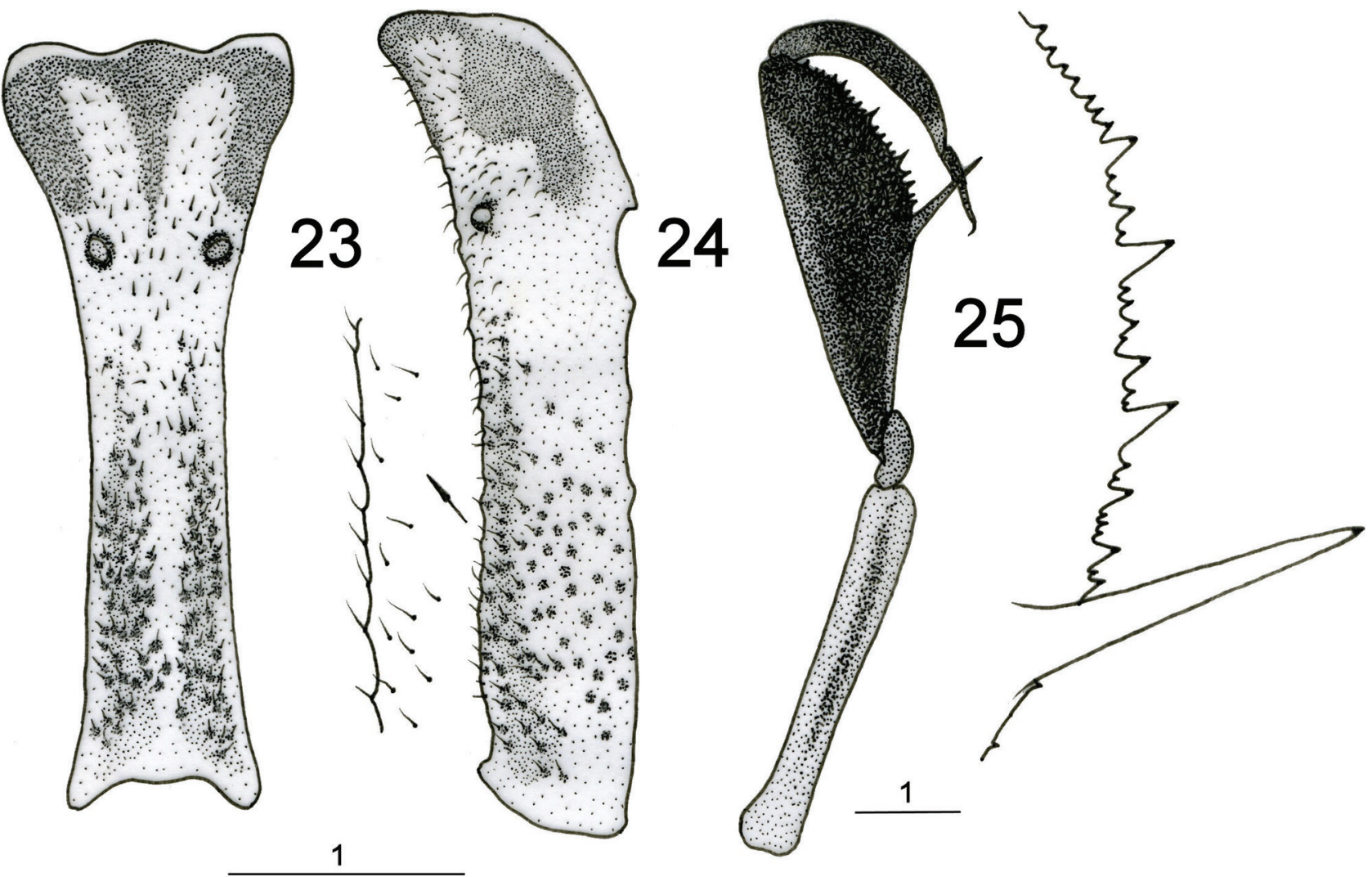

Figs. 23-25.- Mantispa styriaca. 23, Aspecto y pigmentación del pronoto, vista dorsal; 24, Ídem, vista lateral, ampliadas algunas setas; 25, Pata anterior, cara interna, ampliados dentículos del fémur. Escala en mm.

Figs. 23-25.-Mantispa styriaca. 23: Aspect and pigmentation of pronotum, dorsal view; 24, Ditto, lateral view, some magnified setae; 25 , Fore leg, inner face, magnified femoral denticles. Scale in $\mathrm{mm}$. 


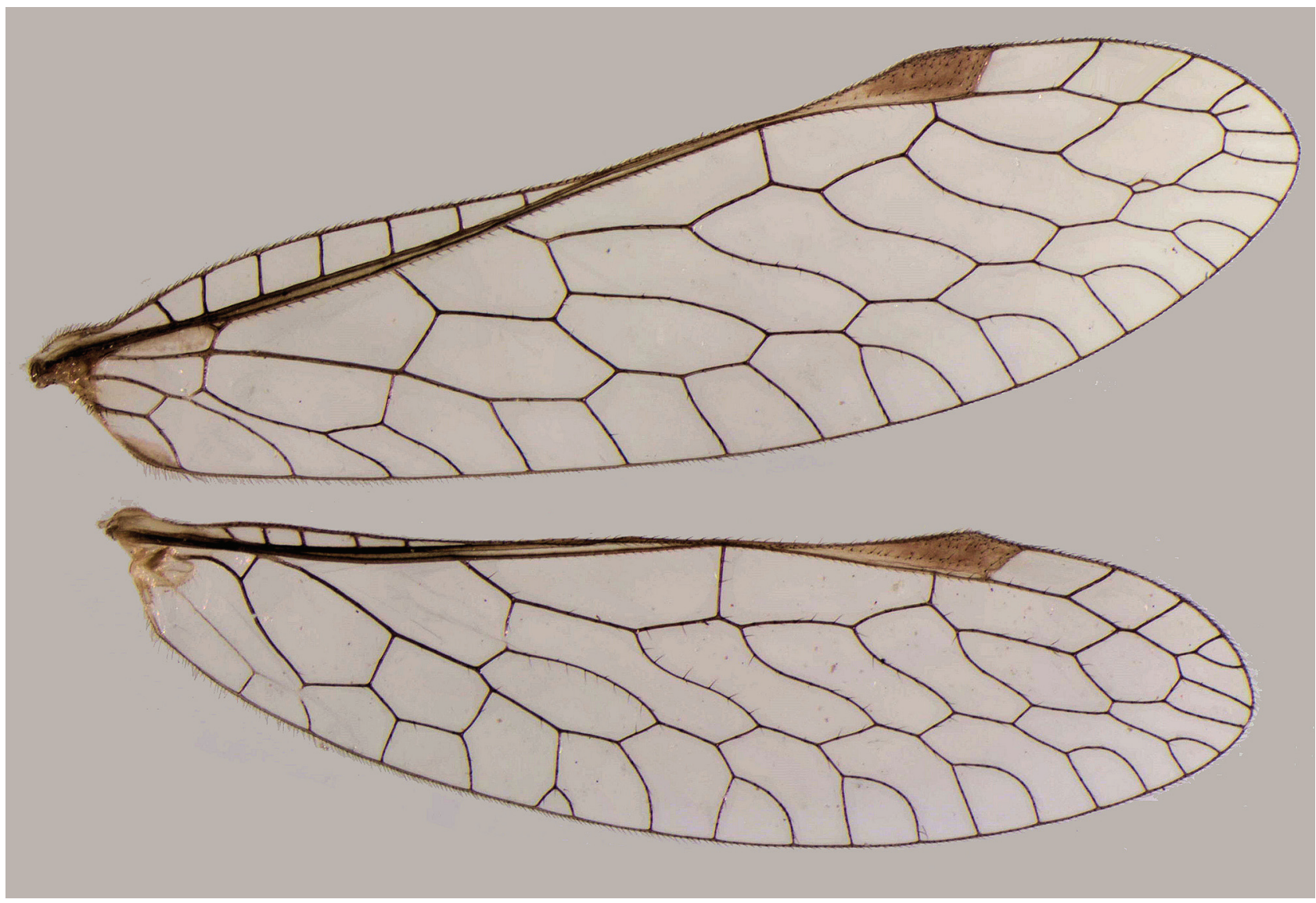

Fig. 26.- Alas de Mantispa styriaca.

Fig. 26.- Mantispa styriaca wings.

existir una relación directa que asocie esta especie de árbol y de insecto, si bien ha sido citada cierta "supuesta" cripsis entre su pigmentación externa y las inflorescencias de Quercus ilex (Séméria, 1992), pero esto sería extensible a las restantes especies ibéricas, quizás excepción hecha de $M$. perla, que es en general de coloración más amarillenta (Figs. 1-9). También en la península ha sido recolectada sobre otros fanerófitos o nanofanerófitos, -bien planifolios: $Q$. suber (9), Q. faginea (5), Q. pyrenaica (3), Q. robur (1), Olea europaea (5), Ceratonia siliqua (4), Prunus dulcis (3), Amigdalus communis (2), Dittrichia viscosa (1) o Eucaliptus globulus (2), -o bien aciculifolios: Pinus halepensis (5), P. sylvestris (3), P. pinaster (3), Juniperus thurifera (6) o Tamarix gallica (1). A veces ha sido recolectada a la luz (tanto machos como hembras), lo que sugiere una cierta actividad nocturna, y nunca la hemos recolectado sobre vegetación herbácea.

En Europa sus imagos han sido citados entre V-IX $\mathrm{m}$, y entre 100-2000 m. En nuestra fauna los imagos se distribuyen entre IV y IX, con imagos mayoritariamente recolectados en los meses más térmicos (VIIVIII), pudiendo desplazarse su fenología a meses más tempranos o tardíos, en función de la latitud/altitud: desde IV en Baleares y sur de Andalucía a IX en zonas eurosiberianas o montanas y esteparias del interior (material consultado y datos ahora anotados). Prefiere zonas de baja-media cota, habiéndose recolectado entre los 10-1.900 m, alcanzando sus mayores cotas en zonas montanas pirenaicas o meridionales (Lérida, Carmeniú: 1.680 m, Granada, Sa. Nevada: 1.900 m). Con frecuencia comparte medios con Mantispa aphavexelte en localidades donde son simpátridas.

Las fases larvarias de esta especie y su biología fueron descritas por Brauer (1852a, 1855a, 1855b, 1869) y Rogenhofer (1862a, 1862b), y nuevos datos, a veces de forma testimonial, fueron anotados por Poujade (1898), Main (1931), Bristowe (1932), Schremmer (1959, 1983), Ghilarov (1962), Poivre (1976), Şengonca (1980) y Dorokhova (1987), y en base a material ibérico fueron, con mayor detalle, descritas por Monserrat \& Díaz-Aranda (1989) (Figs. 20-22).

En base a nuestras observaciones durante las últimas tres décadas, podemos anotar nuevos datos sobre la biología reproductora de esta especie que ahora exponemos: Una hembra recolectada en Badajoz, Burguillos del Cerro, 14.VII.2001, sobre Q. rotundifolia, realizó tres puestas en cautividad. Una durante la noche del 19-20.VII.2001 de 980 huevos, otra el 22.VII.2001 de 406 huevos y otra el 24.VII.2001 de 272 huevos, que suman un total de 1.658 huevos. 


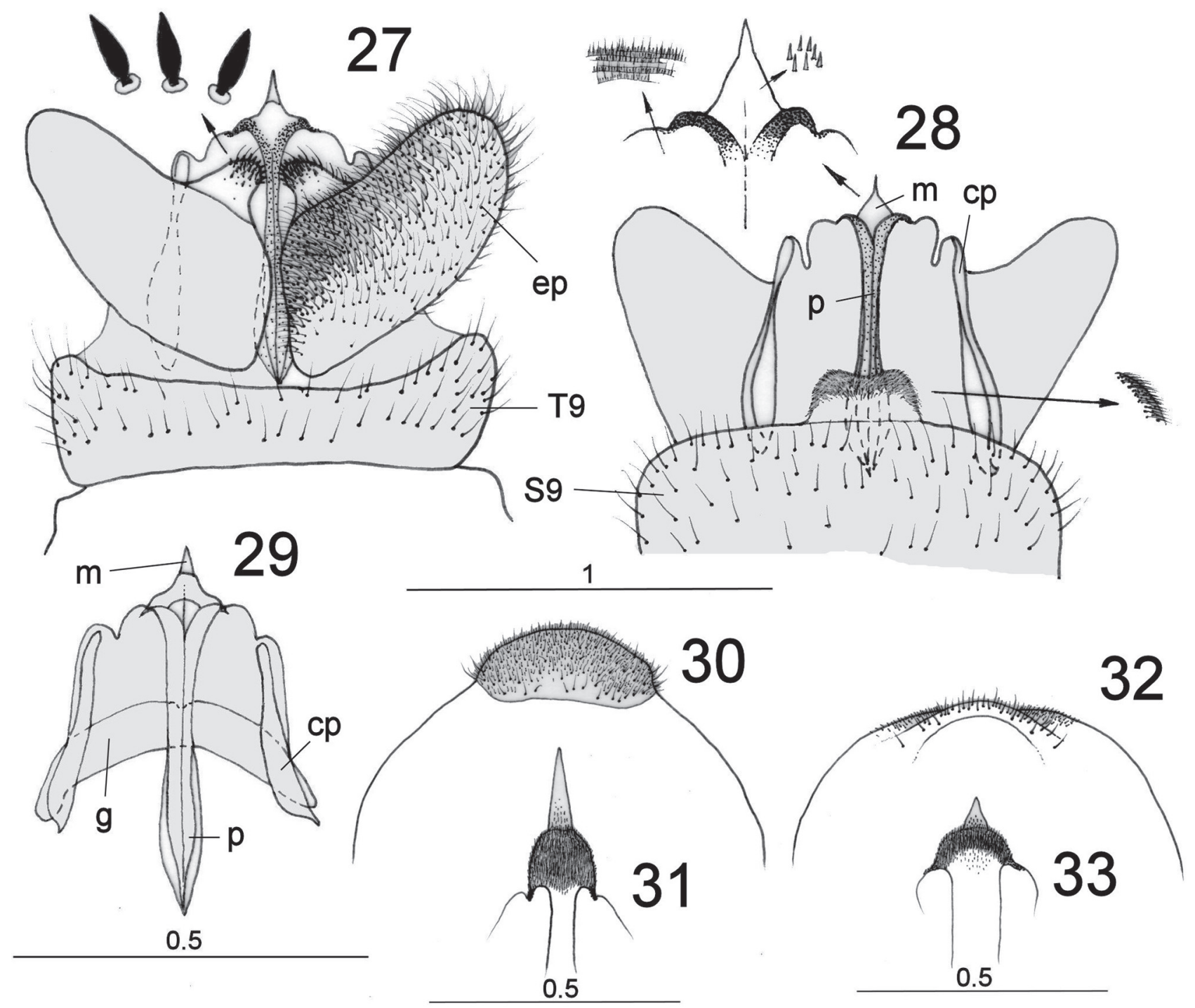

Figs. 27-33.- 27-29, Mantispa styriaca macho: 27, porción terminal del abdomen, vista dorsal (ampliadas algunas setas); 28, idem, vista ventral (ampliadas algunas estructuras); 29, complejo catoprocesos-gonarco, parámeros, vista ventral; 30-31, Mantispa aphavexelte macho: 30, margen caudal del $9^{\circ}$ esternito; 31, mediunco; 32-33, Mantispa perla macho: 32, margen caudal del $9^{\circ}$ esternito; 33 , mediunco. (cp: catoprocesos. ep: ectoprocto, g: gonarco, m: mediunco, p: parámeros, S: esternito, $\mathrm{T}$ : terguito). Escala en $\mathrm{mm}$.

Figs. 27-33.- 27-29, Mantispa styriaca male: 27, terminal portion of abdomen, dorsal view (some magnified setae); 28, ditto, ventral view (some magnified structures); 29, catoprocessus-gonarcus-paramera complex, ventral view; 30-31, Mantispa perla male: 30, caudal margin of 9th esternite; 31, mediuncus; 32-33, Mantispa aphavexelte male: 32, caudal margin of 9th esternite; 33, mediuncus. (cp: catoprocessus, ep: ectoproct, g: gonarcus, m: mediuncus, p: paramera, S: esternite, T: terguite). Scale in mm.

Otra hembra recolectada en Toledo, Urda, el 2.VI.2011, efectuó una puesta de 282 huevos. Tres hembras recolectadas en Granada, El Dornajo, el 10.VII.2013 (1) y el 18.VII.2014 (2) sobre Q. rotundifolia, aportaron interesantes datos: mantenidas aisladas en cautividad y proporcionándole regularmente alimento (mayoritariamente pequeños dípteros), alcanzaron, el primer ejemplar, una longevidad de 37 días, durante los cuales perdió una de sus patas anteriores, sin duda debido a un accidente durante la caza, y en este tiempo realizó 6 puestas (indistintamente por la mañana o por la tarde): el 12.VII.2013 de 422 huevos, el 28.VII.2013 de 281, el 1.VIII.2013 de 166, el 5.VIII.2013 de 222, el 6.VIII.2013 de 130, y el 10.VIII.2013 de 147 huevos (esta puesta sobre la segunda puesta antes citada), que hacen un total de 1.368 huevos (de color rosaanaranjados). A temperatura ambiente las dos primeras puestas eclosionaron, la primera a los 10 días, la segunda a los 13 días. En el caso del segundo ejemplar, alcanzó una similar longevidad de 36 días, durante los cuales efectuó 5 puestas (22.VII.2014 tres puestas y 8.VIII.2014 dos puestas) con un total de 1.216 huevos, con similar tiempos de desarrollo que el caso anterior. A algunos de los neonatos se les puso en forzado contacto con pequeños ejemplares de fólcidos y araneidos (Arachnida, Araneae: Pholcidae, Araneidae) 
introducidos en la misma caja de cultivo, sin haberse observado, 12 días después, ninguna larva sobre estas arañas. Lo más interesante es que, ya que a pesar de la intensa búsqueda no hallábamos entonces sacos ovígeros de arañas, mantuvimos algunas de las puestas en el interior de una nevera doméstica, con el fin de relentizar su metabolismo.Tras 38 días, para neonatas procedentes del primer ejemplar y 100 días para las del segundo, en estas frías condiciones $\left(2-4^{\circ} \mathrm{C}\right)$, muchas de estas larvas neonatas estaban vivas, y retomaron su actividad al rato de mantenerlas a temperatura ambiente, sorprendente hecho que demuestra su capacidad de ayuno y sin duda sugiere la posibilidad de hibernar en este estadio latente. En el caso del tercer ejemplar, alcanzó una mayor longevidad de 54 días, durante los cuales no efectuó ninguna puesta. Otra hembra recolectada en Lérida: Balaguer, el 29.VII.1991, efectuó una puesta de 355 huevos. Otra hembra recolectada sobre eucalipto en Cádiz, Venta del Retín el 9.VI.1988, puso 889 huevos que emergieron 10 días después y cultivados en condiciones de laboratorio, pupaban el 30.VI.1988, y una hembra ex ovo emergía 19 días después (19.VII.1988). Otra hembra recolectada a la luz en Almería, Rambla de Tabernas, 11.VII.1985, puso 3.812 huevos, de los que se obtuvieron ejemplares ex ovo (Figs. 17-19) criados con sacos ovígeros de Lycosa radiata Latreille, 1817. Los huevos, de color amarillo pálido, tornaron a más oscuro conforme el desarrollo embrionario progresaba en condiciones de laboratorio. Los individuos neonatos empezaron a nacer a los nueve días de efectuada cada puesta. El imago permaneció vivo 16 días desde su captura. Similares datos se obtuvieron a partir de una hembra recolectada en Granada, Venta del Chaleco, el 2.VII.1986, que realizó una puesta de huevos blanquecinos, que iban tornando a rosáceo y eran evidentes las manchas metaméricas poco antes de la eclosión, que se produjo a los 9-10 días. Los ejemplares neonatos se colocaron sobre un ejemplar de Lycosa, donde se mantuvieron vivos una semana hasta la muerte de la araña. Una hembra fue observada en Madrid, Los Molinos, el 31.VIII.1989 realizando una puesta sobre una pared de cemento (R. Outerelo com.per.). Una hembra recolectada en Ciudad Real, Alcoba, Parque Nacional de Cabañeros, el 1.VII.2007 sobre Quercus suber, vivió 8 dias, y tras poner huevos y eclosionar a los 12 días a temperatura ambiente, se cultivaron y se obtuvo 1 macho ex ovo en poco más de un mes: el 4.VIII.2007 (34 días). Mayor longevidad mostró una hembra recolectada en Lérida, Ponts, el 20.VI.1991, 27 días durante los que efectuó cuatro puestas a intervalos de 5 días (el 1, 5, 10 y 16.VII.1991), que cultivados entre $28-32{ }^{\circ} \mathrm{C}$., eclosionaban a los 11 días, y se desarrollaron al proporcionarles sacos ovígeros de diversas arañas, algunos ya con arañitas (lo que demuestra el citado uso de allomonas, también en esta especie), adoptaban el color rosáceo del vitelo de los huevos que servían de alimento, a los
15 días mudaban a $3^{\circ}$ estadío, y 2 días después iniciaban su pupación (a los 17 días de nacer). Sus pupas eran blancas-rosáceas, con cápsula cefálica hialina. También entre el material estudiado puede citarse un ejemplar obtenido en Mallorca, Puerto de Pollensa, el 17.IV.1975 de un saco ovígero de araña Zoropsidae (Araneae, Lycosoidea), familia de arañas cribeladas de la que, como tal, no existían datos en relación a los mantíspidos. Por último, y por lo anotado respecto al tiempo en el desarrollo de sus ciclos biológicos y en base a los ejemplares recolectados en algunas localidades (ej. El Dornajo), parace comprobarse, al menos, dos-tres generaciones anuales que se solapan en esta especie en estas latitudes.

Mapa de distribución de esta especie en el área de estudio en la fig. 59.

\section{Mantispa perla Pallas, 1772}

Hagen, 1866a: 291 (dis, rf); Brauer, 1876: 290 (rf); McLachlan, 1902a: 33 (rf), 1902b: 130 (dis); Navás, 1905b: 125 (dis), 1905c: 38 (dis), 1908: 133 (mf, dis), 1924a: 255 (key), 256 (dis, mf), 1925:129 (key), 131 (mf, rf); Monserrat, 1977: 16 (list), 65 (key, rf), 1978a: 61 (bio, dis); Zakharenko, 1987: 622 (rf); Aspöck et al., 1980: 11 (dis), 52 (key), 184 (bio, fen, mf, rf, tx); Şengonca, 1980: 467 (rf); Monserrat \& Díaz-Aranda, 1987: 178 (rf); Aspöck, 1994: 227 (rf); H. Aspöck et al., 2001: 204 (rf); Monserrat \& Triviño, 2013: 15 (list).

Perlamantispa perla (Pallas, 1772)

Principi, 1966: 375 (rf); Monserrat, 1979a: 19 (bio, dis); Aspöck et al., 1980: 184 (rf, tx); Poivre, 1982d: 669 (dis), 1983: 131 (bio, dis, mf); Monserrat, 1984c: 161 (bio, dis), 1985b: 88 (rf), 1986b: 100 (dis); Díaz-Aranda \& Monserrat, 1988b: 221 (rf); Marín \& Monserrat, 1995b: 114 (bio, dis); Monserrat, 1996c: 13 (list); Monserrat \& Triviño, 2013: 15 (list), 23 (rf), 50 (dis).

Mantispa perla variedad icterica Pictet, 1865 (part.)

Pictet, 1865: 58, (d, dis), 108 (dis); Hagen, 1866a: 291 (dis, mf, rf, tx), 1866b: 427 (rf); Bolívar, 1882: 40 (rf); McLachlan, 1902b: 130 (dis, rf); Navás, 1905c: 38 (dis), 1908: 133 (dis,mf), 1923: 163 (bio, dis), 1924a: 257 (dis, mf), 1924b: 130 (dis), 1925: 131 (dis, mf); Monserrat, 1977: 65 (rf), 1980: 184 (bio, dis, rf); Zakharenko, 1987: 622 (rf). La mayor parte de las citas antiguas de esta variedad deberían asignarse, sin un gran margen de error, a Mantispa perla, ya que el estudio de su serie tipo (Fig. 38) así lo confirma y no existen datos para considerarla subespecie distinta de la especie tipo centroeuropea. Sobre la posterior confusión de esta variedad como especie distinta ver discusión en la especie citada a continuación (M. aphavexelte), y la mayoría de las citas bibliograficas existentes con posterioridad han de asignarse a ella, y no a la especie que ahora tratamos. Por el contrario, la cita de Monserrat (1980: 184) como Mantispa perla variedad icterica Pictet, 1865 debe asignarse a la especie que ahora tratamos.

\section{Material estudiado:}

ESPAÑA: Cuenca, Tragacete, s.f., $5 \hat{\jmath} \hat{\jmath}, 2$ 우, T.A.C. (NHM), s.f., $3 \hat{\jmath}, 4$ 우 T.A.C. (NHM) (muy probablemente sean los ejemplares recolectados por Chapman y Champion que McLachlan, 1902b cita en VII-VIII.1901). Madrid, Cercedilla, s.f., 1q, leg.?

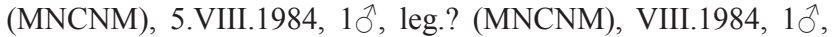
leg.? (MNCNM). Salamanca, Valduciel, 15.VII.1977, 1 ㅇ sobre Quercus suber (VM), Zafrón, 6.VI.1973, 1§* (me*, m*) sobre Quercus pyrenaica, E. Galante (VM), 1§̃, 1으, sobre Quercus 


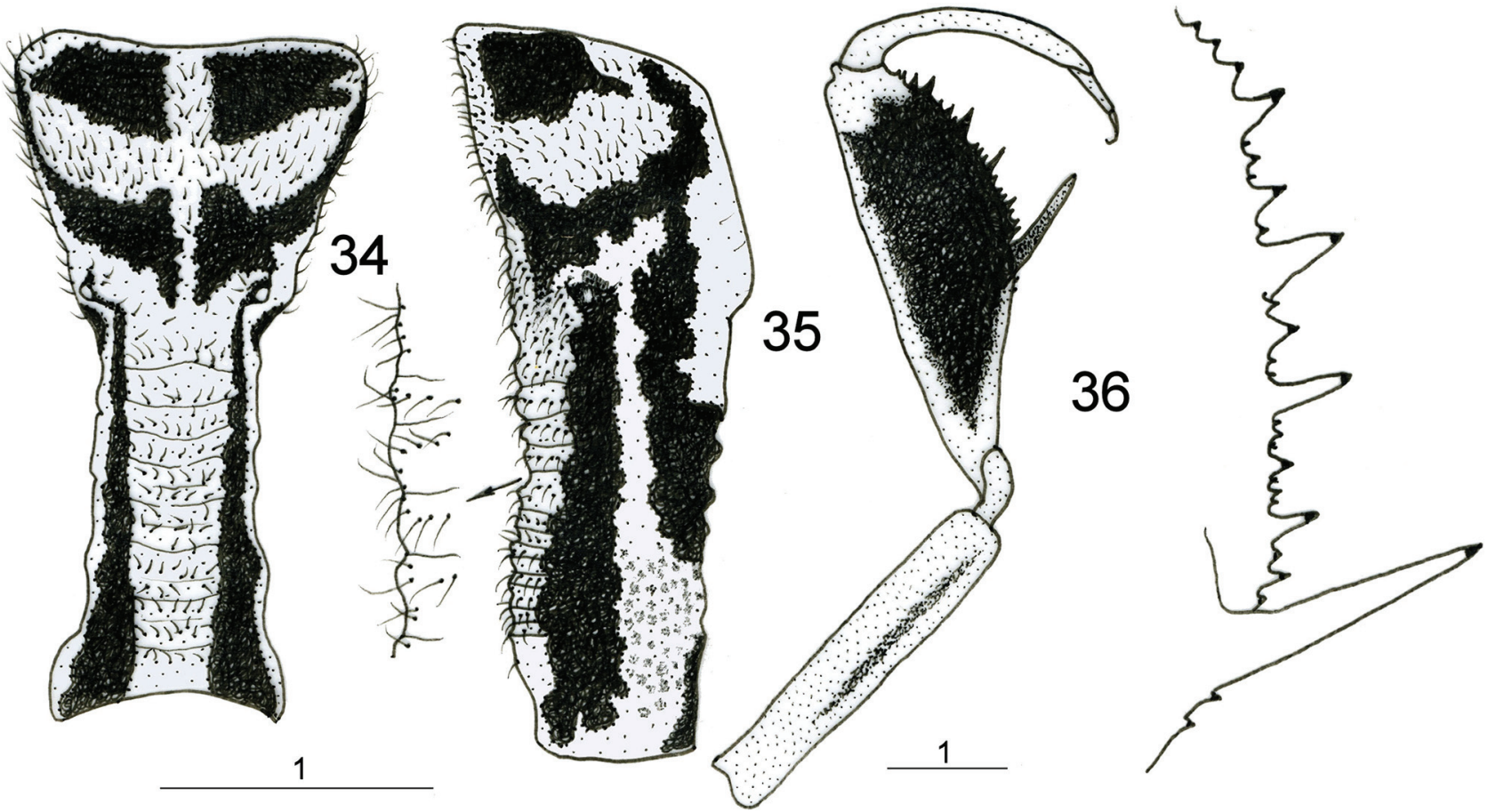

Figs. 34-36.- Mantispa perla. 34, aspecto y pigmentación del pronoto, vista dorsal; 35, ídem, vista lateral, ampliadas algunas setas; 36 , pata anterior, cara interna, ampliados dentículos del fémur. Escala en $\mathrm{mm}$.

Figs. 34-36.- Mantispa perla. 34, aspect and pigmentation of pronotum, dorsal view; 35, ditto, lateral view, some magnified setae; 36 , fore leg, inner face magnified femoral denticles. Scale in $\mathrm{mm}$.

pyrenaica (VM). Segovia, San Ildefonso, s.f., 1ðึ, Bolívar, col. Mazarranedo, Vázquez (MNCNM). Toledo, Sierra de Pelahustán,

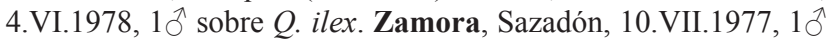
sobre Q. pyrenaica (VM). Zaragoza, Retuerta de Pina, Pina de Ebro, 30TYL29, 400 m, 21.VI.1989, 1 ㅇ sobre Tamarix canariensis, J. Blasco (VM), 11.VI.1992, 1 q sobre Retama sphaerocarpa, J. Blasco (VM), 12.VI.1993, 19* (a*) sobre Retama sphaerocarpa, J. Blasco (VM). PORTUGAL: sin loc., s.f., (129-40) (¿12.IX.1940?), 1ㅇ, leg.? (MNHN).

Especie conocida del centro y sur de Europa, extendida al oeste/centro asiático (Anatolia, Armenia, Cáucaso, Kazajstán, Turkmenistán, Mongolia). En nuestra fauna está más localizada que Mantispa styriaca $\mathrm{o} M$. aphavexelte, y es mucho menos frecuente.

$\mathrm{Su}$ aspecto externo y su pigmentación tegumentaria amarillenta, así como el tinte pardo amarillento de sus alas la hacen inconfundible (Figs. 9, 34-38). Su tegumento es aparillento, a veces intenso (Figs. 9, 38), a veces algo más apagado, pero siempre con abundantes zonas pardas, a veces muy oscuras y contrastadas según se indica. Cabeza amarillenta con una mancha parda oscura tras la base de cada antena y una transversal sobre el vértex. Escapo y pedicelo pardo oscuro en su cara dorsal. Flagelo pardo oscuro. Palpos pálidos.

Tórax con pronoto corto y muy ancho en su mitad anterior, poco más del doble de largo que de ancho (Figs. 34, 35, 38), con características manchas pardas muy oscuras, casi negras y bastante constantes en su diseño, y setas sin prominencias en su base, dorsalmente presenta estrías transversales que le dan un cierto aspecto "anillado" (Figs. 34, 35). Meso y metanoto pardo oscuro con una ancha banda pálida sobre la línea media (Fig. 38). Patas muy pilosas, las anteriores con coxas presentando una banda más oscura en su mitad posterior, cara interna de los fémures pardas muy oscuras, casi negras, salvo una banda pálida entre la articulación con el trocánter y la base de la espina mayor, otra paralela al margen opuesto, y también es más pálido en su porción distal; su cara externa es parda amarillenta pálido, algo más oscura una banda paralela al margen dentado (Fig. 36). Tibia y tarso pardo pálido. Patas medias y posteriores con región ventral de coxas, trocánteres y fémures pardos oscuro, y últimos tarsómeros y porción distal de los restantes algo más oscuros.

Alas iridiscentes, con membrana amarillo parduzco de aspecto ahumado (Figs. 37, 38). Las anteriores con zona basal especialmente oscura. Pterostigma muy alargado y pardo. En la bibliografía hay datos de alas anteriores entre 10,5-22,0 mm, y más específicamente hay datos de alas anteriores entre 16-21 mm para los machos y 15-22 para las hembras, en los ejemplares ibéricos que hemos medido, la longitud de las alas anteriores / posteriores oscila en los machos: 14,0-15,0 mm / 13,0-14,0 mm; en las hembras: $11,2-14,0 \mathrm{~mm} / 10,0-12,5 \mathrm{~mm}$.

Abdomen amarillento con terguitos portando una banda parda dorsal media, contínua e irregular. Esternitos con márgenes laterales pardos muy oscuros y con una banda transversal también oscura y paralela al margen posterior (Figs. 9, 38). Región pleural parda 


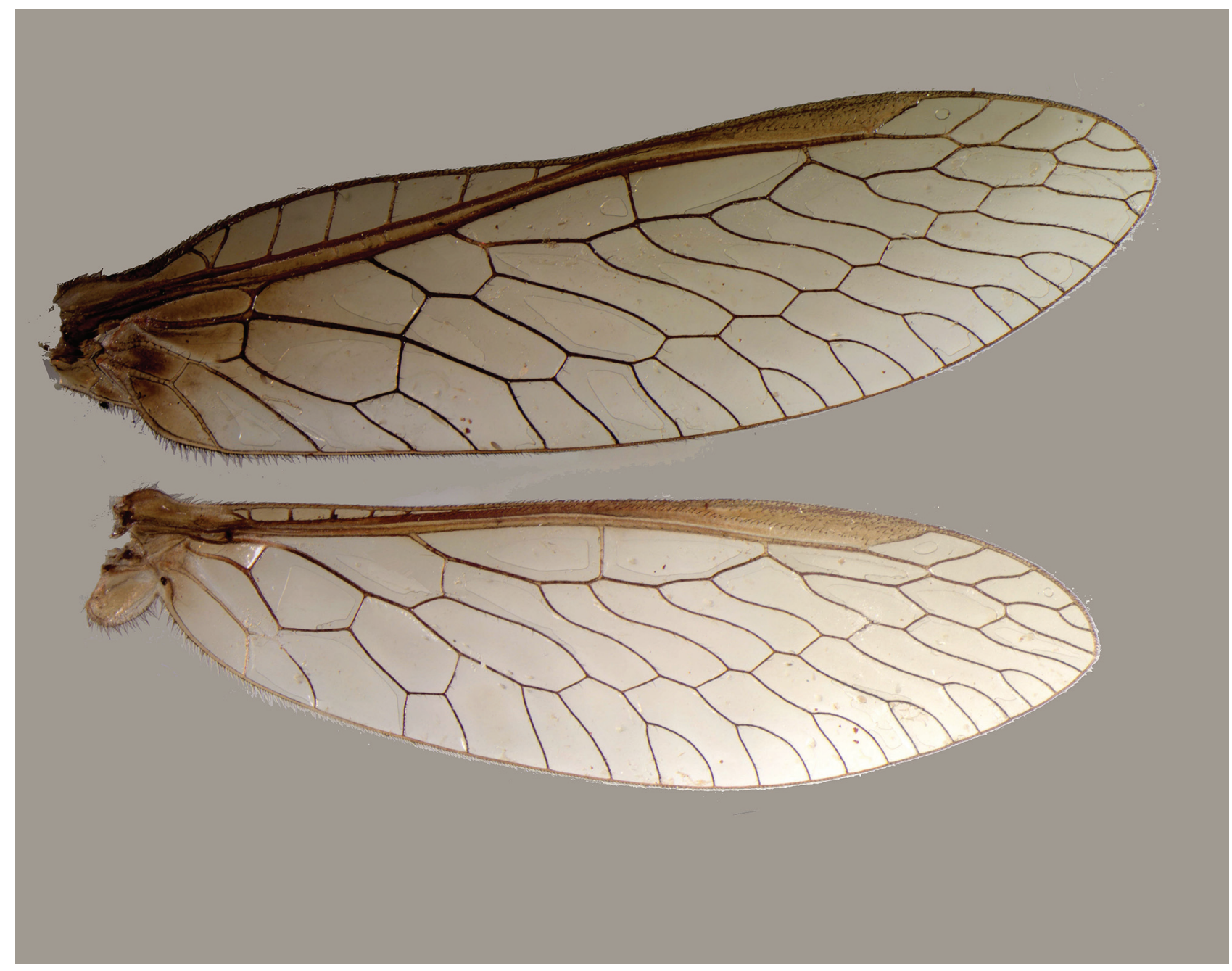

Fig. 37.- Alas de Mantispa perla.

Fig. 37.- Mantispa perla wings.

oscura hacia los terguitos y portando una banda transversal en cada segmento. Aspectos distintivos de la genitalia masculina se anotan en las figs. 32-33, y algunos elementos de la femenina se anotan en la fig. 54.

En nuestra fauna ha sido hallada con mayor frecuencia sobre especies de Quercus, pero de mayor carácter hidrófilo que en otras especies de mantíspidos, sean robles o alcornoques: Quercus pyrenaica (4 ej.), Q. suber (1). También sobre Q. ilex, Retama sphaerocarpa (2) y Tamarix canariensis (1). McLachlan (1902b) cita ejemplares (de identificación incuestionable) sobre pinos en la Serranía de Cuenca, y Poivre (1983) y Lucchese $(1955,1956)$ sugieren para esta especie matorrales claros, chaparros, huertos y campos cultivados, elementos que no coinciden con lo observado por nosotros.

En Europa ha sido citada entre V-VII, con imagos recolectados entre 450-1.600 m. En nuestra fauna, los imagos estudiados han sido recolectados en los meses más térmicos (VI-VIII) y en altitudes que oscilan entre los 250-1.650 m (Zaragoza: Los Monegros-Cuenca: Serranía de Cuenca, Tragacete).
Los estadios larvarios de esta especie fueron descritos por Lucchese $(1955,1956)$ (Fig. 20). Otros datos sobre su biología, morfología y genitalia pueden recabarse en Lucchese $(1955,1956)$ y Poivre $(1983)$.

Su distribución en la península (España y Portugal) está limitada a zonas y enclaves montanos y algo más húmedos que en las otras especies, evitando zonas litorales, y los datos registrados se ofrecen en la fig. 54.

La citada variedad de esta especie Mantispa perla icterica nos sirve de enlace a la siguiente especie considerada.

Mantispa aphavexelte Aspöck \& Aspöck, 1994

Aspöck \& Aspöck, 1994: 104 (rf), 110 (d, dis, tx), 112, 113 (key); Aspöck, 1994: 228 (mf, rf); H. Aspöck et al., 2001: 204 (bio, mf, rf, tx); Monserrat \& Triviño, 2013: 15 (list), 23 (rf), 49 (dis).

Perlamantispa aphavexelte (Aspöck \& Aspöck, 1994) H. Aspöck et al., 2001: 204 (list, tx).

*Mantispa mandarina Navás, 1914

Aspock et al., 1980: 52 (key), 184 (bio, fen, key, mf, tx, rf); Zakharenko, 1987: 623 (tx, rf); Aspöck \& Aspöck, 1994: 102 (rf), 104 (rf), 105 (rf), 106 (mf, tx). 
*Mantispa mandarina (autores, nec Navás, 1914) Aspöck \& Aspöck, 1994: 100 (rf), 110 (mf, tx, rf); H. Aspöck et al., 2001: 204 (list, tx); Monserrat \& Triviño, 2013: 23 (rf).

*Mantispa perla var. lobata Navás, 1912

Navás, 1912: 535 (d); Zakharenko, 1987: 623 (tx); Aspöck \& Aspöck, 1994: 104, 105 (rf, tx).

*Mantispa lobata Navás, 1912

Zakharenko, 1987: 623 (dis, mf, rf, tx); Aspöck \& Aspöck, 1994: 100 (rf), 110 (tx), 113 (key).

*Mantispa lobata autores, nec Navás, 1912

Aspöck \& Aspöck, 1994: 100 (rf), 110 (rf); H. Aspöck et al., 2001: 204 (list, tx).

*Mantispa adelungi Navás, 1912

Aspöck \& Aspöck, 1994: 105 (mf, rf, tx), 113 (key).

*Mantispa perla var. adelungi Navás, 1912

Navás, 1912: 536 (d); Zakharenko, 1987: 623 (rf, tx).

*Mantispa adelungi autores, nec Navás, 1912

Aspöck \& Aspöck, 1994: 100 (rf), 110 (tx); H. Aspöck et al., 2001: 204 (list, tx).

Mantispa perla icterica autores nec Pictet, 1865 (part.) Aspöck et al., 1980: 203 (rf, tx); Aspöck \& Aspöck, 1994: 100 (rf), 108 (rf, tx); Monserrat \& Triviño, 2013: 15 (list).

Perlamantispa perla icterica (autores nec Pictet, 1865) (part.) Aspöck \& Aspöck, 1994: 110 (list); H. Aspöck et al., 2001: 204 (list, tx); Monserrat \& Triviño, 2013: 15 (list).

Mantispa icterica (autores, nec Pictet, 1865) (part) H. Aspöck et al., 2001: 204 (list, tx).

Perlamantispa icterica (autores nec Pictet, 1865) (part.) Monserrat, 1982: 73 (bio, dis); Poivre, 1982d: 669 (bio, dis), 1983: 131 (bio, dis, mf); Monserrat, 1984b: 99 (bio, dis), 1984d: 34 (bio, dis), 1985a: 90 (rf), 1985b: 88 (bio, dis, tx), 1987a: 137 (bio, dis), 1987b: 263 (mf, rf); Monserrat \& DíazAranda, 1987: 178 (bio, dis); Díaz-Aranda \& Monserrat, 1988c: 218 (bio, dis); Aspöck \& Aspöck, 1994: 100 (rf), 108 (tx), 110 (list, tx); Monserrat, 1996c: 13 (list); H. Aspöck et al., 2001: 204 (list, tx); Monserrat, 2013: 289 (rf); Monserrat \& Triviño, 2013: 15 (list), 23 (rf), 50 (dis).

Perlamantispa perla (autores, nec Pallas, 1772) (part.)

Aspöck \& Aspöck, 1994: 110 (list); H. Aspöck et al., 2001: 204 (list, tx).

\section{Material estudiado:}

ESPAÑA: Alicante, Cocentaina, 18.VII.1982, $2+q$ sobre Quercus ilex (VM), Puerto de Biar, 5.VIII.1982, 1 q sobre Q. ilex (VM), Puerto de la Carrasqueta, 18.VII.1982, $1 \delta^{\widehat{ }}$ sobre Pinus halepensis (VM). Almería, Las Estancias, 27.VI.1983, 2 우 sobre Q.ilex (VM). Cáceres, Berzocana, 27.VII.1980, 1 + sobre Q. pyrenaica (VM), Cortijo del Raso, 27.VII.1980, 1 + sobre Eucaliptus sp. (VM), Herreruela, 2.VII.1980, 1 \%* (a*) sobre Q. ilex (VM), La Aliseda, 3.VIII.1980, 1 \% a la luz (VM), Membrio, 2.VII.1980 1 $*_{*}$ (me*) sobre Q. ilex (VM). Cádiz, Sierra del Pinar, 15.VIII.1976, $1 \delta^{*}$ (me*) sobre Q. canariensis (VM). Córdoba, Villanueva, s.f., 19 , G.Ceballos (MNCNM). Cuenca, Huertas del Marquesado, 27.VIII.1985, 1 ㅇ sobre Juniperus thurifera (VM). Granada, El Dornajo, 3707'52.22”N 3²6'57.43”O, 1.750 m, 11.VII.2010, 1 오 sobre Q. rotundifolia (VM), Monachil, 3.VII.1986, 1 ㅇ sobre Q. ilex (VM), Puerto del Molinillo, 3.VII.1986, $1 \delta^{\text {* }}\left(\delta^{*}\right)$ sobre

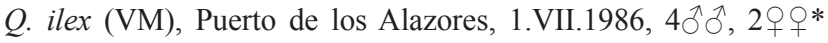
( $\left.{ }^{*}\right)$ sobre $Q$. ilex (VM). Huesca, Barbastro, 20.VIII.1982, $1 \delta^{\Uparrow}$ sobre Q. ilex (VM), Castejón de Sos, 1.VII.1923, 1q, L. Navás (MNCNM). Jaén, Tíscar, 21.IX.1988, 1ð̂, $1 q$ sobre Q. rotundifolia, L. M. Díaz Aranda (VM). Madrid, Madrid, s.f., 1ㅇ, Vázquez (MNCNM), Torres de la Alameda, 11.VI.1984, 1 q sobre Q. rotundifolia, A. Baz (VM), Villaviciosa, 26.VI.1929, 1ठ̂, F.E.
(MNCNM). Murcia, Casa de la Rosa, 4.VII.1982, 1 ㅇ sobre Q.ilex (VM), 1.VIII.1982, 10, $2+q$ sobre Q. ilex (VM). Salamanca, Gargavete, 11.VII.1980, 1 ㅇ sobre Q. rotundifolia (VM).

La relación expuesta se basa en las referencias bibliográficas existentes que afectan a la fauna estudiada, y no es taxonómica y/o sinonímica. Aún así, y según nuestro punto de vista, la identidad de las especies anotadas con un asterisco deberían revisarse. Su inclusión en esta lista está generada por sus citas directas o indirectas en relación a nuestra fauna, y no implica, de momento, relación taxonómica o sinonímica definitivamente segura y confirmada entre ellas.

Sobre esta compleja situación taxonómica conviene detenerse para tratar de aclarar la posición y opiniones vertidas de cada taxa y sus consecuentes referencias en la fauna ibérica. Comencemos con Mantispa perla var. icterica, ya que la situación taxonómica de esta variedad/especie es harto compleja, confusa y, desde nuestro punto de vista, no del todo resuelta.

Descrita por Pictet (1865) de Segovia: "Granjas" (La Granja de San Ildefonso), como variedad de Mantispa perla (Mantispa perla var. icterica), y frecuentemente considerada como simple variedad por un tiempo (Hagen, 1866a la cita de Montpellier y Marsella en Francia, y Navás, 1924a, 1925 la cita de San Fiel en Portugal) y sin categoría taxonómica superior. Empezó a ser considerada como especie válida a partir de ciertas citas, y poco a poco fué ganando peso y consideración, existiendo multitud de citas como especie así considerada (ver citas anteriormente recopiladas), aunque nada tenían que ver estas citas con la descripción y el material de Pictet (1865) (Fig. 38).

Desde luego, estudiados ahora los sintipos del Museo de Zoología Comparada de la Universidad de Harvard (Fig. 38), no hay duda de que, aunque hubiera sido originalmente descrita con categoría de subespecie (y con valor taxonómico según el CINZ), se trata de ejemplares típicos de Mantispa perla, y no hay más que observar los ejemplares de la fig. 38. Por otra parte Poivre (1982d: 699) cita dos ejemplares (우 $ᄋ$ ) de Segovia, "Granjas" (La Granja de San Ildefonso) de la colección Pictet, sitos en el Museo de Ginebra (sin duda parte de los sintipos) y los cita como Mantispa perla. Más tarde los citará de nuevo (Poivre, 1983: 132), junto abundante material de "su" Mantispa icterica ibérico, italiano, francés y de Georgia.

De haber permanecido el asunto así, no pasaría de haber engrosado la lista de sinonimias de M. perla, sin mayor problema. Pero la cuestión es que, desde que Poivre (1982d: 699), en el mismo artículo donde cita estos ejemplares (sintipos) de La Granja de la colección Pictet, crea un neotipo para Mantispa icterica de Francia (Cannet-des-Maures), considerando perdidos los sintipos en los que se basó la descripción de Mantispa perla var. icterica, e inexplicablemente y a pesar que en la descripción de Pictet (1865) y en las figuras que aporta no hay duda sobre su aspecto de 


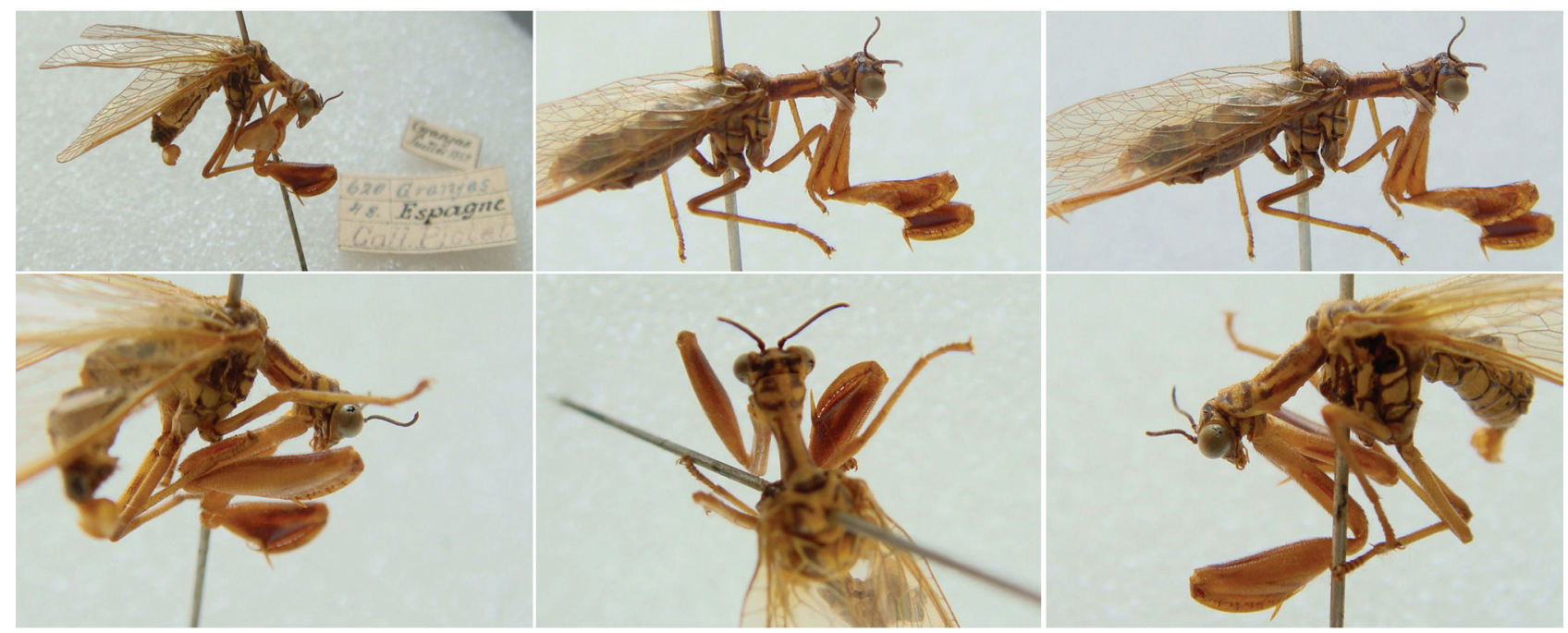

Fig. 38.- Sintipos de Mantispa perla var. icterica. Fotos de Peter Schwendinger \& John Hollier.

Fig. 38. - Sintypes of Mantispa perla var. icterica. Photos by Peter Schwendinger \& John Hollier.

Mantispa perla (Fig. 38), Poivre comenta diferencias de pigmentación y venación entre Mantispa perla y de lo que él considera Mantispa icterica, con escasas diferencias basadas en caracteres que se nos antojan muy sutiles, variables y carentes de interés, algunos bastante sorprendentes como el tinte de los ojos, del pterostigma o el más o menos amarillento, del tono tegumentario general (habitualmente se pierden o atenuan en ejemplares secos), o longitudes y curvatutas de las venas del campo alar, máxime basándose en un único ejemplar (neotipo propuesto), aún así nos llama la atención que mantuviera para esta "nueva especie" caracteres de pigmentación característicos de M. perla, tales como el tipo de manchas en el pronoto y cara interna del fémur anterior (Figs. 34-36).

Más tarde Poivre (1983) (al que en su día le enviamos abundante material ibérico que en él menciona), describe su morfología, genitalia y biología, y la compara con M. perla. A partir de este punto empezó a considerarse especie válida, y a ser citada en posteriores artículos, bien como Mantispa icterica (ej.: Ábrahám \& Papp, 1994) o como Perlamantispa icterica (ej.: Séméria, 1984). No obstante estos datos no se correspondían con los ejemplares descritos por Pictet (Fig. 38), sino con una nueva especie no descrita. La designación del citado neotipo es inválida e incorrecta, habida cuenta de que existe el material tipo de Pictet (o parte de él), y que Aspöck \& Aspöck (1994) y Aspöck (1994) estudian. De hecho, entre el material original de Pictet, existe un ejemplar (P) rotulado como / Type 10427 / Hagen (con los datos de captura de Pictet) en las colecciones de este Museo de Zoología Comparada de Harvard, donde se ha conservado un sintipo de Mantispa perla var. icterica (Fig. 38), no hallando elementos que justifiquen una posible validez como subespecie ibérica de $M$. perla al compararlo con ejemplares de Italia o de Grecia, por lo que esta designación de neotipo (Poivre, 1982d) carece de valor taxonómico, y estos autores asignan toda esta información a una nueva especie (Mantispa aphavexelte Aspöck \& Aspöck, 1994) asignando también a ella lo que Aspöck et al., 1980 habían citado en Europa (y España) como Mantispa mandarina Navás, 1914, especie descrita de China, y cuya opinión había generado numerosas referencias directas o indirectas de esta especie en Europa (Nicoli Aldini, 1983; Poivre, 1983; Zakahrenko, 1987; Devetak, 1992a, 1992b; Popov, 1993, etc.).

Es conocido que no todo el material de la colección de Pictet fue a parar al Musée Academique (precursor del Museo de Historia Natural de Ginebra) (Hollier, 2007), sino que parte del material de la colección de Pictet (padre e hijo) fue a manos de Herman Hagen (1817-1893), cuya colección se encuentra en el Museo de Zoología Comparada de la Universidad de Harvard (Massachussets) (Hollier, 2007; Hollier \& Hollier, 2014). En todo caso, merece citarse que Pictet $(1865: 58,108)$ no designó tipo/ paratipos de su variedad, y parecen conservarse al menos tres sintipos de la serie tipo original (un ejemplar en Harvard y dos en Ginebra). El ejemplar de la serie original de Pictet que cita Hagen (1866a: 291) en su colección personal, pasó con su colección al Museo de Harvard, y es supuesto ejemplar rotulado como / Type 10427 / Hagen (con los datos de captura de Pictet) que mencionan Aspöck \& Aspöck (1994). Pero este ejemplar ha de considerarse lectotipo (y no tipo) y, consecuentemente, todos los demás quedan automáticamente asignados como paralectotipos. Recordemos que el acto de designación de un lectotipo convierte, ipso facto, al resto de sintipos (conocidos o no, mencionados o no, existentes o no) en paralectotipos, dejando de ser, por el mismo motivo, sintipos. 
En cualquier caso, todo lo que Poivre consideró como Mantispa icterica, sean datos de morfología, genitalia o neotipo y material por él citado (especialmente de España, su neotipo de Francia e incluso un ejemplar de Portugal existente en el Museo de París, determinado por L. Navás como Mantispa perla var. icterica), no puede asignarse a lo que hasta entonces se consideraba Mantispa perla icterica, sino a Mantispa aphavexelte Aspöck \& Aspöck, 1994.

Esta problemática situación en la taxonomía de las especies europeas de esta familia acabó siendo muy complicada, al haberse añadido nuevos taxa en su fauna y no existir una uniformidad de criterios: Mantispa icterica (según Poivre), Mantispa mandarina Navás, 1914 (según Aspöck et al., 1980) y Mantispa hauseri Poivre, 1982. En principio Mantispa icterica (según Poivre) y Mantispa mandarina Navás, 1914 (según Aspöck et al., 1980) se corresponden con Mantispa aphavexelte Aspöck \& Aspöck, 1994, y más adelante Mantispa hauseri Poivre, 1982 fue sinonimizada a M. styriaca por Devetak (1992b) y posteriormente por Aspöck \& Aspöck (1994).

Aclarada esta cuestión y transvasada toda esta información de "icterica" a Mantispa aphavexelte Aspöck \& Aspöck, 1994, nada especial acontecería, simplemente y como decimos, transvasando toda la información existente sobre Mantispa perla icterica, Mantispa icterica y Perlamantispa icterica a esta nueva especie. Sin embargo, lo que, en principio se trataba de un endemismo ibérico, empezó a ampliar su distribución geográfica conocida, extendiéndose sus citas por Francia, Italia, Grecia, Marruecos, Anatolia, Armenia, Asia Central, Mongolia (y probablemente China) (Aspöck \& Aspöck, 1994; Aspöck, 1994), entrando en "conflicto" taxonómico con otras especies muy anteriormente descritas del Cáucaso o Asia Central, y acabando por tener una amplia distribución geográfica, extendida desde el sur de Europa a Asia Occidental-Central, como también es el caso de $M$. styriaca, M. perla, M. scabricollis o Nampista auriventris (ver Handschin, 1959a; Aspöck, 1994; Aspöck \& Aspöck, 1994; Aspöck \& Hölzel, 1996; H. Aspöck et al., 2001; Ohl, 2009).

Sobre estas especies asiáticas Zakahrenko (1987) había estudiado los sintipos de las especies rusas (entre otros de Mantispa lobata Navás, 1912, Mantispa adelungi Navás, 1912 y Mantispa mandarina Navás, 1914), y estas dos últimas especies son propuestas como sinonimias de $M$. lobata Navás, 1912, y sobre estas especies Ábrahám \& Papp (1994) mantienen este criterio. Sobre Mantispa lobata Navás, 1912, Zakharenko (1987) concluye que por sus caracteres morfológicos y genitales, es idéntica a las otras especies descritas del centro de Asia (M. adelungi Navás, 1912, M. mandrina Navás, 1914), con diferencias en la coloración del pronoto que podrían entrar en el margen de variabilidad tan frecuente en estas especies euro-asiáticas (Kuwayama, 1924), y en lo que nos compete, según este autor, a esta especie deben asignarse las citas de M. mandarina aportadas por Aspock et al. (1980) en Europa (y Península Ibérica). Según Zakharenko (1987), esta especie es conocida de España, Francia, Rumanía, Italia, Polonia, antigua Yugoslavia, Bulgaria, Grecia, Turquía, norte de China, Cáucaso, Kazakhstán, Asia Central, Mongolia, Baikal y norte de África (Marruecos), distribución que coincide con la anotada para Mantispa aphavexelte Aspöck \& Aspöck, 1994, y cuya morfología es también coincidente. De sus opiniones proceden las referencias de Mantispa lobata (e indirectamente de sus especies sinónimas) que existen en nuestra fauna.

Sin enbargo Aspöck \& Aspöck (1994) y Aspöck (1994) asignan estas citas europeas a Mantispa aphavexelte y consideran a Mantispa mandarina especie diferente y válida, y posteriormente H. Aspöck et al. (2001) consideran a M. lobata Navás, 1912, M. adelungi Navás, 1912 y M. mandarina Navás, 1914 como especies válidas, y como hemos indicado asignan las citas europeas posteriores a la descripción original de estas tres especies a Mantispa aphavexelte Aspöck \& Aspöck, 1994. Aunque tenemos ciertas dudas sobre la identidad de alguna de estas especies en relación con la especie que tratamos, mantenemos este criterio, a la espera de nuevos datos.

Especie conocida del sur de Europa, extendida al norte de África (Marruecos) y oeste/centro asiático (Anatolia, Cáucaso, Armenia, Kazajstán, Mongolia, y probablemente China).

La pigmentación de la membrana de sus alas, su pterostigma alargado, y las manchas de su pronoto y especialmente de la cara interna del fémur anterior la hacen inconfundible (Figs. 39-42).

$\mathrm{Su}$ tegumento es pardo aparillento con abundantes zonas pardas, a veces rojizas, según se indica. Cabeza amarillenta con una mancha parda oscura tras la base de cada antena y una pequeña banda longitudinal sobre la línea media entre ellas, sobre el vértex existe también una línea media y dos arqueadas, una a cada lado y una banda transversal sobre su zona posterior. Antenas con escapo y pedicelo pardos, más oscuros en su cara dorsal. Flagelo pardo rojizo oscuro. Palpos pardos amarillentos pálidos.

Tórax con pronoto alargado y estrecho, portando dos manchas longitudinales pardas oscuras sobre la zona dorsal, dos más tenues a ambos lados de la línea dorsal media anterior, y una banda media en su cara ventral (Figs. 39, 40). Dorsalmente presenta tenues estrías transversales que le dan un leve aspecto "anillado". Setas sin prominencias en su base (Figs. 39, 40). Patas muy pilosas, las anteriores con coxas más oscuras en su mitad posterior, cara interna de los fémures pardas muy oscuras, casi negras, salvo una banda pálida en los márgenes anterior y posterior, y también es mucho más pálida la zona basal del área denticulada y sobre todo en una amplia escotadura en su porción media (Fig. 41), su cara externa es parda amarillenta pálido, algo más oscura al inicio y final del margen dentado. 


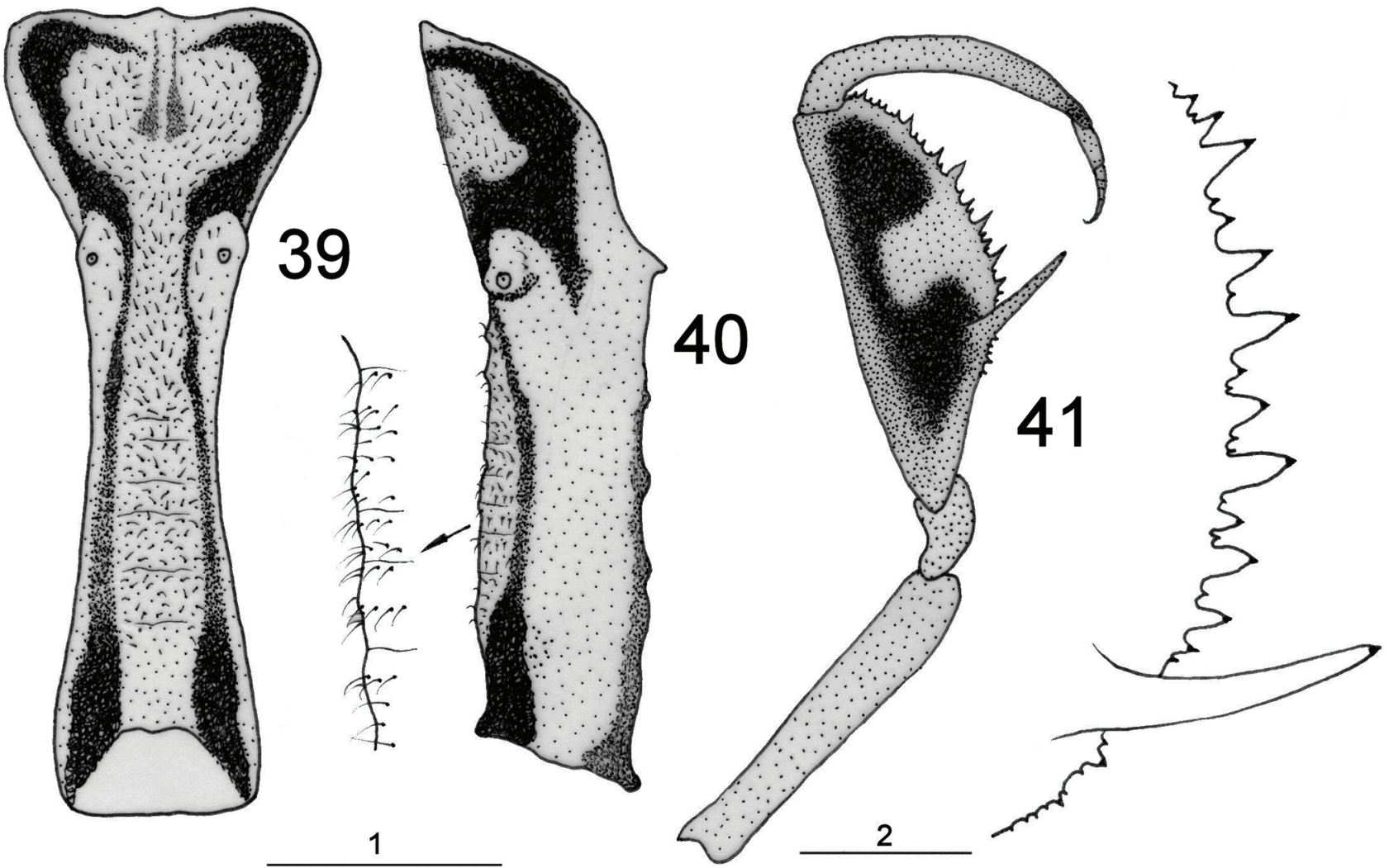

Figs. 39-41.- Mantispa aphavexelte. 39, aspecto y pigmentación del pronoto, vista dorsal; 40, ídem, vista lateral, ampliadas algunas setas; 41 , pata anterior, cara interna, ampliados dentículos del fémur. Escala en $\mathrm{mm}$.

Figs. 39-41.- Mantispa aphavexelte. 39, aspect and pigmentation of pronotum, dorsal view; 40, ditto, lateral view, some magnified setae; 41 , fore leg, inner face, magnified femoral denticles. Scale in $\mathrm{mm}$.

Tibia y tarso pardo pálido. Meso y metanoto con dos bandas laterales pardas oscuras de márgenes irregulares, flanqueando una ancha banda pálida sobre la línea media. Región pleural parda, más oscuras entre los límites de los pleuritos. Patas medias y posteriores con coxas pardas pálidas, trocánteres pardos, fémures con una banda longitudinal parda oscura en su cara ventral, y tarsómeros pardos.

Alas iridiscentes, con membrana desde hialina a muy levemente teñida de amarillo parduzco de aspecto ahumado, sin que la zona basal de las anteriores esté más pigmentada de pardo que el resto de la membrana. Pterostigma muy alargado y pardo rojizo, a veces más pálido (Fig. 42).

En la bibliografía (bajo sus diferentes denominaciones) hay datos de alas anteriores entre 9-22 mm, y más específicamente de 9,0-20,0 $\mathrm{mm}$ en los machos y de 10-22 $\mathrm{mm}$ en las hembras, en los ejemplares ibéricos que hemos medido, la longitud de las alas anteriores / posteriores oscila en los machos: 6,9-14,3 mm / 5,9-13,0 mm; y en las hembras: 6,8-15,2 mm / 5,8$14,1 \mathrm{~mm}$. Como vemos, la amplitud en el tamaño de algunos ejemplares casi duplica al que hallamos en otros, y especialmente en poblaciones del S.E. peninsular podemos hallar ejemplares machos francamente pequeños, que recuerdan lo conocido en Mantispa nana Erichson, 1839 (longitud de las alas anteriores en machos: $6,0-9,0 \mathrm{~mm}$; hembras: $6,5-9,0 \mathrm{~mm}$ ), especie frotropical extendida a la Península Arábica y Marruecos (Poivre, 1980; Ábrahám, com. per.), pero cuya genitalia coincide plenamente con lo citado para la especie que tratamos (Figs. 30, 31).

Abdomen pardo amarillento con tergos portando amplias manchas pardas de aspecto triangulartrapecial sobre la línea media, pleuras pardas oscuras hacia los tergos y los esternos, y esternos amarillentos, más pardos hacia los extremos laterales y portando una banda transversal parda próxima al margen posterior. Aspectos distintivos de la genitalia masculina se anotan en las figs. 30-31, y algunos elementos de la femenina en la fig. 56. Otros datos sobre su biología, morfología y genitalia pueden recabarse en Poivre (1983).

En nuestra fauna ha sido hallada en medios abiertos y soleados, con mayor frecuencia sobre especies de Quercus, especialmente esclerófilas $(Q$. rotundifolia y $Q$. ilex), y en menor frecuencia marcescentes (Q. pyrenaica, $Q$. canariensis). En menor medida sobre coníferas (Pinus y Juniperus) u otros fanerófitos (Eucaliptus). Poivre (1983) sugiere para esta especie zonas boscosas y matorrales espesos, elementos que no coinciden con lo observado por nosotros, que se acercan más a lo anotado por Ábrahám \& Papp (1994). 


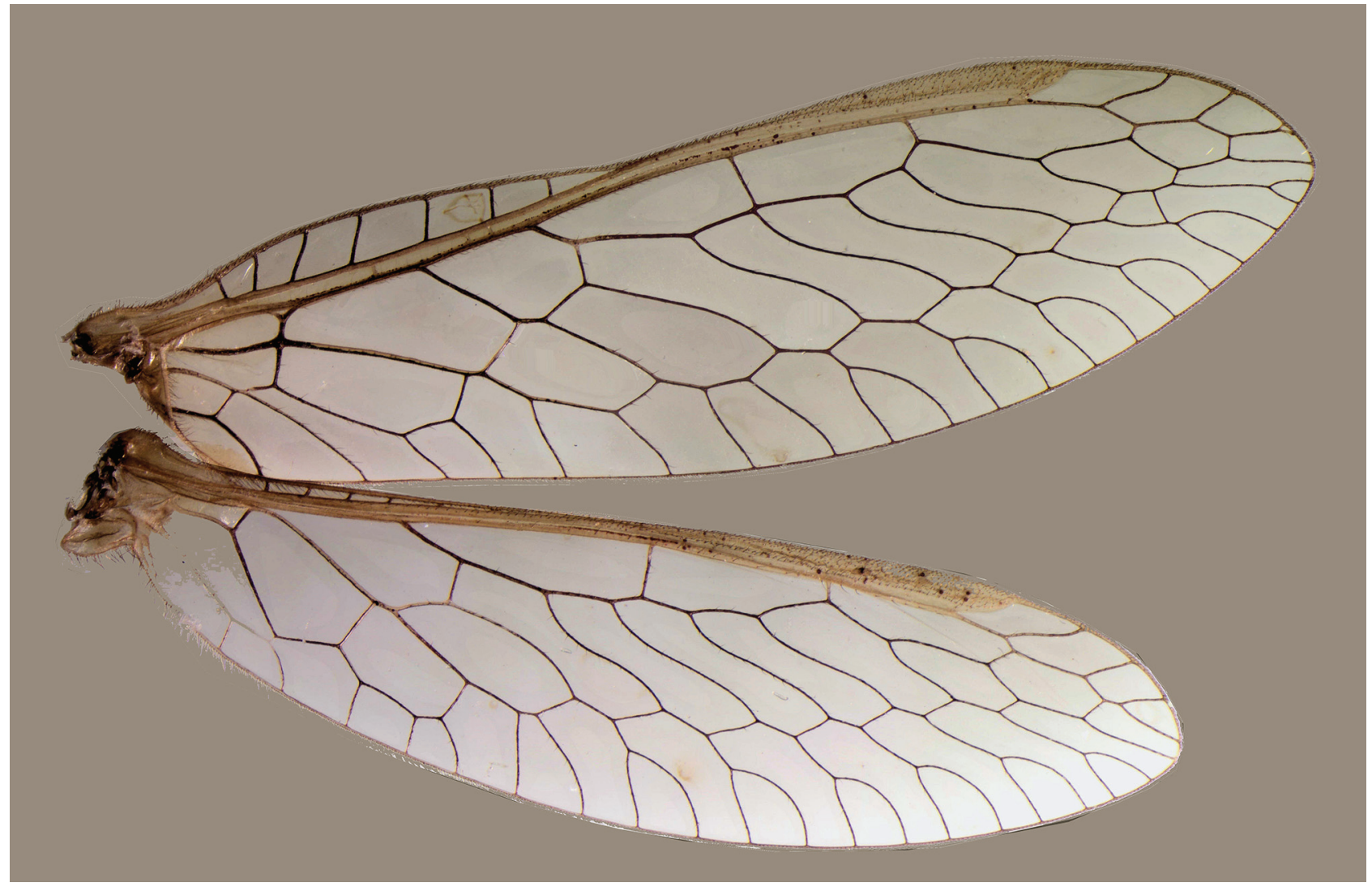

Fig. 42.- Alas de Mantispa aphavexelte.

Fig. 42.- Mantispa aphavexelte wings.

En la bibliografía, y bajo diferentes nombres, ha sido citada en Europa con imagos recolectados entre VI-VIII, y entre 120-1.800 m. En nuestra fauna, sus imagos han sido recolectados entre V-IX, aunque mayoritariamente en los meses más térmicos (VII-VIII), y en altitudes que oscilan entre los 320-1.750 m (Cáceres: La Herreruela-Granada: El Dornajo).

A esta especie debe asignarse el $\hat{\sigma}$ citado por Monserrat (1978a: 61) como Mantispa perla (Pallas, 1772), ya que por entonces Perlamantispa icterica se consideraba simple variedad de Mantispa perla y que había sido recolectado en Cádiz, Sierra del Pinar, 15.VIII.1976 sobre Quercus canariensis. Por el contrario, la cita de un macho como Perlamantispa perla var. icterica Pictet, 1865 de Toledo, Sierra de Pelahustán 4.VI.1978, dada por Monserrat (1980:184), ha de considerarse, como anteriormente indicamos, como perteneciente a $M$. perla. Correcciones similares ya fue anotada por Monserrat (1984b: 99) para un ejemplar O de Alicante, Benifato, y el ejemplar de Cáceres, Berzocana que ahora citamos, fue citado por Poivre (1983: 131) de octubre, por error en la interpretación de la grafia en la fecha de captura (julio).

Con frecuencia comparte medios con $M$. styriaca, $\mathrm{y}$ en algunas localidades son simpátridas. A diferencia de esta especie, de la que se han anotado numerosos nuevos datos, pocos elementos podemos aportar sobre el comportamiento reproductor en Mantispa aphavexelte. Únicamente citar una puesta de 216 huevos realizada por una hembra recolectada en Almería, Las Estancias, 27.VI.1983 sobre Q. ilex.

Mapa de distribución de esta especie en el área de estudio en la fig. 61.

\section{Mantispa incorrupta $\mathbf{n}$. sp.}

urn:1sid:zoobank.org:act:EB55A5B6-819E-47F5A628-A0CBDC7F7ED7

Material tipo: Holotipo: España, Toledo, Fuensalida, $568 \mathrm{~m}$, UTM: 30TVK03, coordenadas: $40^{\circ} 4^{\prime} 21^{\prime \prime} \mathrm{N}, 4^{\circ} 8^{\prime} 10^{\prime \prime} \mathrm{W}$,

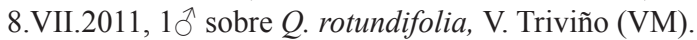

Paratipos: España, Toledo, Fuensalida, 568 m, UTM: 30TVK03, coordenadas: $40^{\circ} 4^{\prime} 21^{\prime \prime} \mathrm{N}, 4^{\circ} 8^{\prime} 10^{\prime \prime} \mathrm{W}, 8$.VII.2011, $20^{\Uparrow} \mathrm{J}^{*}$ (a*, $\left.{ }^{*}, \mathrm{mf}^{*}\right), 3 \circ{ }^{*} *\left({ }^{*}\right)$ sobre $Q$. rotundifolia, V. Triviño (VM). España, Toledo, Fuensalida, 568 m, UTM: 30TVK03, coordenadas: $40^{\circ} 4^{\prime} 21^{\prime \prime} \mathrm{N}, 4^{\circ} 8^{\prime} 10^{\prime \prime} \mathrm{W}, 8$.VII.2011, $10^{\lambda}$ sobre $Q$. rotundifolia, V. Triviño (MNCNM). (Se ha visitado de nuevo la localidad tipo los días 6.VII.2014, 11.VII.2014, 17.VII.2014 y 23.VII. 2014, sin éxito en el hallazgo de nuevos ejemplares).

Depósito del material tipo: Según se ha indicado, en base a las siglas de las instituciones y colecciones anotadas en el Material y Método.

Material complementario: Para comparación con esta especie, se ha estudiado otro material no ibérico de Mantispa scabricollis McLachlan, 1875: TAYIKISTÁN: Gorno-Badakhshan,

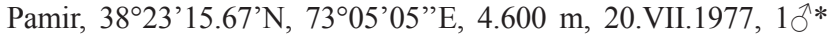




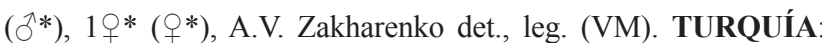
Karacasu-Ileçsi, Geyre, Aphrodisias, 8.VIII.1985, 1 + sobre Olea europaea (VM).

Diagnosis: Esta nueva especie ibérica se distingue a primera vista de las restantes especies europeas por la presencia de antenas no uniformemente pardas, sino con algunos flagelómeros medios muy pálidos (Fig. 43), por la presencia de manchas pardas muy oscuras en los extremos y zona media de las tibias en las patas anteriores alternadas con zonas más pálidas (Figs. 46, 47), por tener el pronoto muy estrecho y alargado, más de cuatro veces tan largo que su parte anterior más ancha, y portar gran cantidad pequeños tubérculos en la base de las setas (Figs. 44, 45), y por poseer pterostigmas pálidos en sus zonas proximal y media (Fig. 48). Otros aspectos de su venación y genitalia en figs. 43-51 y 57.

\section{DESCRIPCIÓN}

Morfología externa. Coloración general bastante variable, desde ejemplares más pálidos a otros más melánicos en los que la pigmentación externa está más marcada y contrastada. En ellos nos basamos al hacer referencia de su coloración tegumentaria.

Cabeza parda con una línea media más pálida sobre el vértex que se trifurca en forma de trébol hacia la región anterior entre la base de las antenas. Palpos pálidos, ojos prado-rojizos. Antenas (Fig. 43) con escapo fusiforme, pedicelo ovoide-cilíndrico, ambos pardo pálidos, algo más oscuros dorsalmente. Flagelo con primer flagelómero pardo pálido, algo más largo que los otros, restantes flagelómeros cuadrados, con marcada diferencia en su setación según cara dorsal o ventral, y ésta se va incrementando conforme se hacen más distales (Fig. 43). Son de color pardo pálido, progresivamente más oscuros, con marcada interrupción de algunos flagelómeros intermedios que son muy pálidos, en machos: del flagelómero $13^{\circ}-15^{\circ}$; en hembras: del flagelómero $14^{\circ}-15^{\circ}, 14^{\circ}-18^{\circ}, 15^{\circ}-19^{\circ}, 16^{\circ}-20^{\circ}$, según los ejemplares. Restantes flagelómeros progresivamente más oscuros. Número de flagelómeros: machos: 22, hembras: 23-26. Último flagelómero piriforme, algo más pálido hacia su mitad apical (Fig. 43).

Tórax con pronoto pardo pálido, más oscuro a ambos lados de la región anterior y levemente a lo largo de su zona lateral (Figs. 44, 45). Portando abundantes pequeñas prominencias en la base de las setas, muy extendidas, salvo en la zona lateralcentral (Figs. 44, 45). Tergos del meso-metanoto irregularmente pardos, dejando una ancha banda media más pálida. Primer par de patas (Figs. 46, 47) con región basal de las coxas portando prominentes setas sobre su región dorso-basal muy oscuras en su origen, su extremo distal es pardo muy oscuro, resto pardo pálido. Trocánter pardo pálido. Fémur en su cara externa pardo, más oscuro en hacia el tercio basal y su extremo distal, y en ejemplares más melánicos tienden a tener más oscura la zona longitudinal central; cara interna parda pálido, más oscura en el extremo distal y en la base del dentículo mayor. Denticulación marginal según Fig. 47. Tibia con fuerte espina distal muy oscura en su base, de color pardo pálido, con dos manchas alternas muy oscuras en los extremos y una muy conspicua en la zona central (Figs. 46, 47). Tarso pardo, más oscuro hacia los extremos. Patas medias y posteriores pardas muy pálidas, con extremo distal

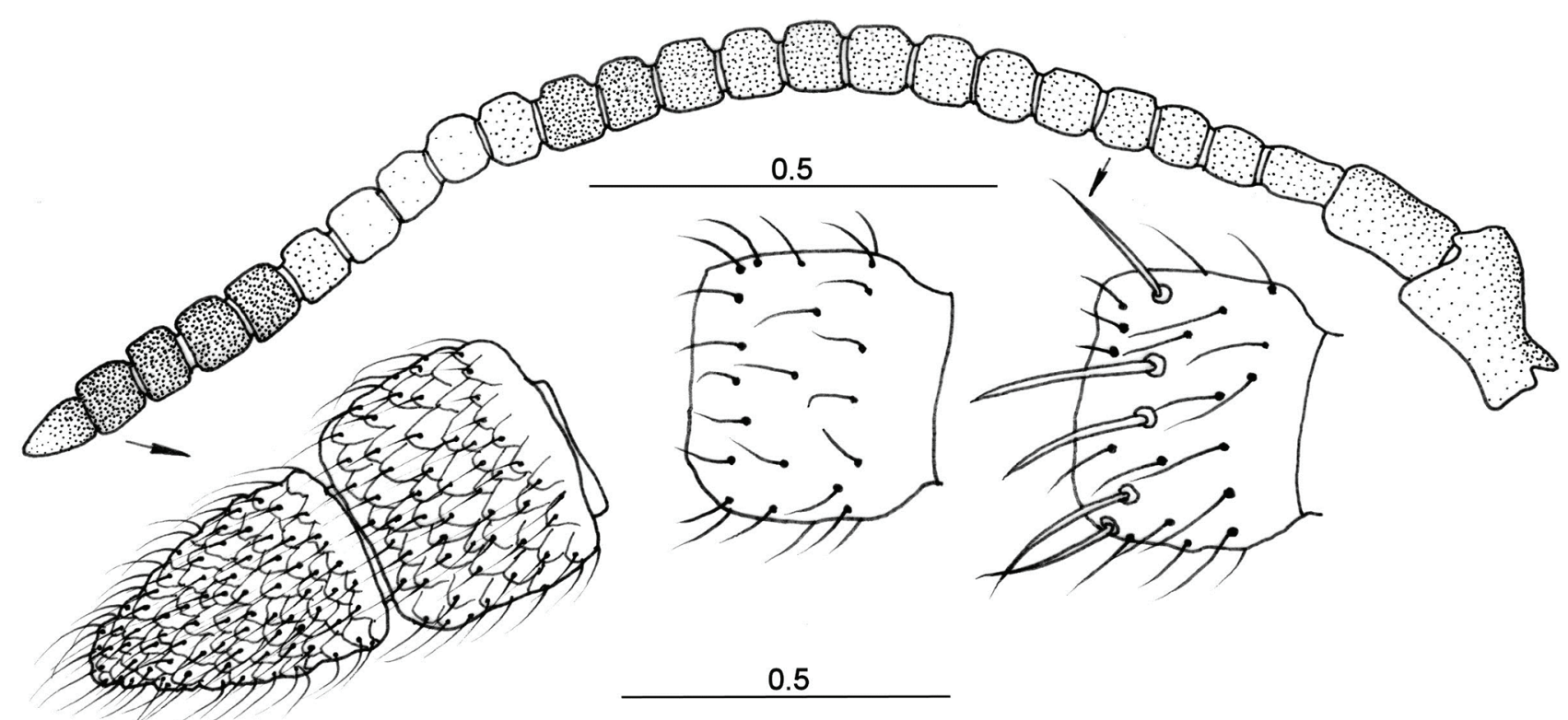

Fig. 43.- Mantispa incorrupta n. sp. Aspecto y pigmentación de la antena, ampliados (dorsal y ventral) los flagelómeros $4^{\circ}, 5^{\circ}$ y dos últimos. Escala en $\mathrm{mm}$.

Fig. 43.- Mantispa incorrupta n. sp. Appearance and pigmentation of the antenna, magnified (dorsal and ventral) 4th, 5th and last two flagellomeres. Scale in $\mathrm{mm}$. 
de las tibias y los cuatro últimos tarsómeros algo más oscuros. Tarsos con primer tarsómero algo más largo que el sumatorio de los restantes. Tarsómeros $1^{\circ}-4^{\circ}$ bilobulados-acorazonados, portando dos grupos de espinas ventrales a cada lado $\left(1^{\circ}: 3,2^{\circ}: 4\right.$ y $3^{\circ}$ y $4^{\circ}$ : 5 espinas), $5^{\circ}$ tarsómero fusiforme y robusto, portando empodio membranoso bilobulado y adherente. Uñas curvas, acabadas en cinco dentículos terminales, extremo de las uñas algo más oscuro.

Alas hialinas, salvo el pterostigma que es pardo muy oscuro, especialmente hacia la zona costal y subcostal, y con su región intermedia de aspecto granuloso, ésta zona y su zona proximal que son más pálidas, y la zona pre-perostigmática entre Sc y R es muy estrecha y algo más oscura que el resto (Fig. 48). Venación según Fig. 48. Longitud del ala anterior/posterior: Machos (7,9/7,0 mm, 6,7/6,3 mm, $6,4 / 5,4 \mathrm{~mm})$. Hembras $(12,8 / 11,4 \mathrm{~mm}, 9,7 / 8,8 \mathrm{~mm}$, 9,5/9,3 mm).

Abdomen pardo pálido, con tergos portando una zona triangular doble sobre la línea media de color pardo más oscura, y esternos cuadrangulares, más oscuros en la zona lateral. Región pleural con una linea oscura longitudinal bordeando los esternos.

\section{Terminalia y genitalia}

Macho: Terguito $8^{\circ}$ y esternito $8^{\circ}$ normales. Terguito $9^{\circ}$ transversal, estrecho; esternito $9^{\circ}$ cuadrangular, de ángulos redondeados y posee en el margen caudal una proyección levemente bilobulada portadora de abundantes sedas (Fig. 50). Ectoprocto robusto, cónico, portando abundante setación en su zona interna y con extremo romo levemente curvado hacia la línea media (Figs. 49, 50). Procesos internos digitiformes, fuertemente armados con gruesas y curvas setas en su cara interna (Figs. 49, 50). Gonarco arciforme, no fusionado sobre la línea media caudal (Fig. 51). Catoprocesos sinuosos, rodeados por una formación membranosa digitiforme armada de fuerte setación sobre su cara interna y su porción apical. Parámeros estrechos, marcadamente ensanchados y espatulados hacia su mitad caudal (Fig. 51). Mediunco membranoso y ancho en su base, y fusiforme dorsalmente, portando ambas estructuras diferente microsetación, su extremo es cónico y de ápice agudo (Figs. 49-51). Hipandrio triangular.

Hembra: Esternito $7^{\circ}$ amplio, con margen caudal semicircular. Esternito $8^{\circ}$ muy pequeño, subtriangular con margen caudal levemente arqueado (Fig. 57).
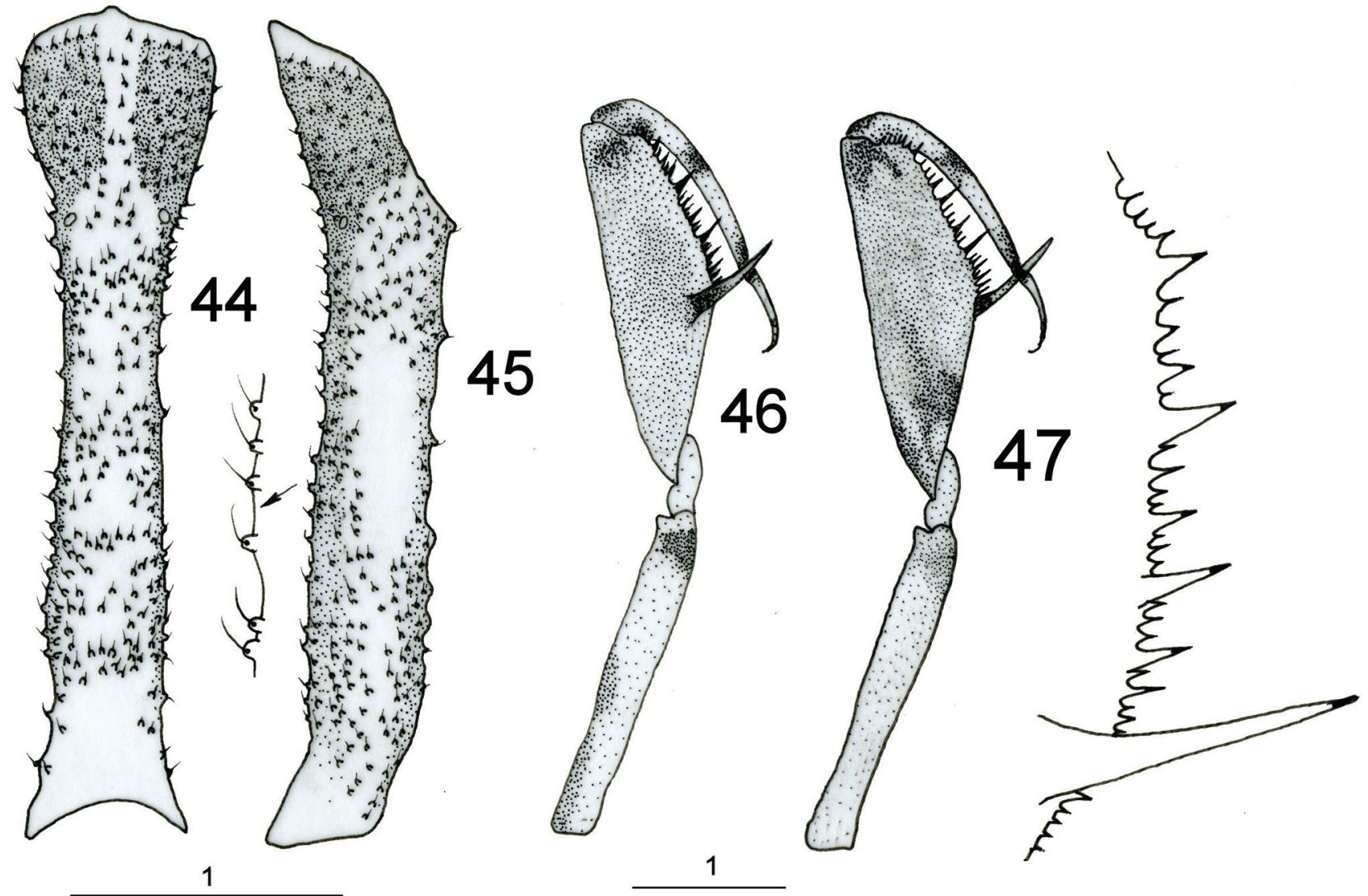

Figs. 44-47.- Mantispa incorrupta n. sp. 44, aspecto y pigmentación del pronoto, vista dorsal; 45, ídem, vista lateral, ampliadas algunas setas; 46, patas anteriores, cara interna; 47, ídem, cara externa, ampliados dentículos del fémur. Escala en mm.

Figs. 44-47.- Mantispa incorrupta n. sp. 44, aspect and pigmentation of pronotum, dorsal view; 45, ditto, lateral view, some magnified setae; 46 , fore legs, inner face; 47 , ditto, external face, magnified femoral denticles. Scale in $\mathrm{mm}$. 


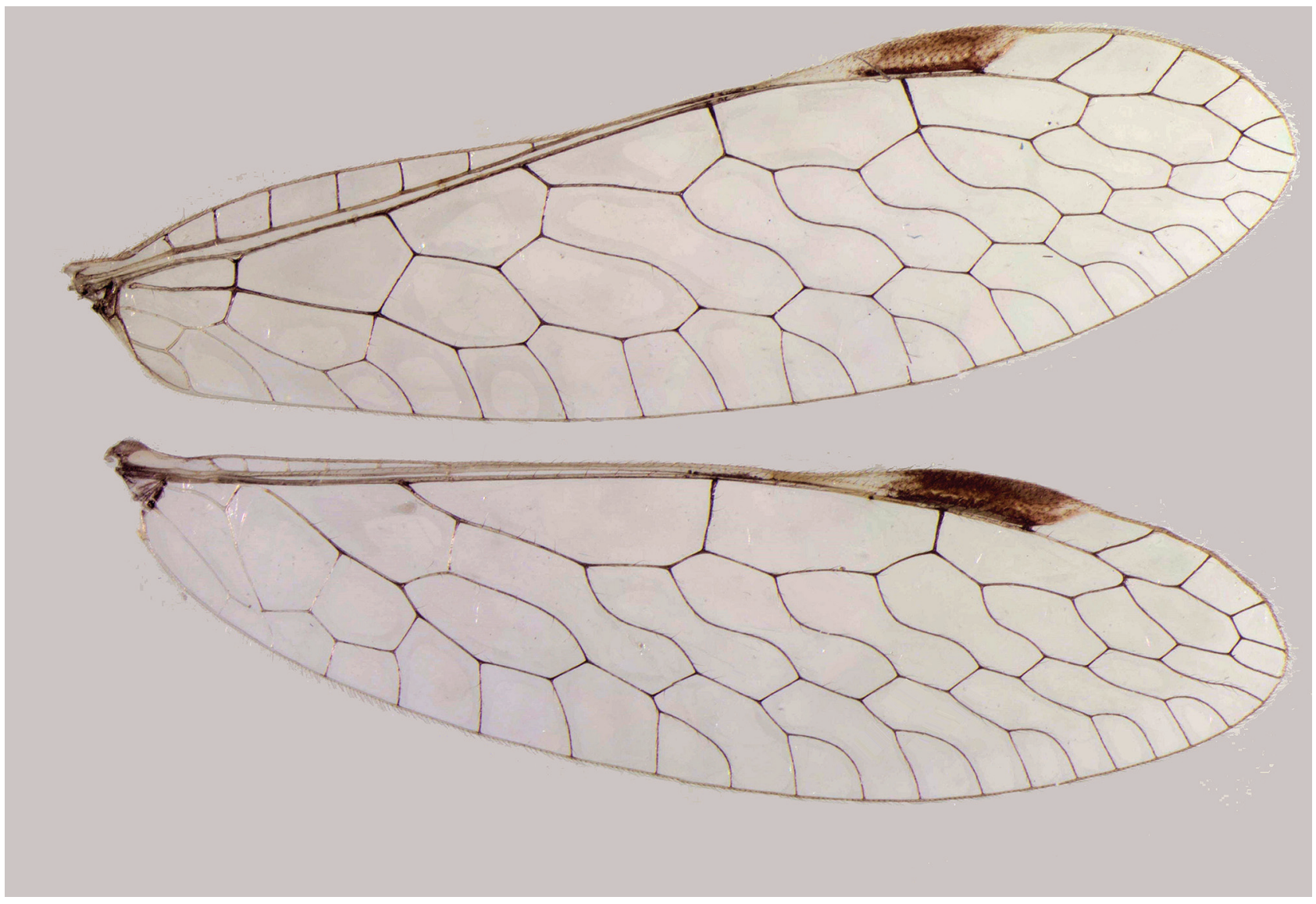

Fig. 48.- Alas de Mantispa incorrupta n. sp.

Fig. 48.- Mantispa incorrupta n. sp. wings.

Terguito $9^{\circ}$ estrecho. Gonapófisis laterales semiesféricas. Ectoprocto ovoide. Porción basal de la espermateca cilíndrica, con varias vueltas iniciales en círculo y dos más distales en forma de ocho. Porción distal de la espermateca tenue, su tercio basal estrecho y curvo, los dos tercios distales portadores de abundantes micotúbulos, el segundo tercio se va ensanchando fuertemente antes de finalizar en un corto proceso terminal cónico, algo más esclerificado y portador de micotúbulos más cortos.

Derivatio nominis: Del latín incorruptus: 1. adj. Que está sin corromperse; 2 . adj. No dañado ni pervertido. Dedicamos esta nueva y bella especie a la honestidad y la dignidad humanas, virtudes naturales que deberían estar mucho más extendidas en los países, gobiernos, políticos, empresarios, banqueros y entidades públicas y privadas, entre los que, con demasiada frecuencia, la corrupción, la codicia y la falta de escrúpulos y de decencia nos están llevando a un mundo cada vez más infeliz, más injusto y más desencantado.

Discusión: Como hemos anotado, esta nueva especie ibérica se distingue a primera vista de las restantes especies europeas por la presencia de antenas no uniformemente pardas, sino con algunos flagelómeros medios muy pálidos (Fig. 43), por la presencia de manchas pardas muy oscuras en los extremos y zona media de las tibias en las patas anteriores alternadas con zonas más pálidas (Figs. 46, 47), por tener un extremadamente largo y delgado pronoto (Figs. 44, 45), similar a lo que hallamos en algunas especies del género Eumantispa Okamoto, 1910, sobre el que existen muy abundantes pequeños tubérculos en la base de las setas (Figs. 44, 45), y por poseer pterostigmas pálidos en su zona media (Fig. 48), así como por otros aspectos de su venación y genitalia (Figs. 48-51, 57). Al margen de estos caracteres, puede repararse en las alas anteriores (Fig. 48), cuyo campo subcostal es mucho más estrecho, especialmente en su zona prepterostigmática, que en M. perla o M. aphavexelte (Figs. 37, 42), asemejándose más a $M$. styriaca, en la que su fuertemente dilatado pterostigma las diferencia a simple vista (Figs. 26, 48).

Son varias las especies afrotropicales o neotropicales con antenas bicolores [y Mantispa zonaria Navás, 1925 o Dicromantispa interrupta (Say, 1825) son buenos ejemplos] y/o con tubérculos en la base de las setas del pronoto (Poivre, 1980, 1982a, 1982b) (Mantispa nana Erichson, 1839 o Mantispa zonaria Navás, 1925), pero muy raramente en las especies 


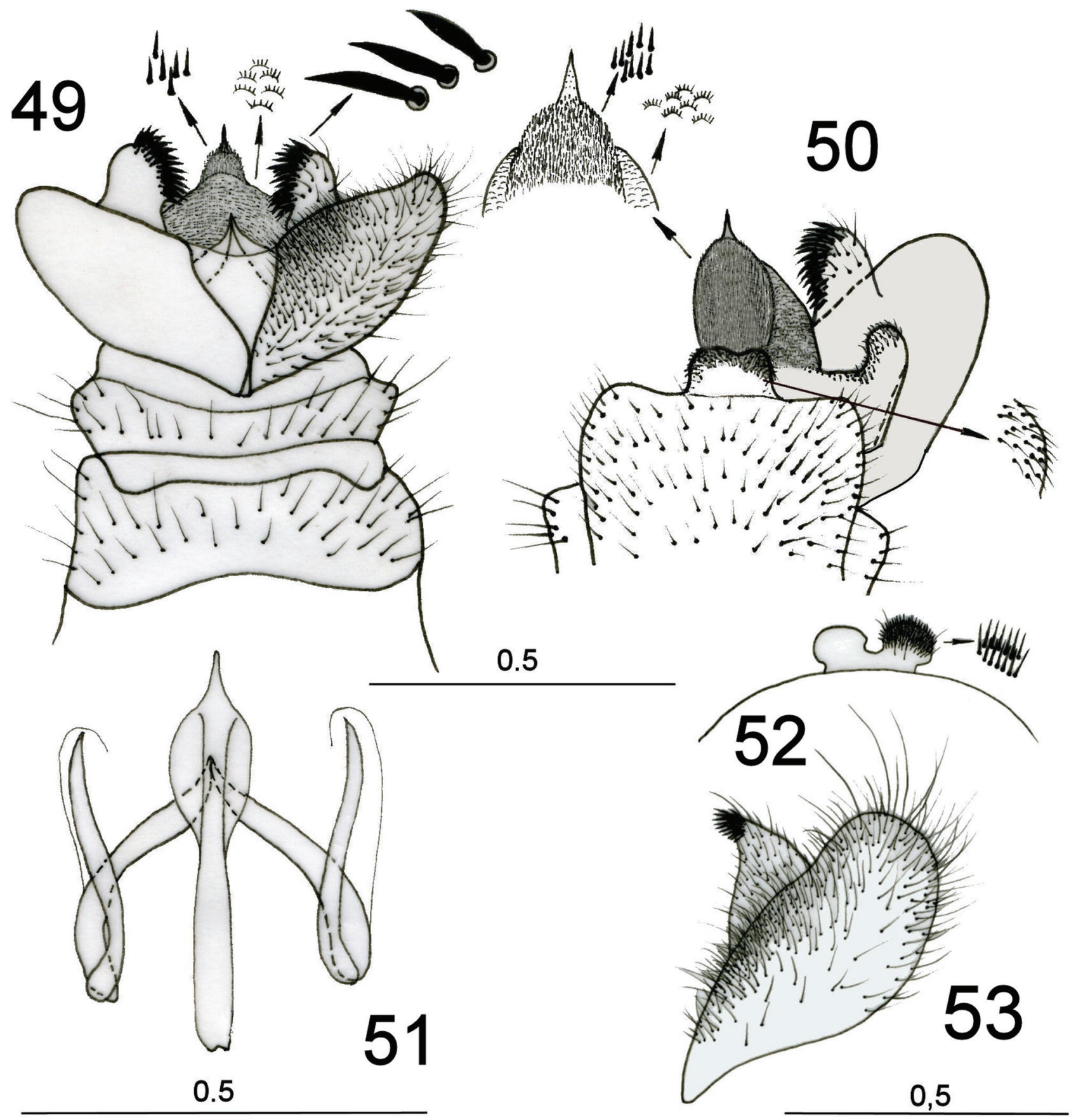

Figs. 49-53.- 49-51, Mantispa incorrupta n. sp., macho: 49, porción terminal del abdomen, vista dorsal (ampliadas algunas estructuras); 50, ídem, vista ventral (ampliadas algunas estructuras); 51, complejo catoprocesos-gonarco, parámeros, vista ventral; 52-53, Mantispa scabricollis macho: 52, margen caudal del esternito $9^{\circ}$; 53, ectoprocto, vista dorsal. Escala en mm.

Figs. 49-53.-49-51, Mantispa incorrupta n. sp., male: 49, terminal portion of abdomen, dorsal view (some magnified structures); 50, ditto, ventral view (some magnified structures); 51, catoprocessus-gonarcus-paramera complex, ventral view. 52-53, Mantispa scabricollis male: 52, caudal margin of the 9th esternite; 53 , ectoproct, dorsal view. Scale in mm.

europeas. Sólo Mantispa scabricollis McLachlan, 1875, especie pontomediterránea conocida de Anatolia, Israel, Armenia, Cáucaso, Irak, Irán, Afganistán, Tadshikistán y Turkestán, y citada de Europa en las islas griegas de Lesbos, Chios y Rodas, posee los citados tubérculos, aunque en un mucho menor número (Figs. 44, 45; Aspöck et al., 1980: 78, fig. 409).
Comentemos algunos elementos de estas especies potencialmente próximas en relación a la nueva especie ahora descrita.

Descartando las especies neotropicales, y con respecto a las especies afrotropicales del grupo de $M$. nana (M. nana, M. verruculata, $M$. zonaria, $M$. tenella o $M$. capeneri), alguna transferida por Snyman et al. (2012) 
54

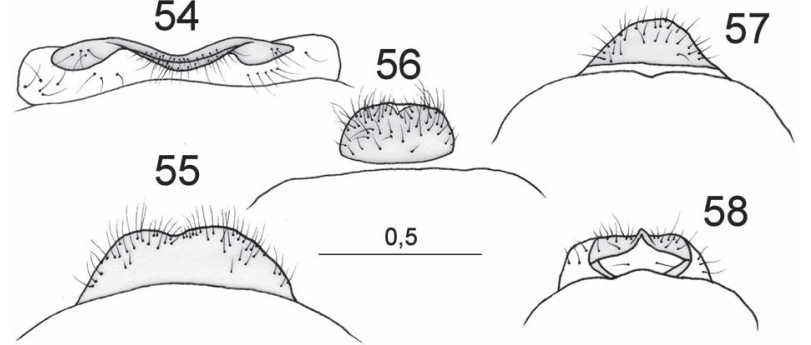

Figs. 54-58.- Esternito $8^{\circ}$ femenino, vista ventral de: 54 , M. perla; 55, M. styriaca; 56, M. aphavexelte; 57, M. incorrupta n. sp.; 58, M. scabricollis.

Figs. 54-58. - Female 8th sternite, ventral view of: 54, M. perla; 55, M. styriaca; $56, M$. aphavexelte; $57, M$. incorrupta n. sp.; 58, M. scabricollis.

al cuestionado género Afromantispa, esta nueva especie comparte ciertos caracteres de coloración antenal y tegumentaria, así como de morfología alar con $M$. nana y M. tenella (ver Poivre, 1980, 1981a). Pero en función de los datos conocidos, no consideramos que los elementos de la genitalia masculina las vinculen con esta nueva especie (Poivre, 1980, 1981a; Snyman et al., 2012).

Por otra parte el medio mediterráneo continental donde se ha encontrado $M$. interrupta (encinar disperso en un campo de cereales en el centro de la Península Ibérica) no se corresponde con la presencia de especies africanas en nuestra fauna, relegadas al sur peninsular, y especialmente a su árido sudeste.

En el caso de las especies europeas, consideramos que es una especie próxima a Mantispa scabricollis, aunque, en realidad, es muy escasa la información disponible sobre esta especie, o sobre sus sinonimias propuestas por Zakharenko (1987): Mantispilla minuta Kozhanchikov, 1949 = Mantispa minuta (Kozhanchikov, 1949) [nec Zeugomantispa minuta (Fabricius, 1775) $=$ Mantispa minuta Fabricius, 1775] = Mantispa caucasica Handschin, 1959, en particular sobre su morfología genital (Aspöck et al., 1980), a veces descrita de forma bastante esquemática o más bien testimonial (McLachlan, 1875; Kozhanchikov, 1949; Handschin, 1959c; Şengonca, 1980; Zakharenko, 1987; Aspöck \& Aspöck, 1994; Aspöck, 1996). Nosotros hemos contado con material de comparación en el que complementamos los datos diferenciales entre ambas especies (Figs. 43-53, 57-58).

En la bibliografía hay datos de longitud de alas anteriores de M. scabricollis entre 7,5-20 mm (en los ejemplares de esta especie que hemos estudiados, la longitud de las alas anteriores/posteriores oscila en el macho entre: $10,3 / 9,0 \mathrm{~mm}$, y en las hembras entre: $8,0-10,0 / 7,1-9,1 \mathrm{~mm})$. En los ejemplares ibéricos de $M$. incorrupta n. sp. que hemos medido, la longitud de las alas anteriores parece significativamente menor en los machos, y oscila entre 6,4-7,9 mm, y en las hembras entre 9,5-12,8 mm, aunque este caracter es muy variable, según hemos anotado. No así con otros caracteres de morfología externa, entre las que destacamos la presencia en $M$. incorrupta n. sp. de antenas con escapo y pedicelo pardo pálidos, más oscuros dorsalmente, y no uniformemente pardo pálidos, y especialmente flagelo marcadamente bicolor (Fig. 43), y no uniformemente pardo. El pronoto en M. incorrupta n. sp. porta significativamente muchos más tubérculos y setas que en M. scabricollis (Figs. 44, 45), y las manchas del fémur en esta especie posee en su cara externa, y especialmente en la interna, una amplia mancha pálida bajo el margen dentado, muy marcado en el especimen estudiados de Anatolia y material de Tadshikistán (Kozhanchikov, 1949), que no existe en $M$. incorrupta $\mathbf{n}$. sp., y la tibia alternativamente parda-pálida es también un caracter particular en esta nueva especie (Figs. 46, 47). También respecto a la genitalia masculina $M$. scabricollis difiere de $M$. incorrupta n. sp., entre otros caracteres, en la forma del ectoprocto y de sus procesos internos (Figs. 49, 50, 52, 53) y en el aspecto marcadamente bilobulado, y no simplemente sinuoso, del proceso del margen caudal del esternito $9^{\circ}$, así como el tipo de setas existente sobre él (Figs. 50, 52).

Respecto a algunos elementos de la genitalia femenina, comentamos el aspecto del $8^{\circ}$ esternito (Fig. 57), que es bastante distinto al que hallamos en los ejemplares de M. scabricollis de Pamir (Tayikistán) que hemos estudiado (Fig. 58), y que también parecen muy diferentes a lo que Aspöck et al. (1980: 78, figs. 405-407) anotan para un ejemplar de esta especie de Anatolia (Turquía), hecho que no ocurre con la genitalia masculina del ejemplar de Kios (Grecia) que estos autores utilizan para ilustrar la genitalia masculina de esta especie (Aspöck et al., 1980: 77, figs. 398-404). Esto demuestra, una vez más, que la taxonomía de las especies de Mantispidae de esta zona del este mediterráneo-oriente próximo/occidental no parece del todo dilucidada ni definitivamente resuelta.

En cualquier caso, y como ocurre en tantos otros taxa de diversas familias de neurópteros (y en multitud de especies de otras familias de otros órdenes), Mantispa incorrupta $\mathbf{n}$. sp. sería la especie vicariante de M. scabricollis en el Mediterráneo Occidental, y su presencia en la Península Ibérica sugiere de este linaje un origen preglaciar, quedando ambas poblaciones separadas por aquellos infranqueables elementos cuaternarios, hecho que también podría sugerir una mayor distribución ancestral en la zona continental europea, hoy limitada a las citadas islas griegas (Lesbos, Chios y Rodas) y a la Península Ibérica. No se descarta pues que aparezcan nuevos elementos meridionales en las penínsulas centrales europeas.

Mapa de distribución de esta especie en el área de estudio en la fig. 62. 
Tabla 1.- Datos sobre la amplitud altitudinal de imagos recolectados en la Península Ibérica.

Table 1.- Data on the altitudinal amplitude of imagoes collected in the lberian Peninsula.

\begin{tabular}{|c|c|}
\hline m & 1010025050075010001250150017502000 \\
\hline $\begin{array}{l}\text { Mantispa } \\
\text { styriaca }\end{array}$ & ---- \\
\hline $\begin{array}{l}\text { Mantispa } \\
\text { aphavexelte }\end{array}$ & --- \\
\hline $\begin{array}{l}\text { Mantispa } \\
\text { perla }\end{array}$ & ----- \\
\hline $\begin{array}{l}\text { Mantispa } \\
\text { incorrupta }\end{array}$ & --- \\
\hline
\end{tabular}

\section{Datos comparativos sobre la distribución altitudinal y fenológica de los mantíspidos en la Península Ibérica e Islas Baleares:}

No cabe duda que los factores abióticos como la latitud, altitud, el fotoperiodo natural y/o la temperatura/climatología a lo largo del año condicionan e influyen en la actividad, ciclos biológicos y distribución de las especies y sus poblaciones. En el caso de los mantíspidos, a todos estos elementos se suman sus particulares exigencias en su desarrollo juvenil que han sido citadas, siendo factores que también condicionan, limitan e influyen en su distribución geográfica, altitudinal y fenológica.

En la Península Ibérica e Islas Baleares, y en función de su distribución altitudinal, las especies de esta familia se segrega parcialmente en cotas que oscilan entre bajas $(10 \mathrm{~m})$ a relativamente elevadas $(1.900 \mathrm{~m})$. Aunque lo hemos mencionado anteriormente en cada especie en la Tabla 1 anotamos ahora de modo gráfico y comparativo la amplitud altitudinal de los datos conocidos en estas especies en nuestra fauna:

Sobre su fenología en nuestra fauna, y de modo general, las citas de los imagos se distribuyen entre abril y septiembre, y son mucho más abundantes en los meses de julio y agosto. Por las particulares exigencias y la aleatoriedad en el éxito de su desarrollo larvario que anteriormente hemos citado, las fenologías en esta familia no se ajustan exclusivamente a las condiciones ambientales que habitualmente rigen en otras familias de neurópteros, y en función de los tiempos requeridos para encontrar un hospedador adecuado (araña hembra y su puesta) es indudable que las generaciones se solapen con muy diferentes tiempos en su desarrollo, incluso entre individuos de una misma población y/o puesta. Aún así, el proporcionalmente corto tiempo empleado en su desarrollo preimaginal, que anteriormente hemos citado como ejemplo en $M$. styriaca, y por la presencia de imagos a lo largo de varios meses, es evidente que, al menos en esta especie y en $M$. aphavexelte, se producen y solapan varias generaciones a lo largo del año, y al menos dos en M. perla. Por los datos ahora anotados, parece deducirse una mayor abundancia general de hembras, y no parece sugerirse en Iberia la hibernación en estado adulto. Aunque lo hemos mencionado en cada una de las especies, en la Tabla 2 anotamos, de modo comparativo, la fenología de todos los datos recopilados y estudiados en nuestra fauna.

\section{Consideraciones sobre la distribución geográfica de la familia Mantispidae en nuestra fauna}

También en esta parcela, los requerimientos biológicos de las especies de esta familia, en particular de sus estadios juveniles, priman, o al menos condicionan y se solapan, sobre otros componentes abióticos, ambientales, fito-sociológicos y/o ecológicos que determinan la distribución de muchas especies de neurópteros de otras familias en nuestra fauna. En cualquier caso, la distribución de las especies de mantíspidos en la Península Ibérica muestra una cierta segregación, acorde con la distribución general de las especies. Entre ellas Mantispa styriaca es la más extendida, ocupando en la zona de estudio tanto áreas eurosiberianas como mediterráneas (Fig. 59), reflejo de esta capacidad más ubiquista muestra en su distribución ocupando amplias zonas extramediterráneas del centro de Europa. Mayor termicidad presenta M. aphavexelte, que también presenta una amplia distribución en la península, pero sólo ocupa sus zonas de influencia mediterránea (Fig. 61), mientras que mucho más estenoica, local y restringida parece $\operatorname{presentar} M$. perla, que dentro de este área parece estar limitada a zonas de mayor humedad hambiental. Por último y de momento, sólo tenemos datos de una localidad

Tabla 2.- Datos sobre la frecuencia mensual de imagos recolectados en la Península lbérica.

Table 2.- Data on the monthly frequency of imagos collected in the Iberian Peninsula.

\begin{tabular}{lcccccccc}
\hline Machos/Hembras & III & IV & V & VI & VII & VIII & IX & X \\
\hline Mantispa styriaca & & $2 / 0$ & $7 / 10$ & $10 / 15$ & $43 / 64$ & $24 / 33$ & $8 / 6$ & \\
Mantispa aphavexelte & & & $1 / 0$ & $9 / 3$ & $6 / 15$ & $3 / 6$ & $1 / 1$ & \\
Mantispa perla & & & & $3 / 4$ & $2 / 4$ & $2 / 0$ & \\
Mantispa incorrupta & & & & & $4 / 3$ & & & \\
\hline
\end{tabular}



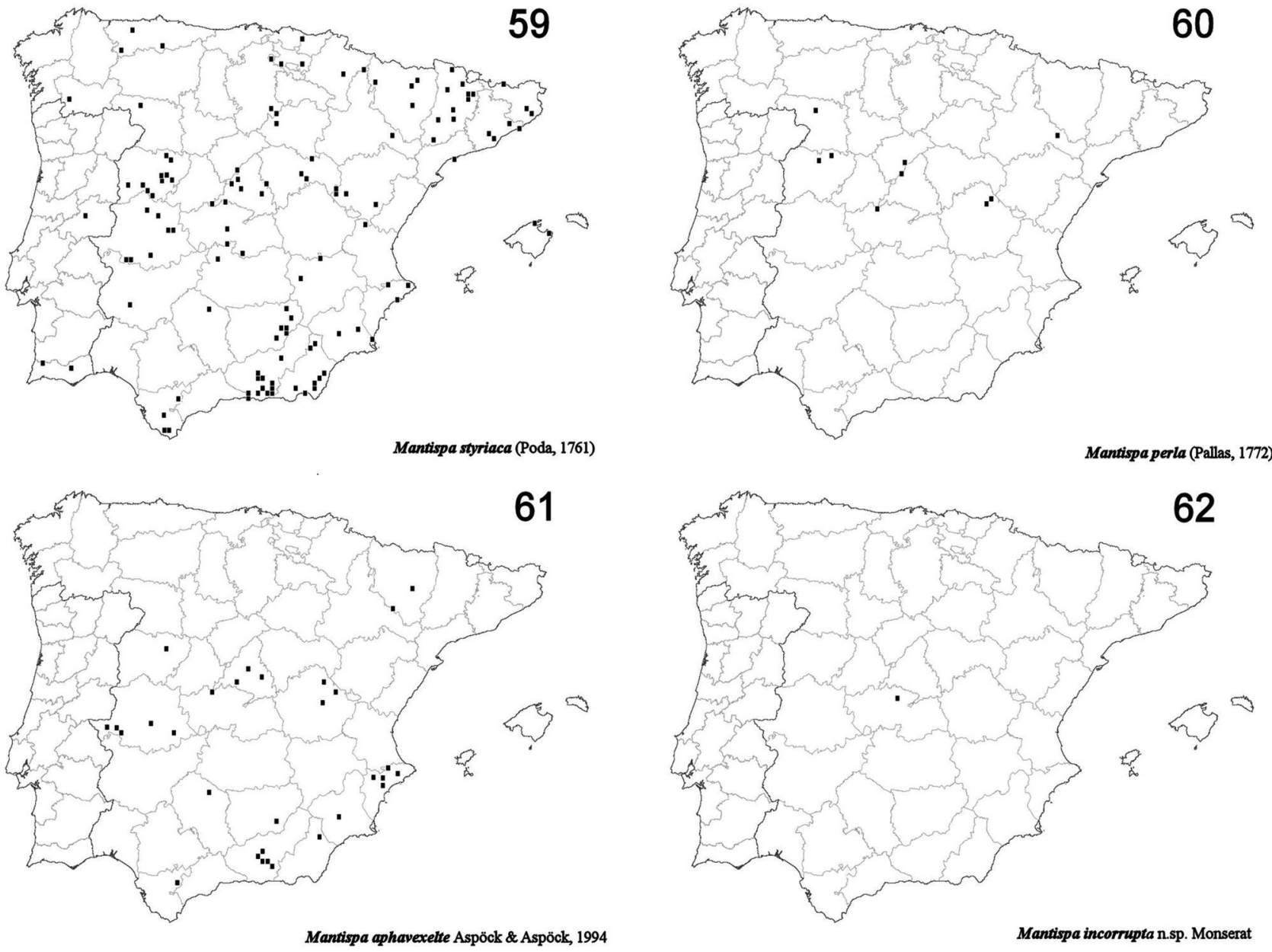

Figs. 59-62.- Distribución geográfica de las especies íbero-baleares de Mantispidae. Actualizado de Monserrat \& Triviño (2013).

Figs. 59-62.- Geographical distribution of Iberian-Balearic Mantispidae species. Actualized from Monserrat \& Triviño (2013).

para $M$. incorrupta, representando otro ejemplo más de poblaciones relictas de especies de neurópteros preglaciares que han robrevivido en la península en determinados enclaves.

\section{Agradecimientos}

Esta contribución forma parte del Proyecto coordinado de $\mathrm{I}+\mathrm{D}+\mathrm{i}$ Fauna Ibérica (Neuroptera) CGL2010-22267-C07-05. Deseamos agradecer a las instituciones, amigos y compañeros citados en el material estudiado por permitirnos el estudio del material citado de sus colecciones o por el envío de los datos y/o ejemplares de sus colecciones particulares o de sus centros de investigación, en especial a Peter C. Barnard, Oliver S. Flint y Gary F. Hevel. También deseamos manifestar nuestro sincero agradecimiento a las autoridades de las diferentes Comunidades Autónomas por facilitarnos los correspondientes permisos de muestreos para la toma de datos en los espacios protegidos visitados estos años. A Peter Schwendinger, John Hollier, Jorge Almeida, Enrique Gil Alcubilla, Isidro Martínez, Francisco Rodríguez, Marcello Romano y Rinaldo Nicoli Aldini por sus fotografías, a Jose Antonio Barrientos por la identificación de las arañas, a Victor Krivokhatskiy, Çetin Şengonca, Levente Ábrahám, Alexi Popov, John Hollier, Peter Schwendinger, Oliver S. Flint, Jr. y Gary F. Hevel por sus opiniones y ayuda, a David Papenberg por su ayuda en las traduciones de algunos textos, a Fernando Acevedo y especialmente a Víctor Triviño por su ayuda en los últimos muestreos realizados, y a E. Ruiz por su ayuda en el tratamiento de las imágenes.

\section{Referencias}

Ábrahám, L. \& Mészáros, Z., 2006. Further studies on the daily activity pattern of Neuroptera with some remarks on the diurnal activites. Acta Phytopathologica et Entomologica Hungarica, 41: 275-286.

Ábrahám, L. \& Papp, Z., 1994. Mantispids species in the Hungarian fauna with some taxonomical remarks (Neuroptera: Mantispidae). Folia Historico-Naturalia Musei Matraensis, 19: 69-75.

Acker, T. S., 1960. The comparative morphology of the male terminalia of Neuroptera (Insecta). Microentomology, 24: 25-83.

Ansorge, J. \& Schlüter, T., 1990. The earliest chrysopid: Liassochrysa stigmatica n. g., n. sp. from the Lower Jurassic of Dobbertin, Germany. Neuroptera International, 6(2): 87-93.

Archibald, S. B. \& Makarkin, V. N., 2004. New genus of minute Berothidae (Neuroptera) from Early Eocene amber of British Columbia. Canadian Entomologist, 136: 61-76. http://dx.doi.org/10.4039/n03-043. 
Askew, R. R., 1971. Parasitic insects. American Elsevier. New York. 316 pp.

Aspöck, H., 1992. The Neuropteroidea of Europe: a review of present knowledge (Insecta). In: M. Canard, H. Aspöck \& M. W. Mansell (eds.). Current Research in Neuropterology (Proceedings of the Fourth International Symposium on Neuropterology, 24-27 June 1991, Bagnères-de-Luchon). Toulouse: 43-56.

Aspöck, H., 1999. Beschreibungen und Abbildungen von Mantispiden in der frühen entomologischen Literature und Österreichs Beitrag zur Erforschung der Fanghafte (Neuropterida: Neuroptera: Mantispidae). In: H. Aspöck (ed.). Neuopterida: Raphidioptera, Megaloptera, Neuroptera. Kamelhälse, Schlammfliegen, Ameisenlöwen. Stapfia 60/Kataloge des Oberösterreichischen Landesmuseums. Neue Folge, 138: 209-244.

Aspöck, H., Aspöck, U. \& Hölzel, H., 1980. Die Neuropteren Europas, 2 vols. Goecke \& Evers. Krefeld. Vol. I, 495 pp., vol. II, 355 pp.

Aspöck, H. \& Hölzel, H., 1996. The Neuropteroidea of North Africa, Mediterranean Asia and of Europe: a comparative review (Insecta). In: M. Canard, H. Aspöck \& M. W. Mansell (eds.). Pure and Applied Research in Neuropterology (Proceedings of the Fifth International Symposium on Neuropterology, 2-6 May 1994, Cairo). Toulouse: 31-86.

Aspöck, H., Hölzel, H. \& Aspöck, U., 2001. Kommentierter Katalog der Neuropterida (Insecta: Raphidioptera, Megaloptera, Neuroptera) der Westpaläarktis. Denisia, 2: $1-606$.

Aspöck, U., 1992. Crucial points in the phylogeny of the Neuroptera (Insecta). In: M. Canard, H. Aspöck \& M. W. Mansell (eds.). Current Research in Neuropterology (Proceedings of the Fourth International Symposium on Neuropterology, 24-27 June 1991, Bagnères-deLuchon). Toulouse: 63-73.

Aspöck, U., 1994. Die Mantispiden Europas (Neuropteroidea: Neuroptera: Mantispidae). Verhandlungen des 14 Internationalen Symposiums für Entomofaunistik in Mitteleuropa. SIEEC. München: 224-230.

Aspöck, U., 1995. Neue hypothesen zum System der Neuropterida. Mitteilungen der Deutschen Gesellschaft für Allgemeine und Angewandte Entomologie, 10: 633-636.

Aspöck, U., 1996. Die Mantispiden Europas (Neuropteroidea: Neuroptera: Mantispidae). Verhandlungen des 14. Internationalen Symposiums über Entomofaunistik in Mitteleuropa (SIEEC), München: 224-230.

Aspöck, U., 2002. Phylogeny of the Neuropterida (Insecta: Holometabola). Zoologica Scripta, 31(1): 51-55. http:// dx.doi.org/10.1046/j.0300-3256.2001.00087.x.

Aspöck, U. \& Aspöck, H., 1994. Zur Nomenklatur der Mantispiden Europas (Insecta: Neuroptera: Mantispidae). Annalen des Naturhistorischen Museums in Wien, 96B: 99-114.

Aspöck, U. \& Aspöck, H., 2010. Landmarks towards a phylogeny-based classification of the Neuropterida (Insecta: Endopterygota). In: D. Devetak, S. Lipovšek $\&$ A. E. Arnett (eds.). Proceedings of the 10th International Symposium on Neuropterology, 22-25 June 2008, Piran. University of Maribor. Maribor: 67-74.
Aspöck, U., Aspöck, H. \& Haring, E., 2003. Phylogeny of the Neuropterida - morphological evidence and the molecular advocatus diaboli. Entomologische Abhandlungen, 61: 157-158.

Aspöck, U., Haring, E. \& Aspöck, H., 2012. The phylogeny of the Neuropterida: long lasting and current controversies and challenges (Insecta: Endopterygota). Arthropod Systematics \& Phylogeny, 70: 119-129.

Aspöck, U. \& Mansell, M. W., 1994. A revision of the family Rhachiberothidae Tjeder, 1959, stat. n. (Neuroptera). Systematic Entomology, 19: 181-206. http:// dx.doi.org/10.1111/j.1365-3113.1994.tb00587.x.

Aspöck, U. \& Nemeschkal, H. L., 1998. A cladistic analysis of the Berothidae (Neuroptera). In: S. P. Panelius (ed.). Neuropterology 1997 (Proceedings of the Sixth International Symposium on Neuropterology, 13-16 July 1997, Helsinki). Acta Zoologica Fennica, 209: 45-63.

Aspöck, U., Plant, J. D. \& Nemeschkal, H. L., 2001. Cladistic analysis of Neuroptera and their systematic position within Neuropterida (Insecta: Holometabola: Neuropterida: Neuroptera). Systematic Entomology, 26:73-86.http://dx.doi.org/10.1046/j.1365-3113.2001. 00136.x.

Auber, J., 1958. Faune terrestre et d'eau douce des Pyrénées-Orientales. 3. Névroptéroïdes. Vie et Milieu, 9: 1-42.

Austin, A. D., 1985. The function of spider egg sacs in relation to parasitoids and predators, with special reference to the Australian fauna. Journal of Natural History, 19: 359-376.

Balduf, W. V., 1939. The bionomics of entomophagous Insects. Vol. 2. John S. Swift Co. Chicago. [iii] + 384 pp.

Banks, N., 1912. Notes on Nearctic Mantispidae. Proceedings of the Entomological Society of Washington, 14: 178-179.

Banks, N., 1913. Synopses and descriptions of exotic Neuroptera. Transactions of the American Entomological Society, 39: 201-242.

Batra, S. W. T., 1972. Notes on the behavior and ecology of the mantispid, Climaciella brunnea occidentalis. Journal of the Kansas Entomological Society, 45: 334-340.

Beck, J., 2005. Wasp-mimicking Mantispidae (Insecta: Neuroptera) from Sabah, Malaysia. Sepilok Bulletin, 3: 37-40.

Berg, C., 1899. Los mantíspidos de la República Argentina. Comunicaciones del Museo Nacional de Buenos Aires, 1: 139-145.

Birabén, M., 1960. Mantispa (Neuroptera) parasita en el cocón de Metepeira (Araneae). Neotropica, 6: 61-64.

Bissett, J. L. \& Moran, V. C., 1967. The life history and coccon spinning behaviour of a South African mantispid (Neuroptera: Mantispidae). Journal of the Entomological Society of Southern Africa, 30: 82-95.

Bode, A., 1953. Die Insektenfauna des Ostniedersächsischen Oberen Lias. Palaeontographica: Beiträge zur Naturgeschichte der Vorwelt, A103: 1-375.

Bohigas, M. \& Sanchez, A., 1917. Catáleg dels insectes del Museu pertanyents als orders: ParaneuropteraEphemeroptera-Plecoptera-Neuroptera-MegalopteraRhaphidioptera-Embioptera-Mecoptera-Psocoptera- 
Trichoptera. Publicacions de la Junta de Ciències Naturals de Barcelona, Anuari, 2(1): 301-326.

Bolívar, I., 1882. Sobre la estructura de las patas prensoras de la Mantispa perla Pall. Anales de la Sociedad Española de Historia Natural, 11: 35-40.

Bowden, J. \& Morris, M. G., 1975. The influence of moonlight on catches of insects in light-traps in Africa. III. The effective radius of a mercury-vapour light-trap and the analysis of catches using effective radius. Bulletin of Entomological Research, 65: 303-348.

Boyden, T. C., 1983. Mimicry, predation and potential pollination by the mantispid, Climaciella brunnea var. instabilis (Say) (Mantispidae: Neuroptera). Journal of the New York Entomological Society, 91: 508-511.

Brauer, F., 1852a. Verwandlungsgeschichte der Mantispa pagana. Archiv für Naturgeschichte, 18(1):1-2.

Brauer, F., 1852b. Versuch einer Gruppirung der Gattungen in der Zunft Planipennia mit besonderer Rücksicht auf die früheren Stände. Stettiner Entomologische Zeitung, 13: 71-77.

Brauer, F., 1855a. Beiträge zur Kenntniss des inneren Baues und der Verwandlung der Neuropteren. Verhandlungen des Zoologisch-Botanischen Vereins in Wien, 5: 701-726.

Brauer, F., 1855b. Beiträge zur Kenntniss der Verwandlung der Neuropteren. Verhandlungen des Zoologisch-Botanischen Vereins in Wien, 5: 777-786.

Brauer, F., 1867. Beitrag zur Kenntniss der Mantispiden-Gattungen. Verhandlungen der Kaiserlich-Königlichen Zoologisch-Botanischen Gesellschaft in Wien, 17: 281-286.

Brauer, F., 1868. Verzeichniss der bis jetzt bekannten Neuropteren in Sinne Linné's. Erster Abschnitt. Verhandlungen der Kaiserlich-Königlichen ZoologischBotanischen Gesellschaft in Wien, 18: 359-416, 711-742.

Brauer, F., 1869. Beschreibung der Verwandlungsgeschichte der Mantispa styriaca Poda und Betrachtungen über die sogenannte Hypermetamorphose Fabre's. Verhandlungen der Kaiserlich-Königlichen ZoologischBotanischen Gesellschaft in Wien, 19: 831-840.

Brauer, F., 1876. Die Neuropteren Europas und insbesondere Oesterreichs mit Rücksicht auf ihre geographische Verbreitung. Festschrift zur Feier des fünfundzwanzigjährigen Bestehen Kaiserlich-Koniglichen ZoologischBotanischen Gesellschaft, Wien: [263]-300.

Brauer, F., 1887. Beitrag zur Kenntnis der Verwandlung der Mantispiden-Gattung Symphrasis Hg. Zoologischer Anzeiger, 10: 212-218.

Bristowe, W. S., 1932. Mantispa, a spider parasite. Entomologist's Monthly Magazine, 68: 222-224.

Brushwein, J. R., 1987a. Bionomics of Lomamyia hamata (Neuroptera: Berothidae). Annals of the Entomological Society of America, 80: 671-679.

Brushwein, J. R., 1987b. Observations on Lomamyia longicollis (Neuroptera: Berothidae) in South Carolina. Journal of the Kansas Entomological Society, 60: 150-152.

Brushwein, J. R. \& Culin, J. D., 1991. Modified rearing and maintenance techniques for Mantispa viridis (Neuroptera: Mantispidae). Florida Entomologist, 74: 446-452.

Brushwein, J. R., Culin, J. D. \& Hoffman, K. M., 1995a. Development and reproductive behavior of Mantispa viridis Walker (Neuroptera, Mantispidae). Journal of Entomological Science, 30: 99-111.

Brushwein, J. R., Hoffman, K. M. \& Culin, J. D., 1992. Spider (Araneae) taxa associated with Mantispa viridis (Neuroptera: Mantispidae). Journal of Arachnology, 20(3): 153-156.

Brushwein, J. R., Hoffman, K. M. \& Culin, J. D., 1995 b. Seasonal phenology and overwintering of Mantispa viridis Walker (Neuroptera, Mantispidae) in South Carolina. Journal of Entomological Science, 30: 112-119.

Burmeister, H. C. C., 1839. Handbuch der Entomologie. Zweiter Band. Besondere Entomologie. Zweite Abtheilung. Kaukerfe. Gymnognatha. (Zweite Hälfte; vulgo Neuroptera). T. C. F. Enslin. Berlin. xii + 757-1050 pp.

Buys, S. C., 2008. Observations on the biology of Anchieta fumosella (Westwood 1867) (Neuroptera Mantispidae) from Brazil. Tropical Zoology, 21:91-95.

Caposcale, R., 1971. Hallazgo de Mantispa decorata Erichson parasitando la ooteca de una Lycosa poliostoma (Koch) (Neuroptera, Mantispidae; Araneae, Lycosidae). Revista Brasileira de Biologia, 31: 367-370.

Charpentier, T., 1825. Horae entomologicae, adjectis tabulis novem coloratis. A. Gosohorsky. Wratislaviae. xvi + $255 \mathrm{pp}$.

Cockerell, T. D. A., 1921. Fossil arthropods in the British Museum. - VI. Oligocene insects from Gurnet Bay, Isle of Wight. Annals and Magazine of Natural History, (9), 7: 453-480.

Davidson, J. A., 1969. Rearing Mantispa viridis Walker in the laboratory (Neuroptera, Mantispidae). Entomological News, 80: 29-31.

DeGeer, C., 1778. Mémoires pour servir à l'histoire des insectes, T. VII. Hosselberg. Stockholm. 950 pp.

Dejean, A. \& Canard, M., 1990. Reproductive behaviour of Trichoscelia santareni (Navas) (Neuroptera: Mantispidae) and parasitization of the colonies of Polybia diguetana R. du Buysson (Hymenoptera: Vespidae). Neuroptera International, 6(1): 19-26.

Devetak, D., 1992a. Rdeči seznam ogroženih mrežekrilcev (Neuroptera s. 1.) v Sloveniji. Varstvo Narave, 17: 111-115.

Devetak, D., 1992b. Present knowledge of the Megaloptera, Raphidioptera and Neuroptera of Yugoslavia (Insecta: Neuropteroidea). In: M. Canard, H. Aspöck \& M. W. Mansell (eds.). Current Research in Neuropterology (Proceedings of the Fourth International Symposium on Neuropterology, 24-27 June 1991, Bagnères-deLuchon). Toulouse: 107-118.

Díaz-Aranda, L. M. \& Monserrat, V. J., 1988a. Contribución al conocimiento de los neurópteros de Jaén (Insecta, Neuroptera). Boletín de la Asociación Española de Entomología. 12: 111-123.

Díaz-Aranda, L. M. \& Monserrat, V. J., 1988b. Contribución al conocimiento de los neurópteros de Teruel (Insecta, Neuropteroidea). Boletín de la Asociación Española de Entomología, 12: 215-231.

Díaz-Aranda, L. M. \& Monserrat, V. J., 1988c. Contribución al conocimiento de los Neurópteros de Granada (Insecta, Neuropteroiea). Actas III Congreso Ibérerico Entomología, Granada: 211-227. 
Díaz-Aranda, L. M., Monserrat, V. J. \& Marín, F., 1986. Contribución al conocimiento de los neurópteros de Guadalajara (Insecta, Neuropteroidea). Actas VIII Jornadas Asociación Española de Entomología, Sevilla: 1131-1141.

Dorokhova, G. I., 1987. [Order Neuroptera.] In: G. S. Medvedev. Opredeliteli po faune SSSR, 4(153): 36-96 (en ruso).

Downes, M. F., 1985. Emergence of Austromantispa imbecilla (Gerstaecker) (Neuroptera: Mantispidae) from the retreat web of Mopsus penicillatus (Karsch) (Araneae: Salticidae). Australian Entomological Magazine, 12: 54.

Duelli, P., 1994. Rote Liste der gefährdeten Netzflügler der Schweiz. In: P. Duelli (ed.). Rote Listen der gefährdeten Tierarten der Schweiz. Bundesamt für Umwelt, Wald und Landschaft. BUWAL-Reihe Rote Listen und EDMZ. Bern: 64-65.

Eggenreich, U. \& Kral, K., 1990. External design and field of view of the compound eyes in a raptorial neuropteran insect, Mantispa styriaca. Journal of Experimental Biology, 148: 353-365.

Eltringham, H., 1932. On an extrusible glandular structure in the abdomen of Mantispa styriaca Poda (Neuroptera). Transactions of the Royal Entomological Society of London, 80: 103-105. http://dx.doi. org/10.1111/j.1365-2311.1932.tb00084.x.

Enderlein, G., 1910. Klassifikation der Mantispiden nach dem material des Stettiner Zoologischen Museums. Stettiner Entomologische Zeitung, 71: 341-379.

Engel, M. S., 2004. Thorny lacewings (Neuroptera: Rhachiberothidae) in Cretaceous amber from Myanmar. Journal of Systematic Palaeontology, 2: 137-140. http:// dx.doi.org/10.1017/S1477201904001208.

Engel, M. S. \& Grimaldi, D. A., 2007. The neuropterid fauna of Dominican and Mexican amber (Neuropterida, Megaloptera, Neuroptera). American Museum Novitates, 3587: 1-58. http://dx.doi.org/10.1206/0003-0082(2007) 3587[1:TNFODA]2.0.CO;2.

Erichson, W. F., 1839. Beiträge zu einer Monographie von Mantispa, mit einleitenden Betrachtungen über die Ordnungen der Orthopteren und Neuropteren. Zeitschrift für die Entomologie, 1: 147-173.

Esben-Petersen, P., 1914. Australian Neuroptera. Part i. Proceedings of the Linnean Society of New South Wales, 39: 635-645.

Esben-Petersen, P., 1917a. Neue und wenig bekannte Mantispiden. Arkiv för Zoologi, 11(10): 1-15.

Esben-Petersen, P., 1917b. Australian Neuroptera. Part iii. Proceedings of the Linnean Society of New South Wales, 42: 203-219.

Esben-Petersen, P., 1918. Results of Dr. E. Mjöberg's Swedish Scientific Expeditions to Australia 1910-1913. 18. Neuroptera and Mecoptera. Arkiv för Zoologi, 11(26): 1-37.

Esben-Petersen, P., 1923. Australian Neuroptera. Part v. Proceedings of the Linnean Society of New South Wales, 48: 593-600.

Esben-Petersen, P., 1928. New and little-known Neuroptera from the Dutch East Indies. Treubia, 10: 225-230.

Esben-Petersen, P., 1929a. Australian Neuroptera. [Part] VI. Queensland Naturalist, 7: 31-35.
Esben-Petersen, P., 1929b. Fauna Buruana. Neuroptera. Treubia, 7(Supp): 101-104.

Fabricius, J. C., 1775. Systema entomologiae, sistens insectorvm classes, ordines, genera, species, adiectis synonymis, locis, descriptionibvs, observationibvs. Kortii. Flensbvrgi et Lipsiae. 832 pp.

Fabricius, J. C., 1787. Mantissa Insectorvm sistens eorvm species nvper detectas adjectis characteribvs genericis, differentiis specificis, emendationibvs, observationibvs. Tome 1. Chr. G. Proft. Hafniae. 519 pp.

Ferris, G. F., 1940. The morphology of Plega signata (Hagen) (Neuroptera: Mantispidae). Microentomology, 5: 33-56.

Fink, L. S., 1986. Costs and benefits of maternal behaviour in the green lynx spider (Oxyopidae, Peucetia viridans). Animal Behaviour, 34: 1051-1060.

Fink, L. S., 1987. Green lynx spider egg sacs: sources of mortality and the function of female guarding (Araneae, Oxyopidae). Journal of Arachnology, 15: 231-239.

Fraser, F. C., 1952. New species of Neuroptera in the Museum National d'Histoire Naturelle, Paris. Revue Française d'Entomologie, 19: 55-64.

Fraser, F. C., 1953. Contribution à l'étude de la zone d'inondation du Niger (mission G. Remaudière 1950). I. - Odonata, Neuroptera and Mecoptera. Bulletin de l'Institut Française d'Afrique Noire, 15: 1523-1528.

George, L. D. \& George, N. L., 1975. A new record of mantispid reared from spider. Pan-Pacific Entomologist, 51: 90.

Gepp, J., 1981. Rote Liste der gefährdeten Netzflüglerarten der Steiermark (Megaloptera, Raphidioptera und Planipennia). Steirischer Naturschutzbrief, Sonderheft 3: 91-96.

Gepp, J., 1983. Rote Liste der gefährdeten Netzflügler Österreichs (Megaloptera, Raphidioptera und Planipennia). In: Rote Listen gefährdeter Tiere Österreichs. Bundesministeriums für Gesundheit und Umweltschutz. Wein: 145-147.

Gepp, J., 1984. Erforschungsstand der Neuropteren-Larven der Erde (mit einem Schlüssel zur larvaldiagnose der Familien, einer Übersicht von 340 beschreibenen Larven und 600 Literaturzitaten). In: J. Gepp, H. Aspöck \& H. Hölzel (eds.). Progress in World's Neuropterology (Proceedings of the 1st International Symposium on Neuropterology, 22-26 September 1980, Graz). Graz: 183-239.

Gepp, J., 1986. Biology and larval diagnosis of central European Neuroptera (a review of present knowledge). In: J. Gepp, H. Aspöck \& H. Hölzel (eds.). Recent Research in Neuropterology (Proceedings of the 2nd International Symposium on Neuropterology, 21-23 August 1984, Hamburg). Graz: 137-144.

Gepp, J., 1990. An illustrated review of egg morphology in the families of Neuroptera (Insecta: Neuropteroidea). In: M. W. Mansell \& H. Aspöck (eds.). Advances in Neuropterology (Proceedings of the Third International Symposium on Neuropterology, 3-4 February 1988, Berg en Dal, Kruger National Park). South African Department of Agricultural Development. Pretoria: 131-149. 
Gerstaecker, [C. E.] A., 1884. Vier Decaden von Neuropteren aus der Familie Megaloptera Burm. Mitt[h]eilungen aus dem Naturwissenschaftlichen Verein für Neu-Vorpommern und Rugen, 16: 1-49.

Gerstaecker, C. E. A., 1885. Zwei fernere Decaden Australischer Neuroptera Megaloptera. Mitt[h]eilungen aus dem Naturwissenschaftlichen Verein für Neu-Vorpommern und Rugen, 16:84-116.

Gertsch, W. J., 1979. American spiders. Van Nostrand Reinhold. New York. 274 pp.

Ghilarov, M. S., 1962. The larva of Dilar turcicus Hag. and the position of the family Dilaridae in the order Planipennia. Entomologicheskoe Obozrenie, 41: 402-416.

Ghosh, S. K. \& Sen, S., 1977. Check-list of Indian Planipennia (Order Neuroptera). Records of the Zoological Survey of India, 73: 277-326.

Gilbert, C. \& Rayor, L. S., 1983. First record of mantisfly (Neuroptera: Mantispidae) parasitizing a spitting spider (Scytodidae). Journal of the Kansas Entomological Society, 56: 578-580.

Grimaldi, D. A., 2000. A diverse fauna of Neuropterodea in amber from the Cretaceous of New Jersey. In: D. Grimaldi (ed.). Studies on fossils in amber, with particular reference to the Cretaceous of New Jersey. Backhuys. Leiden: 259-303.

Grimaldi, D. A. \& Engel, M. S., 2005. Evolution of the Insects. Cambridge University Press. New York. $\mathrm{xv}+$ $755 \mathrm{pp}$.

Grimaldi, D. A., Engel, M. S. \& Nascimbene, P. C., 2002. Fossiliferous Cretaceous amber from Myanmar (Burma): its rediscovery, biotic diversity, and peleontological significance. American Museum Novitates, 3361: 1-72. http://dx.doi.org/10.1206/0003-0082(2002)361\%3C0001:FCAFMB\%3E2.0.CO;2

Guérin-Méneville, F. É., 1838. Mantispe. Mantispa. Illiger. Magasin de Zoologie, (1), 8: 1-2.

Guérin-Méneville, F. É., 1844. Iconographie du règne animal de G. Cuvier, ou représentation d'après nature de l'une des espèces les plus remarquables, et souvent non encore figurées, de chaque genre d'animaux. Insectes. Paris, $576 \mathrm{pp}$.

Güsten, R., 1996. A review of epidermal glands in the order Neuroptera (Insecta). In: M. Canard, H. Aspöck \& M. W. Mansell (eds.). Pure and Applied Research in Neuropterology (Proceedings of the Fifth International Symposium on Neuropterology, 2-6 May 1994, Cairo). Toulouse: 129-146.

Hagen, H. A., 1858. Russlands Neuropteren. Stettiner Entomologische Zeitung, 19(1-3): 110-134.

Hagen, H. A., 1866a. Die Neuropteren Spaniens nach Ed. Pictet's Synopsis des Neuroptères d'Espagne. Genève 1865. 8. tab. 14 col. und Dr. Staudingers Mittheilungen. Stettiner Entomologische Zeitung, 27: 281-302.

Hagen, H. A., 1866b. Hemerobidarum Synopsis Synonymica. Stettiner Entomologische Zeitung, 27: 369-462.

Hagen, H. A., 1877. Symphrasis, eine neue MantispidenGattung. Stettiner Entomologische Zeitung, 38: 208-211.

Handlirsch, A., 1906-1908. Die fossilen Insekten und die Phylogenie der rezenten Formen. W. Engelmann. Leipzig.
1430 pp. (Para años de publicación de sus apartados puede consultarse Oswald, 2013a, 2013b).

Handschin, E., 1935. Indo-australische Neuropteren und Mecopteren. Revue Suisse de Zoologie, 42: 683-714.

Handschin, E., 1959a. Mantispa styriaca (Poda 1761). Vierteljahrsschrift der Naturforschenden Gesellschaft in Zürich, 104:105-114.

Handschin, E., 1959b. Zur systematischen Stellung von Entanoneura und Climaciella. Verhandlungen der Schweizerischen Naturforschenden Gesellschaft, 139: 172-173.

Handschin, E., 1959c. Beiträge zu einer Revision der Mantispiden (Neuroptera). I Teil. Mantispiden des Musee Royal du Congo Belge, Tervuren. Revue de Zoologie et de Botanique Africaines, 59: 185-227.

Handschin, E., 1960a. Beiträge zu einer Revision der Mantispiden (Neuroptera). II Teil. Mantispiden des "Musée Royal du Congo Belge", Tervuren. Revue de Zoologie et de Botanique Africaines, 62: 181-245.

Handschin, E., 1960b. Zur Revision süd-amerikanischer Mantispiden. Revue Suisse de Zoologie, 67: 523-560.

Handschin, E., 1960c. Nampista auriventris (Guérin) 1838 (Neuropt. Planip.). Mitteilungen der Schweizerischen Entomologischen Gesellschaft, 33: 155-160.

Handschin, E., 1961. Beiträge zur Kenntnis der Gattungen Euclimacia, Climaciella und Entanoneura Enderlein 1910 im indo-australischen Faunengebiet. Nova Guinea, Zoology, 15: 253-301.

Handschin, E., 1963. Beitrag zur Kenntnis der Neuropterenfauna von Madagascar. Mitteilungen der Schweizerischen Entomologischen Gesellschaft, 35: 211-226.

Haring, E. \& Aspöck, U., 2004. Phylogeny of the Neuropterida: a first molecular approach. Systematic Entomology, 29: 415-430. http://dx.doi.org/10.1111/j. 0307-6970.2004.00263.x.

Heiber, C. S., 1984. Egg predators of the cocoons of the spider Mecynogea lemniscata (Araneae: Araneidae): rearing and population data. Florida Entomologist, 67: 176-178.

Hirata, S.-I., 1999. [Biology of mantispid larvae.] Insectarium, 36: 4-10 (en japonés).

Hirata, S.-I. \& Ishii, M., 2001. Factors affecting fecundity of the mantispid, Eumantispa harmandi (Navas) (Neuroptera: Mantispidae). Scientific Report of the Graduate School of Agriculture and Biological Sciences Osaka Prefecture University, 53: 31-36.

Hirata, S.-I., Ishii, M. \& Nishikawa, Y., 1995. First instar larvae of mantispids, Mantispa japonica McLachlan and Eumantispa harmandi (Navás) (Neuroptera: Mantispidae), associating with spiders (Araneae). Japanese Journal of Entomology, 63: 673-680.

Hoffman, C. H., 1936. Notes on Climaciella brunnea var. occidentalis Banks (Mantispidae - Neuroptera). Bulletin of the Brooklyn Entomological Society, 31: 202-203.

Hoffman, K. M., 1989. Taxonomic status of Mantispa sayi, Mantispa fuscicornis, and Mantispa uhleri (Neuroptera: Mantispidae). Proceedings of the Entomological Society of Washington, 91: 637-639.

Hoffman, K. M., 1992. Systematics of the Mantispinae (Neuroptera: Mantispidae) of North, Central and 
South America. Ph.D. dissertation. Clemson University. Clemson. xiii +501 pp.

Hoffman, K. M., 2002. Family Mantispidae. In: N. D. Penny (ed.). A Guide to the Lacewings (Neuroptera) of Costa Rica. Proceedings of the California Academy of Sciences, 53(12): 251-275 (texto), 419-432 (figuras).

Hoffman, K. M. \& Brushwein, J. R., 1989. Species of spiders (Araneae) associated with the immature stages of Mantispa pulchella (Neuroptera: Mantispidae). Journal of Arachnology, 17: 7-14.

Hoffman, K. M. \& Brushwein, J. R., 1990. Spider (Araneae) taxa associated with the immature stages of Mantispa interrupta (Neuroptera: Mantispidae). Entomological News, 101: 23-28.

Hoffman, K. M. \& Brushwein, J. R., 1992. Descriptions of the larvae and pupae of some North American Mantispinae (Neuroptera: Mantispidae) and development of a system of larval chaetotaxy for Neuroptera. Transactions of the American Entomological Society, 118: 159-196.

Hoffman, K. M. \& Hamilton, S. W., 1988. First record of a mantispine larva (Neuroptera: Mantispidae) associated with an adult caddisfly (Trichoptera: Leptoceridae). Entomological News, 99: 161-163.

Hollier, J. \& Hollier, A. 2014. François-Jules Pictet and the Neuroptera. Antenna, 38(2): 95-102.

Hollier, J. A., 2007. Continuitè entre le Musée Acadèmique et le Muséum actuel - 1'exemple des "Névroptères du musée" de F.-J. Pictet. Bulletin Romand d'Entomologie, 24: 51-54.

Hölzel, H., 1999. Verzeichnis der Netzfluegler Kaerntens (Neuropterida). In: T. Rottenburg, C. Wieser, P. Mildner \& W. E. Holzinger (eds.). Rote Listen gefaehrdeter Tiere Kaerntens. Band 15. Naturschutz. Klagenfurt: 413-416.

Hungerford, H. B., 1936. The Mantispidae of the Douglas Lake, Michigan Region, with some biological observations (Neurop.). Entomological News, 47: 69-72, 85-88.

Hungerford, H. B., 1939. A note on Mantispidae. Bulletin of the Brooklyn Entomological Society, 34: 265.

Illiger, J. K. W., 1798. Genus Mantispa. In: Verzeichnis der käfer Preussens, entworfen von Johann Gottlieb Kugelann a ausgearbeitet von Johann Karl Wilhelm Illiger. Mit einer vorrede des professors und pagenhofmeisters Helwig in Braunschweig, und dem angehängten versuche einer natürlichen ordnungs- und gattungs-folge der insekten. Halle: 499.

Jarzembowski, E. A., 1980. Fossil insects from the Bembridge Marls, Palaeogene of the Isle of Wight, southern England. Bulletin of the British Museum of Natural History, Geology, 33: 237-293.

Jedlička, L., 2001. Red (Ecosozological) List of Neuroptera of Slovakia. In: D. Baláž, K. Marhold \& P. Urban (eds.). Red List of Plants and Animals of Slovakia. Ochrana Prírody. Banská Bystrica, Suppl. 20: 108-109.

Jepson, J. S., Heads, S. W., Makarkin, V. N. \& Ren, D., 2013. New Fossil Mantidflies (Insecta: Neuroptera: Mantispidae) from the Mesozoic of North-Eastern
China. Palaeontology, 56(3): 603-613. http://dx.doi. org/10.1111/pala.12005.

Johnson, J. B. \& Hagen, K. S., 1981. A neuropterous larva uses an allomone to attack termites. Nature (London), 289: 506-507. http://dx.doi.org/10.1038/289506a0.

Kaston, B. J., 1938. Mantispidae parasitic on spider egg sacs. Journal of the New York Entomological Society, 46: 147-153.

Kaston, B. J., 1940. Another Mantispa reared. Bulletin of the Brooklyn Entomological Society, 35:21.

Keeler, K. H., 1978. Insects feeding at extrafloral nectarines of Ipomoea carnea (Convolvulaceae). Entomological News, 89(7-8): 163-168.

Khramov, A. V., 2013. New mantidflies (Neuroptera: Mantispidae) from the Upper Jurassic of Kazakhstan. Insect Systematics \& Evolution, 44: 221-230. http://dx.doi. org/10.1163/1876312X-44032094.

Killebrew, D. W., 1981. Mantispa in a Peucetia egg case. Journal of Arachnology, 10: 281-282.

Kis, B., Nagler, C. \& Mândru, C., 1970. Insecta: Neuroptera (Planipennia). Fauna Republicii Socialiste România, 8(6): 1-343.

Kishida, K., 1929. [On the oviposition of a clubionid spider, Chiracanthium rubicundulum.] Lansania, 1: 73-74 (en japonés).

Klimaszewski, J. \& Kevan, D. K. McE., 1986. A new lacewing-fly (Neuroptera: Planipennia) from Canadian Cretaceous Amber, with an analysis of its fore wing characters. Entomological News, 97: 124-132.

Kozhanchikov, I. V., 1949. [New Mantispidae (Neuroptera) from Tadshikistan.] Entomologicheskoe Obozrenie, 30: 353-358 (en ruso).

Kral, K., 1989. Fine structure of the larval eyes of Mantispa sp. (Neuroptera: Planipennia, Mantispidae). International Journal of Insect Morphology and Embryology, 18: 135-143.

Kral, K., 1990. The Planipennia eye using Mantispa styriaca (Poda, 1761) (Mantispidae) as an example. Neuroptera International, 6(1): 51-56.

Kral, K., 2013. Vision in the mantispid: a sit-and-wait and stalking predatory insect. Physiological Entomology, 38: 1-12. http://dx.doi.org/10.1111/phen.12004.

Kral, K., Herbst, K. \& Pabst, M. A. 1990. The compound eye of Mantispa styriaca (Neuroptera: Planipennia). Zoologische Jahrbücher, Abteilung für Allgemeine Zoologie und Physiologie der Tiere, 94: 333-343.

Kral, K., Vernik, M. \& Devetak, D., 2000. The visually controlled prey-capture behaviour of the European mantispid Mantispa styriaca. Journal of Experimental Biology, 203: 2117-2123.

Krivokhatsky, V. A., 1995. Katalog tipovykh ekzemplyarov kollektsii zoologicheskogo instituta RAN. Nasekomye setchatokrylye (Neuroptera). Zoologicheskii Institut RAN. Sankt-Peterburg. 18 pp.

Kuroko, H., 1961. On the eggs and first-instar larvae of two species of Mantispidae. Esakia, Occasional Papers of the Hikosan Biological Laboratory, 3:25-32.

Kuwayama, S., 1924. Notes on the Japanese Mantispidae, with Special Reference to the Morphological Characters. 
Journal of the College of Agriculture, Hokkaido Imperial University, 15: 237-267.

Kuwayama, S., 1962. A revisional synopsis of the Neuroptera in Japan, Pacific Insects, 4(2): 325-412.

Lambkin, K. J., 1986a. A revision of the Australian Mantispidae (Insecta: Neuroptera) with a contribution to the classification of the family. I. General and Drepanicinae. Australian Journal of Zoology, Supplementary Series, 116: 1-142. http://dx.doi.org/10.1071/ AJZS116.

Lambkin, K. J., 1986b. A revision of the Australian Mantispidae (Insecta: Neuroptera) with a contribution to the classification of the family. II. Calomantispinae and Mantispinae. Australian Journal of Zoology, Supplementary Series, 117: 1-113. http://dx.doi.org/10.1071/ AJZS117.

Lambkin, K. J., 1987. The Australian Mantispidae (Neuroptera): supplementary notes. General and Applied Entomology, 19: 11-14.

Lambkin, K. J. \& New, T. R., 1994. Australian Mantispidae (Neuroptera): supplementary notes 2. Journal of the Australian Entomological Society, 33: 117-121.

Larsson, S. G., 1978. Baltic Amber -a palaeobiological Study. Entomonograph, 1: 1-192.

Leach, W. E., 1815. Entomology. In: D. Brewster (ed.). Edinburgh Encyclopaedia, 9(1): 57-172.

Lewis, R. T., 1911. Note on the larva of Mantispa. Journal of the Quekett Microscopical Club, 11: 213-216.

Linnaeus, C., 1767. Systema natura per regna tria naturae secundum classes, ordines, genera, species, cum characteribus, differentiis, synonymis, locis. Editio duodecima reformata. Tom. I. Pars II. Laurentii Salvii. Holmiae. pp. 533-1327.

Linsley, E. G. \& MacSwain, J. W., 1955. Two new species of Plega from Mexico (Neuroptera, Mantispidae). Pan-Pacific Entomologist, 31: 15-19.

Lucchese, E., 1955. Ricerche sulla Mantispa perla Pallas (Neuroptera Planipennia - Fam. Mantispidae). [I.] Nota preventiva su nuovi reperti concernenti l'etologia della larva della 1a età. Annali della Facoltà di Agraria della [R.] Università degli Studi di Perugia, 11: 242-262.

Lucchese, E., 1956. Ricerche sulla Mantispa perla Pallas (Neuroptera Planipennia - Fam. Mantispidae). II. Contributo su nuovi reporti biologici e morfologici concernenti l'adulto, la larva della I. et ... e la completa evoluzione di questa nella sua sede definitiva. Annali della Facoltà di Agraria della [R.] Università degli Studi di Perugia, 12: 83-213.

Machado, R. J. P. \& Rafael, J. A., 2010. Taxonomy of the Brazilian species previously placed in Mantispa Illiger, 1798 (Neuroptera: Mantispidae), with the description of three new species. Zootaxa, 2454: 1-61.

McKeown, K. C. \& Mincham, V. H., 1948. The biology of an Australian mantispid (Mantispa vittata Guérin). Australian Zoologist, 11: 207-224.

MacLeod, E. G., 1964. A comparative morphological study of the head capsule and cervix of larval Neuroptera (Insecta). Ph.D. dissertation. Harvard University. Cambridge. [iii] + 528 pp., 35 lám.
MacLeod, E. G. \& Adams, P. A., 1967. A review of the taxonomy and morphology of the Berothidae, with the description of a new subfamily from Chile (Neuroptera). Psyche, 74: 237-265.

MacLeod, E. G. \& Redborg, K. E., 1982. Larval Platymantispine mantispids (Neuroptera: Planipennia): possibly a subfamily of generalist predators. Neuroptera International, 2(1): 37-41.

Main, H., 1931. A preliminary note on Mantispa. Proceedings of the Royal Entomological Society of London, 6: 26.

Makarkin, V. N., 1990a. Novye setchatokrylye (Neuroptera) iz verkhnego mela Azii. In: I. A. Akimov (ed.). Novosti faunistiki $i$ sistematiki. Sbornik nauchnyhk trudov. Naukova Dumka Publ. Kiev: 63-68.

Makarkin, V. N., 1990b. A check-list of the NeuropteraPlanipennia of the USSR far east, with some taxonomic remarks. Acta Zoologica Hungarica, 36: 37-45.

Makarkin, V. N., 1996. Fossil Neuroptera of the Lower Cretaceous of Baisa, East Siberia. Part 5. Mantispidae. Russian Entomological Journal, 5(1-4): 91-93.

Makarkin, V. N., 1999. Fossil Neuroptera from the Lower Cretaceous of Baisa, East Siberia. Part 6. Mesithonidae (Insecta). Neues Jahrbuch für Geologie und Palaontologie, Monatshefte, 1999: 705-712.

Mansell, M. W., 1986. 19. Order Neuroptera. In: C. H. Scholtz \& E. Holm (eds.). Insects of Southern Africa. Butterworths. Durban: 181-187.

Mansell, M. W., 2010. Towards a catalogue of Afrotropical Lacewings and Alderflies (Neuroptera, Megaloptera). In: D. Devetak, S. Lipovšek \& A. E. Arnett (eds.). Proceedings of the 10th International Symposium on Neuropterology, 22-25 June 2008, Piran. University of Maribor. Maribor: 1-10.

Marín, F., 1994. Las comunidades de neurópteros de la provincia de Albacete (Insecta: Neuropteroidea). Al-Basit, Estudios albacetenses, 34: 247-304.

Marín, F. \& Monserrat, V. J., 1990. Contribución al conocimiento de los Neurópteros de Soria (Insecta, Neuropteroidea). Boletín de la Asociación española de Entomología, 14: 219-230.

Marín, F. \& Monserrat, V. J., 1991. Contribución al conocimiento de los neurópteros de Albacete (Insecta, Planipennia). Jornadas sobre el Medio Natural Albacetense. Albacete, 1990: 179-184.

Marín, F. \& Monserrat, V. J., 1995a. Contribución al conocimiento de los Neurópteros de Valencia (Insecta, Neuroptera). Boletín de la Asociación española de Entomología, 19(3-4): 35-49.

Marín, F. \& Monserrat, V. J., 1995b. Contribución al conocimiento de los neurópteros de Zaragoza (Insecta, Neuropteroidea). Zapateri, Revista Aragonesa de Entomología, 5: 109-126.

Mayer, H. \& Kral, K., 1993. Electrophysiological and optical studies of the spectral sensitivity of Mantispa styriaca (Neuroptera: Planipennia). Mitteilungen der Deutschen Gesellschaft für Allgemeine und Angewandte Entomologie, 8: 709-713.

McEwen, P. K. \& Oswald, J. D., 1998. Neuroptera on the Internet. In: S. P. Panelius (ed.). Neuropterology 1997 
(Proceedings of the Sixth International Symposium on Neuropterology, 13-16 July 1997, Helsinki). Acta Zoologica Fennica, 209: 151-152.

McKeown, K. C. \& Mincham, V. H., 1948. The biology of an Australian mantispid (Mantispa vittata Guérin). Australian Zoologist, 11: 207-224.

McLachlan, R., 1867. New genera and species, \&c., of neuropterous insects; and a revision of Mr. F. Walker's British Museum Catalogue of Neuroptera, part ii. (1853), as far as the end of the genus Myrmeleon. Journal of the Linnean Society of London, Zoology, 9: 230-281.

McLachlan, R., 1875. Setchatokrylye (Neuroptera). In: A. P. Fedchenko (ed.). Puteshestvie v Turkestan. Vypusk 8. Tom II. Zoogeograficheskiia izsliedovania. Chast V. S.-Peterburg. Moskva: ii + 1-60.

McLachlan, R., 1902a. Trichoptera, Planipennia, and Odonata collected by Lord Walsingham in the vicinity of Granada (Spain) in 1901. Entomologist's Monthly Magazine, 38:33-34.

McLachlan, R., 1902b. An annotated list of NeuropteraPlanipennia collected in central Spain by Dr. T. A. Chapman and Mr. G. C. Champion in July and August 1901. Entomologist's Monthly Magazine, 13: 129-131.

Merti, C., 1940. Contribucion al estudio de Mantispa decorata Erd. (Hemip. Cor.) [sic]. Revista de la Sociedad Entomológica Argentina, 10: 304-307.

Milliron, H. E., 1940. The emergence of a Neotropical mantispid from a spider egg sac. Annals of the Entomological Society of America, 33: 357-360.

Minter, L. R., 1990. A comparison of the eggs and first-instar larvae of Mucroberotha vesicaria Tjeder with those of other species in the families Berothidae and Mantispidae (Insecta: Neuroptera). In: M. W. Mansell, \& H. Aspöck (eds.). Advances in Neuropterology (Proceedings of the Third International Symposium on Neuropterology, 3-4 February 1988, Berg en Dal, Kruger National Park). South African Department of Agricultural Development. Pretoria: 115-129.

Miyake, T., 1910. The Mantispidae of Japan. Journal of the College of Agriculture, Tohoku Imperial University, 2: 213-221.

Miyake, T., 1911. [Review and criticism on "The Mantispidae of Japan" by Mr. Okamoto.] Dobutsugakkai Zasshi, 23: 17-19 (en japonés).

Monserrat, V. J., 1977. Los Neurópteros del Guadarrama. Trabajos de la Cátedra de Entomología, Facultad de Biología, Universidad Complutense de Madrid, 17: 1-57.

Monserrat, V. J., 1978a. Primera contribución al conocimiento de los Neurópteros de Cádiz (Insecta, Neuroptera, Planipennia). Boletín de la Real Sociedad Española de Historia Natural, Sección Biológica, 76: 57-70.

Monserrat, V. J., 1978b. Contribución al conocimiento de los Neurópteros de Orense (Neu. Planipennia). Boletín de la Asociación Española de Entomologia, 2: 169-184.

Monserrat, V. J., 1979a. Sobre los Neurópteros Ibéricos (II); (Neuroptera, Planipennia). Boletín de la Asociacion Española de Entomologia, 3: 17-21.

Monserrat, V. J., 1979b. Segunda contribución al conocimiento de los neurópteros de Cádiz (Insecta, Planipennia).
Boletín de la Real Sociedad Española de Historia Natural, Sección Biológica, 77: 409-417.

Monserrat, V. J., 1980. Contribución al conocimiento de los Neurópteros de Toledo. Graellsia, [1978], 34: 177-193.

Monserrat, V. J., 1982. Contribución al conocimiento de los Neurópteros de Cáceres. Graellsia, 38: 67-84.

Monserrat, V. J., 1984a. Contribución al conocimiento de los neurópteros de Salamanca (Neur., Planipennia). Eos, [1983], 59: 165-177.

Monserrat, V. J., 1984b. Contribución al conocimiento de los neurópteros de Alicante (Neur., Planipennia). Mediterranea, Serie Biología, 7: 91-116.

Monserrat, V. J., 1984c. Contribución al conocimiento de los neurópteros de Zamora (Neur., Planipennia). Miscellània Zoològica, 8: 153-163.

Monserrat, V. J., 1984d. Contribución al conocimiento de los neurópteros de Huesca (Neur., Planipennia). Pirineos, 121: 29-50.

Monserrat, V. J., 1985a. Contribución al conocimiento de los neurópteros de Lugo (Neur., Planipennia). Trabajos Compostelanos de Biología, 12: 87-98.

Monserrat, V. J., 1985b. Contribución al conocimiento de los Neurópteros (Neuroptera: Planipennia) de Murcia. Anales de Biología (Biología Animal), 1: 81-94.

Monserrat, V. J., 1985c. Lista de los tipos de Mecoptera y Neuroptera (Insecta) de la colección L. Navás, depositados en el Museo de Zoología de Barcelona. Miscellània Zoològica, 9: 233-243.

Monserrat, V. J., 1986a. Longinos Navás, his neuropterological work and collection. In: J. Gepp, H. Aspöck \& H. Hölzel (eds.). Recent Research in Neuropterology (Proceedings of the 2nd International Symposium on Neuropterology, 21-23 August 1984, Hamburg). Graz: 173-176.

Monserrat, V. J., 1986b. Sobre los Neurópteros ibéricos (IV) (Neur.). Boletín de la Asociación española de Entomología, 10: 95-105.

Monserrat, V. J., 1987a. Contribución al conocimiento de los Neurópteros de Almería (Neur., Planipennia). Graellsia, [1986], 42: 131-147.

Monserrat, V. J., 1987b. Els megalòpters, Els Rafidiòpters, Els Planipennis: crisopes, reis de formigues i afins. Història Natural dels Països Catalans, t. 10, 2. Fundació Enciclopèdia Catalana. Barcelona: 251-265.

Monserrat, V. J., 1988. Revisión de los diláridos ibéricos (Neuropteroidea, Planipennia: Dilaridae). Eos, 64: 175-205.

Monserrat, V. J., 1996a. Larval Stages of European Nemopteridae, with Systematic Considerations on the Family Nemopteridae (Insecta, Neuroptera). Deutsche Entomologische Zeitschrift, 43(1): 99-121.

Monserrat, V. J., 1996b. On the larval stages of European Nemopterinae (Insecta: Neuroptera: Nemopteridae). In: M. Canard, H. Aspöck \& M. W. Mansell (eds.). Pure and Applied Research in Neuropterology (Proceedings of the Fifth International Symposium on Neuropterology, 2-6 May 1994, Cairo). Toulouse: 193.

Monserrat, V. J., 1996c. Lista de los neurópteros de Aragón (Megaloptera, Raphidioptera, Planipennia). Catalogus entomofauna Aragonesa, 11: 11-17. 
Monserrat, V. J., 2005. Catálogo de los Neurópteros de Baleares con nuevos datos sobre su fauna (Insecta: Neuroptera). Bolletí de la Societat d'Hisòria Natural de les Balears, 48: 71-85.

Monserrat, V. J., 2006. Nuevos datos sobre algunas especies de la familia Berothidae (Insecta: Neuroptera). Heteropterus Revista de Entomología, 6: 173-207.

Monserrat, V. J., 2008. Nuevos datos sobre algunas especies de Nemopteridae y Crocidae (Insecta: Neuroptera). Heteropterus Revista de Entomología, 8(1): 1-33.

Monserrat, V. J., 2011. Sobre algunas especies de neurópteros de la península Ibérica y de las Islas Canarias de posición taxonómica problemática o con citas dudosas o cuestionables (Insecta, Neuroptera: Megaloptera, Planipennia). Boletín de la Sociedad Entomológica Aragonesa, 49:153-178.

Monserrat, V. J., 2013. Los Neurópteros (Neuroptera). In: F. Ruano, M. Tierno de Figueroa y A. Tinaut (eds). Los Insectos de Sierra Nevada. 200 años de historia, Vol. 1. Asociación Española de Entomología. Granada: 281-309.

Monserrat, V. J., 2014. Los berótidos de la Península Ibérica (Insecta, Neuropterida, Neuroptera: Berothidae). Heteropterus Revista de Entomología, 14(1): 31-54.

Monserrat, V. J. \& Díaz-Aranda, L. M., 1987. Contribución al conocimiento de los neurópteros (Neur.: Raphidioptera, Planipennia) de Cuenca. Boletín de la Asociación Española de Entomología, 11: 171-189.

Monserrat, V. J. \& Díaz-Aranda, L. M., 1989. Estadios larvarios de los Neurópteros Ibéricos. V: Mantispa styriaca (Poda, 1761) (Planipennia: Mantispidae). Neuroptera International, 5(4): 189-204.

Monserrat, V. J., Marín, F. \& Díaz-Aranda, L. M., 1994. Contribución al conocimiento de los neurópteros de Lérida (Insecta, Neuroptera). Zoologia Baetica, 5: 41-64.

Monserrat, V. J. \& Martínez, M. D., 1995. On the Possible Myrmecophily of Nemopterinae Larvae (Neuroptera: Nemopteridae). Sociobiology, 26(1): 55-68.

Monserrat, V. J. \& Triviño, V., 2013. Atlas de los neurópteros de la Península Ibérica e Islas Baleares (Insecta, Neuroptera: Megaloptera, Raphidioptera, Planipennia) I Atlas of the Iberian and Balearic lacewings (Insecta, Neuroptera: Megaloptera, Raphidioptera, Planipennia). Monografías de la Sociedad Entomológica Aragonesa, vol. 13. Zaragoza. 154 pp., 136 mapas.

Nakahara, W., 1912a. [Studies on the Mantispidae of Japan.] Dobutsugakkai Zasshi, 24: 558-566 (en japonés).

Nakahara, W., 1912b. [On the Japanese Mantispidae.] Konchu Sekai, 16: 12-15, 51 (en japonés).

Nakahara, W., 1912c. [On the scientific name of Eumantispa sasakii and its synonymy.] Dobutsugakkai Zasshi, 24: 332-336 (en japonés).

Navás, L., 1900. Notas entomológicas. III. Neurópteros del Montseny (Barcelona). Actas de la Sociedad Española de Historia Natural, 29: 92-96.

Navás, L., 1905a. Neurópters de Montserrat. Butlletí de la Institució Catalana d'Història Natural, (1), 5: 72.

Navás, L., 1905b. Notas zoológicas. VIII. Mis excursiones durante el verano de 1904. Boletín de la Sociedad Aragonesa de Ciencias Naturales, 4: 107-131.
Navás, L., 1905c. Catálogo descriptivo de los insectos Neurópteros de los alrededores de Madrid. Revista de la Real Academia de Ciencias Exactas Fisicas y Naturales de Madrid, 2: 521-574.

Navás, L., 1908. Neurópteros de España y Portugal [part 3]. Brotéria (Zoológica), 7: 5-131.

Navás, L., 1909. Mantíspidos nuevos [I]. Memorias de la Real Academia de Ciencias y Artes de Barcelona, (3)7: 473-485.

Navás, L., 1910. Neurópteros chilenos (1a serie). Revista Chilena de Historia Natural, 14: 235-241.

Navás, L., 1912. Quelques Mantispides (Insectes Névroptères) du Musée Zoologique de l'Academie Impériale des Sciences de St. Pétersbourg. Akademiia nauk SSSR, Zoologicheskii Muzei, Ezhegodnik, 16: 535-538.

Navás, L., 1913. Notas entomológicas, 2.a serie. 5. Cuatro pequeñas colecciones de Neurópteros de la península Ibérica. Boletín de la Sociedad Aragonesa de Ciencias Naturales, 12: 77-89.

Navás, L., 1914a. Mantíspidos nuevos (Segunda [II] serie). Memorias de la Real Academia de Ciencias y Artes de Barcelona, (3), 11: 83-103.

Navás, L., 1914b. Neurópteros de Oceanía. Primera [I] serie. Revista de la Real Academia de Ciencias Exactas Físicas y Naturales de Madrid, 12: 464-483.

Navás, L., 1914c. Neurópteros de Oceanía. Segunda [II] serie. Revista de la Real Academia de Ciencias Exactas Físicas y Naturales de Madrid, 12: 645-653.

Navás, L., 1914d. Algunos Neurópteros del Museo de Oxford. I serie. Boletín de la Sociedad Aragonesa de Ciencias Naturales, 13: 61-68.

Navás, L., 1914e. Notas entomológicas [2.a serie]. 10. Neurópteros de Mallorca. Boletín de la Sociedad Aragonesa de Ciencias Naturales, 13: 185-192.

Navás, L., 1916. Excursions entomològiques al nort de la provincia de Lleida. Butlletí de la Institució Catalana d'Història Natural, (1), 16: 150-158.

Navás, L., 1919a. Excursiones entomológicas por Cataluña durante el verano de 1918. Memorias de la Real Academia de Ciencias y Artes de Barcelona, (3), 15: 181-214.

Navás, L., 1919b. Notas entomológicas. 2.a serie. 16. Excursión anual de la Sociedad Aragonesa de Ciencias Naturales al valle de Ordesa (Huesca) (22-29 de Julio de 1918). Boletín de la Sociedad Ibérica de Ciencias Naturales, 19: 37-44.

Navás, L., 1921a. Mis excursiones científicas del verano de 1919. Memorias de la Real Academia de Ciencias y Artes de Barcelona, (3), 17: 143-169.

Navás, L., 1921b. Excursiones cientificas realizadas durante el verano de 1920. Asociación Española para el Progreso de las Ciencias. Congreso de Oporto, 4: 59-74.

Navás, L., 1922. Excursions entomològiques de l'istiu de 1922 (26 de juny - 26 de juliol). Arxius de l'Institut de Ciències, Institut d'Estudis Catalans, Secció de Ciències, 8: 1-34.

Navás, L., 1923. Excursiones por Aragón durante el verano de 1923. Boletín de la Sociedad Ibérica de Ciencias Naturales, 22: 161-176. 
Navás, L., 1924a. Entomologia de Catalunya. Neuròpters. Fasc. I. Neuròpters propis. Fauna de Catalunya, Institut d'Estudis Catalans, Secció de Ciències. Barcelona. 271 pp.

Navás, L., 1924b. Mis excursiones entomológicas del verano de 1924. Brotéria (Zoológica), 21: 115-150.

Navás, L., 1925. Sinopsis de los Neurópteros (Ins.) de la Península Ibérica. Memorias de la Sociedad Ibérica de Ciencias Naturales, 4: 1-150.

Navás, L., 1928. Insectos neotropicos. $3^{\mathrm{a}}$ serie. Revista Chilena de Historia Natural, 31: 316-328.

Navás, L., 1929a. Insectos exóticos Neurópteros y afines del Museo Civico de Génova. Annali del Museo Civico di Storia Naturale Giacomo Doria, 53: 354-389.

Navás, L., 1929b. Insectos Neurópteros del Museo de Hamburgo. Memorias de la Real Sociedad Española de Historia Natural, 15: 315-322.

Navás, L., 1930a. Insecta nova. Series XV. Memorie dell'Accademia Pontifica dei Nuovi Lincei, (2), 14: 409-418.

Navás, L., 1930b. Spedizione di S. A. R. Il Duca degli Abruzzi alle sorgenti dell'Uebi Scebeli - Risultati Zoologici. Descrizione di una nuova Mantispilla. Annali del Museo Civico di Storia Naturale Giacomo Doria, 55: 27-28.

Navás, L., 1931. Mantispidae. In: V. van Straelen (ed.). Résultats scientifiques du voyage aux Indes Orientales Néerlandaises de LL. AA. RR. le Prince et la Princesse Léopold de Belgique. Mémoires du Musée Royal d'Histoire Naturelle de Belgique, Hors Série, 4(2): 7-10.

Navás, L., 1933. Insecta orientalia. XII series. Memorie dell'Accademia Pontifica dei Nuovi Lincei, (2), 17: 75-108.

Nel, A. D., 1989. Deux nouveaux Mantispidae (Planipennia) fossiles de l'Oligocene du sud-est de la France. Neuroptera International, 5(2): 103-109.

New, T. R., 1986. A review of the Biology of Neuroptera Planipennia. Neuroptera International, Supplemental Series, 1: 1-58.

New, T. R., 1989. Planipennia, Lacewings. In: Handbuch der Zoologie, IV, 30. Walter de Gruyter. Berlin. 132 pp.

New, T. R., 1998. Preliminary survey of the Mantispidae of south east Asia. In: S. P. Panelius (ed.). Neuropterology 1997 (Proceedings of the Sixth International Symposium on Neuropterology, 13-16 July 1997, Helsinki). Acta Zoologica Fennica, 209: 175-181.

New, T. R., 2003. The Neuroptera of Malesia. Fauna Malesiana, 4: viii +204 pp.

New, T. R. \& Haddow, A. J., 1973. Nocturnal flight activity of some African Mantispidae (Neuroptera). Journal of Entomology Series A, General Entomology, 47: 161-168. http://dx.doi.org/10.1111/j.1365-3032.1973.tb00021.x.

Nicoli Aldini, R., 1983. Note sulla geonemia di alcuni Neurotteri Planipenni italiani. Giornale Italiano de Entomologia, 3(1): 123-127.

Nicoli Aldini, R., Letardi, A. \& Pantaleoni, R. A., 2012. State of the art on Neuropterida of Sicily and Malta. Biodiversity Journal, 3(4): 445-458.

O’Brien, L. C. \& Redborg, K. E., 1997. Copulation duration in the Spider Philodromus vulgaris (Hentz) (Araneae:
Philodromidae) and its influence on the evolution of host transfer behavior during cannibalism by Mantispa uhleri Banks (Neuroptera: Mantispidae). Journal of Insect Behavior, 10: 469-477. http://dx.doi.org/10.1007/ BF02765371.

Ocharan, R., Ocharan, F. J. \& Anadón, A., 2012. Neurópteros de la Reserva de la Biosfera de Muniellos (Asturias, Norte de España) (Neuroptera s. s., Megaloptera y Raphidioptera). Boletín de la Sociedad entomológica Aragonesa, 50: 421-429.

Ohl, M., 2004a. Annotated catalog of the Mantispidae of the World (Neuroptera). Contributions on Entomology International, 5: [ii] + 131-262.

Ohl, M., 2004b. A new wasp-mimicking species of the genus Euclimacia from Thailand (Neuroptera, Mantispidae). Denisia, 13: 193-196.

Ohl, M., 2005. Toward a global inventory of Mantispidae the state-of-the-art in mantispid taxonomy. In: R. A. Pantaleoni, A. Letardi \& C. Corazza (eds.). Proceedings of the Ninth International Symposium on Neuropterology, Ferrara. Annali del Museo Civico di Storia Naturale di Ferrara, 8:79-86.

Ohl, M., 2007a. Toward a global inventory of Mantispidae - the state-of-the-art in mantispid taxonomy. In: R. A. Pantaleoni, A. Letardi \& C. Corazza (eds.). Proceedings of the Ninth International Symposium on Neuropterology, 20-23 June 2005, Ferrara). Annali del Museo Civico di Storia Naturale di Ferrara, 8: 79-86.

Ohl, M., 2007b. Die Mantispiden der Arabischen Halbinsel - ein Zwischenbericht. DGaaE Nachrichten, 21(3): 146.

Ohl, M., 2009. A revision of the mantispid genus Nampista (Neuropterida, Mantispidae). Zoosystematics and Evolution, 85(2): 189-198. http://dx.doi.org/10.1002/ zoos.200900003.

Ohl, M., 2011. Aboard a spider - A complex developmental strategy fossilized in amber. Naturwissenschaften, 98: 453-456. http://dx.doi.org/10.1007/s00114-011-0783-2.

Ohl, M., 2012. The primary types of Mantispidae (Neuropterida) in the Museum für Naturkunde, Berlin - An annotated catalogue. Zoosystematics and Evolution, 88(1): 97-124. http://dx.doi.org/10.1002/zoos.201200010.

Olivier, G. A., 1792. Encyclopedie méthodique. Histoire naturelle. Vol. 7 (Insectes). Paris. 827 pp.

Opler, P. A. 1981. Polymorphic mimicry of polistine wasps by a neotropical Neuropteran. Biotropica, 13:165-176.

Oswald, J. D., 2013a. Neuropterida species of the world. A catalogue of the Species-Group names of the Extant and Fossil Neuroptera, Megaloptera, Raphidioptera and Glosselytrodea (Insecta: Neuropterida) of the World. Version 3.0. Disponible en. http://lacewing.tamu.edu/SpeciesCatalogue/index.html (última consulta julio 2014).

Oswald, J. D., 2013b. Bibliography of the Neuropterida. An Annotated Bibliography and Digital Library of the Literature of the Extant and Fossil Neuroptera, Megaloptera, Raphidioptera and Glosselytrodea (Insecta: Neuropterida) of the World, Version 10.0. Disponible en: http://lacewing.tamu.edu/Bibliography/index.html (última consulta julio 2014).

Oswald, J. D. \& Penny, N. D., 1991. Genus-group names of the Neuroptera, Megaloptera and Raphidioptera of the 
world. Occasional Papers of the California Academy of Sciences, 147: 1-94.

Pallas, P. S., 1772. Spicilegia zoologica, quibus novae imprimis et obscurae animalium species iconibus, descriptionibus atque commentariis illustrantur, cura P. S. Pallas. Vol. 1, Fasc. 9. Neuropterida. G. A. Lange. Berolini.

Panfilov, D. V., 1980. Novye predstaviteli setcharokrylykh (Neuroptera) iz yury Karatau. In: V. G. Dolin, D. V. Panfilov \& A. G. Ponomarenko. Pritykina, L. N. Iskopaemye nasekomye mezozoya. Akademiya Nauk Ukrainskoi SSR, Institut Zoologii, Naukova Dumka. Kiev: 82-111.

Parfin, S. I., 1958. Notes on the bionomics of the Mantispidae (Neuroptera: Planipennia). Entomological News, 69: 203-207.

Parker, F. D. \& Stange, L. A., 1965. Systematic and biological notes on the tribe Platymantispini (Neuroptera: Mantispidae) and the description of a new species of Plega from Mexico. Canadian Entomologist, 97: 604-612.

Paulian, R., 1957. Les Mantispidae Malgaches (Neuroptera). Naturaliste Malgache, 9: 75-81.

Penny, N. D., 1982a. Neuroptera of the Amazon Basin. Part 6. Mantispidae. Acta Amazonica, 12: 415-463.

Penny, N. D., 1982b. Review of the generic level classification of the New World Mantispidae (Neuroptera). Acta Amazonica, 12: 209-223.

Penny, N. D. \& Da Costa, C. A., 1983. Mantispídeos do Brasil (Neuroptera: Mantispidae). Acta Amazonica, 13: 601-687.

Peterson, A., 1960. Larvae of Insects. An introduction to Nearctic species. Part II. Coleoptera, Diptera, Neuroptera, Siphonaptera, Mecoptera, Trichoptera. 4th ed. Edwards Brothers. Ann Arbor. 416 pp.

Peterson, A., 1967. Larvae of Insects. An introduction to Nearctic species. Part II. Coleoptera, Diptera, Neuroptera, Siphonaptera, Mecoptera, Trichoptera. Edwards Brothers. Ann Arbor: 352-361.

Pictet, F. J., 1836. Mémoire sur le genre Sialis de Latreille, et considérations sur la classification de l'ordre des Névroptères. Annales des Sciences Naturelles, Zoologie et Biologie Animale, (2), 5: 69-80.

Pictet, F. J., 1865. Synopsis des Névroptères d'Espagne. Section II Neuroptera. H. G. Baillière \& F. Savy. Genève. pp. 51-84, 108-114, 116-117, pl. 4-8.

Poda, N., 1761. Insecta musei Graecensis, quae in ordines, genera et species juxta systema naturae Caroli Linnaei digessit. Jaonnem Baptistam Dietrich. Graecii. $127+$ [index] pp. Notas: Edición Facsímil: 1915, W. Junk, Berlin. Neuropterida: "Neuroptera" (sensu lato), pp. 11-12, 95-101.

Poinar, G. O., 2006. Feroseta priscus (Neuroptera: Mantispidae), a new genus and species of mantidflies in Dominican amber. Proceedings of the Entomological Society of Washington, 108: 411-417.

Poinar, G. \& Buckley, R., 2011. Doratomantispa burmanica n. gen., n. sp. (Neuroptera: Mantispidae), a new genus of mantidflies in Burmese amber. Historical Biology, 23: 169-176.

Poivre, C., 1974. La patte prothoracique des Mantispidés et ses récepteurs sensoriels fémoraux. Bulletin du Muséum
National d'Histoire Naturelle, 3ème série Zoologie, 183: 1633-1648.

Poivre, C., 1976. Observations sur la biologie, le comportement et le phénomène de convergence chez les Mantispides (Planipennes). Entomologiste, 32(1): 2-19.

Poivre, C., 1978. Morphologie externe comparée de Gerstaeckerella gigantea Enderlein [Planipennia, Mantispidae]. Annales de la Société Entomologique de France (N.S.), 14: 191-206.

Poivre, C., 1980. Nouvelle description et morphologie externe comparée de Mantispa nana Erichson (Planipennia, Mantispidae). Neuroptera International, 1(1): 35-41.

Poivre, C., 1981a. Morphologie comparative et systématique de mantispides d'Afrique et d'Europe (Neuroptera, planipennia). Thèses Université de Nancy, Groupe Sciences. $256 \mathrm{pp}$.

Poivre, C., 1981b. Mantispides du Cameroun I (Neuroptera, Planipennia). Neuroptera International, 1(2): 77-89.

Poivre, C., 1981c. Mantispides du Cameroun II. Nouvelle description et morphologie externe comparée de Sagittalata lugubris et $S$. jucunda (Neuroptera, Planipennia). Neuroptera International, 1(3): 110-121.

Poivre, C., 1982a. Mantispides nouveaux d'Afrique et d'Europe (Neuroptera, Planipennia) (1ère partie). Neuroptera International, 1(4): 175-205.

Poivre, C., 1982b. Mantispides nouveaux d'Afrique et d'Europe (Neuroptera, Planipennia), (seconde partie). Neuroptera International, 2(1): 3-25.

Poivre, C., 1982c. Les Mantispidés du Muséum d'Histoire naturelle de Genève. I. (Insecta, Planipennia). Revue Suisse de Zoologie, 89: 375-378.

Poivre, C., 1982d. Les Mantispidés du Muséum d'Histoire naturelle de Genève. II. (Insecta, Planipennia). Revue Suisse de Zoologie, 89: 667-672.

Poivre, C., 1983. Morphologie externe comparee des Perlamantispa du sud de l'Europe. Perlamantispa perla (Pallas, 1772) et P. icterica (Pictet, 1865) (Planipennia, Mantispidae). Neuroptera International, 2(3): 129-143.

Poivre, C., 1984a. Les mantispides de 1'Institut Royal des sciences Naturelles de Belgique (Insecta, Planipennia). 1ère Partie: Especes d'Europe, d'Asie et D'Afrique. Neuroptera International, 3(1): 23-32.

Poivre, C., 1984b. Les Mantispidés du Muséum d'Histoire naturelle de Genève. III. (Insecta, Planipennia). Revue Suisse de Zoologie, 91: 635-646.

Poivre, C., 1985a. Mantispides du Cameroun III. Nouvelle description de Rectinerva braconidiformis (Planipennia, Mantispidae). Neuroptera International, 3(4): 195-200.

Poivre, C., 1985b. Les mantispides de 1'Institut Royal des sciences Naturelles de Belgique (Insecta, Planipennia). 2e Partie: Especes d'Océanie. Neuroptera International, 3(3): 127-132.

Poivre, C., 1986. Les mantispides de 1'Institut Royal des sciences Naturelles de Belgique (Insecta, Planipennia). 3e Partie: Especes d'America. Neuroptera International, 4(2): 85-95.

Poivre, C., 1991. Les mantispidés de l'Académie des Sciences de Californie (Insecta, Neuroptera). 1ère partie: genres Mantispa, Eumantispa et Sagittalata. Neuroptera International, 6(4): 207-212. 
Popov, A., 1973. Über die präimaginalen Stadien paläarktischer Vertreter der Ordnung Neuroptera und Versuch einer neuen systematischen Gruppierung der Familien mit Rücksicht auf ihre morphologischen und ökologischen Besonderheiten. Bulletin de l'Institut de Zoologie et Musée, Academie Bulgare des Sciences, Section de Biology, 37: 79-101.

Popov, A., 1993. Raphidiopteren und Neuropteren aus Bulgarien in den Sammlungen des Nationalmuseums in Prag. Historia naturalis bulgarica, 4: 16-28.

Poujade, G. A., 1898. Observation sur les moeurs de Mantispa styriaca Poda [Nevr.]. Bulletin de la Société Entomologique de France, 1898: 347.

Principi, M. M., 1943. La Nothochrysa italica Rossi ed i suoi singolari costumi (Neuroptera - Chrysopidae). Bollettino della Società Entomologica Italiana, 75: 117-118.

Principi, M. M., 1952. Ricerche zoologiche sul Massiccio del Pollino (Lucania-Calabria). VI. Neurotteri. Annuario dell'Istituto e Museo di Zoologia dell'Università di Napoli, 4(10):1-22.

Principi, M. M., 1966. Contributi allo studio dei Neurotteri Italiani. XVIII. Neurotteri della Basilicata, della Calabria e della Sicilia. Memorie del Museo Civico di Storia Naturale di Verona, 14:363-388.

Pröse, H. \& Gruppe, A., 2003. Rote Liste gefährdeter Netzflügler (Neuropteroidea) Bayerns. Beiträge zum Artenschutz, 166: 95-98.

Rambur, J. P., 1842. Histoire Naturelle des Insectes, Névroptères. Librairie encyclopédique de Roret. Fain et Thunot. Paris. [xviii] +534 pp.

Redborg, K. E., 1979. The developmental ecology of the Mantispidae (Neuroptera, Mantispidae). Ph.D. Dissertation. University of Illinois. Urbana. 183 pp. 20 figures. 30 tables.

Redborg, K. E., 1981. Mantispidae (Insecta: Neuroptera) parasitic on spider egg sacs: an update of a pioneering paper by B. J. Kaston. Journal of Arachnology, 10: 92-93.

Redborg, K. E., 1982. Interference by the mantispid Mantispa uhleri with the development of the spider Lycosa rabida. Ecological Entomology, 7: 187-196. http://dx. doi.org/10.1111/j.1365-2311.1982.tb00657.x.

Redborg, K. E., 1983. A mantispid larva can preserve its spider egg prey: evidence for an aggressive allomone. Oecologia, 58: 230-231. http://dx.doi.org/10.1007/BF00399222.

Redborg, K. E., 1985. Spider (Arachnida: Araneae) boarding following egg sac penetration by Mantispa uhleri Banks (Neuroptera: Planipennia) with comments on the evolution of phoresy on spiders in the Mantispidae. Neuroptera International, 3(4): 201-208.

Redborg, K. E., 1998. Biology of the Mantispidae. Annual Review of Entomology, 43: 175-194. http://dx.doi. org/10.1146/annurev.ento.43.1.175.

Redborg, K. E. \& Macleod, E. G., 1983. Climaciella brunnea (Neuroptera: Mantispidae): a mantispid that obligately boards spiders. Journal of Natural History, 17: 63-73. http://dx.doi.org/10.1080/00222938300770041.

Redborg, K. E.\& Macleod, E. G., 1984. Maintenance feeding of first instar mantispid larvae (Neuroptera, Mantispidae) on spider (Arachnida, Araneae) hemolymph. Journal of Arachnology, 11: 337-341.

Redborg, K. E. \& Macleod, E. G., 1985. The developmental ecology of Mantispa uhleri Banks (Neuroptera: Mantispidae). Illinois Biological Monographs, 53: 1-130.

Redborg, K. E. \& Redborg, A. H., 2000. Resource partitioning of spider hosts (Arachnida, Araneae) by two mantispid species (Neuroptera, Mantispidae) in an Illinois woodland. Journal of Arachnology, 28: 70-78. http:// dx.doi.org/10.1636/0161-8202(2000)028\%5B0070: RPOSHA\%5D2.0.CO;2.

Rehn, J. W. H., 1939a. Anisoptera Schneider a homonym (Neuroptera: Mantispidae). Entomological News, 50: 82.

Rehn, J. W. H., 1939b. Studies in North American Mantispidae. Transactions of the American Entomological Society, 65: 237-263.

Ren, D. \& Guo, Z.-G., 1996. On the new fossil genera and species of Neuroptera (Insecta) from the Late Jurassic of northeast China. Acta Zootaxonomica Sinica, 21: 461-480.

Reynoso-Velasco, D., 2007. Mantispidae (Insecta: Neuroptera) de México. In: E. Estrada, A. Equihua, C. Luna \& J. L. Rosas (eds.). Entomología Mexicana. Vol. 6. Sociedad Mexicana de Entomología A. C. Mexico: 1408-1412.

Reynoso-Velasco, D. \& Contreras-Ramos, A., 2008. Mantispidae (Neuroptera) of Mexico: distribution and key to genera. Annals of the Entomological Society of America, 101: 703-712. http://dx.doi.org/10.1603/ 0013-8746(2008)101\%5B703:MNOMDA\%5D2. $0 . \mathrm{CO} ; 2$.

Reynoso-Velasco, D. \& Contreras-Ramos, A., 2009. Mantispidae (Neuroptera) of Mexico's National University biological stations Chamela and Los Tuxtlas. Proceedings of the Entomological Society of Washington, 111: 708713. http://dx.doi.org/10.4289/0013-8797-111.3.708.

Reynoso-Velasco, D. \& Contreras-Ramos, A., 2010. Overview of the taxonomic and biological knowledge of Mexican Mantispidae (Insecta: Neuroptera). In: D. Devetak, S. Lipovšek \& A. E. Arnett (eds.). Proceedings of the 10th International Symposium on Neuropterology, 22-25 June 2008, Piran. University of Maribor. Maribor: 269-276.

Rice, M. E., 1985. Spiderling survival in a Mantispa (Neuroptera, Mantispidae) infested egg sac. Journal of Arachnology, 13: 139-140.

Rice, M. E., 1986. Communal oviposition by Mantispa fuscicornis (Say) [sic] (Neuroptera: Mantispidae) and subsequent larval parasitism on spiders (Arachnida: Araneida) in south Texas. Journal of the Kansas Entomological Society, 59: 121-126.

Rice, M. E., 1987. Morphological variation in Plega dactylota (Neuroptera: Mantispidae) and status of its subspecies. Journal of the Kansas Entomological Society, 60: 341-344.

Rice, M. E. \& Peck, W. B., 1991. Mantispa sayi (Neuroptera: Mantispidae) parasitism on spiders (Araneae) in Texas, with observations on oviposition and larval survivorship. Annals of the Entomological Society of America, 84: 52-57.

Richardson, M. W., 1976. Micropredators of spiders. Ph.D. dissertation. Southern Illinois University. Carbondale. $211 \mathrm{pp}$. 
Riek, E. F., 1967. Structures of unknown, possibly stridulatory, function of the wings and body of Neuroptera; with an appendix on other endopterygote orders. Australian Journal of Zoology, 15: 337-348.

Riek, E. F., 1970. Neuroptera (Lacewings). In: The insects of Australia. Melbourne University Press. Melbourne: 472-494.

Roble, S. M., 1986. A new spider host association for Mantispa viridis (Neuroptera, Mantispidae). Journal of Arachnology, 14: 135-136.

Rogenhofer, A., 1862a. Beitrag zur Kenntniss der Entwicklungsgeschichte von Mantispa styriaca Poda (pagana Fab.). Verhandlungen der Kaiserlich-Königlichen Zoologisch-Botanischen Gesellschaft in Wien, 12: 583-586 [613-616]

Rogenhofer, A., 1862b. Note on the life history of Mantispa styriaca. Bericht über die Versammlung Deutscher Naturforscher und Arzte, 37: 166-167.

Röhricht, W., 2002. Neuroptera.com. Neuropteren im Internet - nutzt das was? Galathea, Berichte des Kreises Nürnberger Entomologen e. $V$., Supplement 13: 31-36.

Scheffer, S., 1992. Transfer of a larval mantispid during copulation of its spider host. Journal of Insect Behavior, 5: 797-801. http://dx.doi.org/10.1007/BF01047988.

Schlüter, T., 1986. The fossil Planipennia - a review. In: J. Gepp, H. Aspöck \& H. Hölzel (eds.). Recent Research in Neuropterology (Proceedings of the 2nd International Symposium on Neuropterology, 21-23 August 1984, Hamburg). Graz: 103-111.

Schlüter, T. \& Stürmer, W., 1984. Die Identifikation einer fossilen Rhachiberothinae-Art (Planipennia: Berothidae oder Mantispidae) aus mittelkretazischem Bernstein NW-Frankreichs mit Hilfe röntgenographischen Methoden. In: J. Gepp, H. Aspöck \& H. Hölzel (eds.). Progress in World's Neuropterology (Proceedings of the 1st International Symposium on Neuropterology, 22-26 September 1980, Graz). Graz: 49-55.

Schrank, F. P., 1781. Enumeratio Insectorum Avstriae indigenorum. Klett \& Franck. Avgvstae Vindelicorvm. [xxii] $+548 \mathrm{pp}$.

Schremmer, F., 1959. Freilandbeobachtungen zur Eiablage von Mantispa pagana Fbr. (Neuroptera, Planipennia). Zeitschrift für Morphologie und Ökologie der Tiere, 48: 412-423.

Schremmer, F., 1983. Beitrag zur Entwicklungsgeschichte und zum Kokonbau von Mantispa styriaca. Zeitschrift der Arbeitsgemeinschaft Österreichischer Entomologen, 35: 21-26.

Scopoli, J. A., 1763. Entomologia Carniolica, exhibens insecta Carnioliae indigena et distributa in ordines, genera, species, varietates, methodo Linneana. Ioannis Thomae Trattner. Vindobonae. [38] + $418+$ [1] pp.

Séméria, Y., 1984. Contribution à une géonémie des Mantispidae de France (Neuroptera). III.- Observations nouvelles et mises au point. L'Entomologiste, 40(3): 125-126.

Séméria, Y., 1992. Conjonction morpho-chromatique entre Mantispa styriaca (Poda) (Neuroptera, Mantispidae) et les chatons floraux de Quercus ilex et Quercus suber (Fagacées). Contribution à l'étude des ressemblances problématiques dans les systèmes naturels. Neuroptera International, 7(1-2): 7-11.

Şengonca, Ç., 1980. Türkiye Mantispidae (Insecta: Neuroptera) faunasi üzerinde taksonomik arastirmalar. Tübitak VII. Bilim kongresi, TBAG Biyoloji Seksiyonu, 6-10 Ekim 1980, Kusadasi-Aydin. Tübitak yayinlari No. 545. Ankara: 457-473.

Shi, C., Ohl, M., Wunderlich, J. \& Ren, D., 2014. A remarkable new genus of Mantispidae (Insecta, Neuroptera) from Cretaceous amber of Myanmar and its implications on raptorial foreleg evolution in Mantispidae. Cretaceous Research, publicado online 5 Junio 2014. http://dx.doi.org/10.1016/j.cretres.2014.04.003.

Smith, F., 1863. Descriptions of Brazilian honey bees belonging to the genera Melipona and Trigona, which were exhibited, together with samples of their honey and wax, in the Brazilian court of the international exhibition of 1862. Transactions of the Royal Entomological Society of London, 11(6): 497-512. http://dx.doi. org/10.1111/j.1365-2311.1863.tb01298.x.

Smith, R. C., 1934. Notes on the Neuroptera and Mecoptera of Kansas, with keys for the identification of species. Journal of the Kansas Entomological Society, 7: 120-145.

Snyman, L. P., Ohl, M., Mansell, M. W. \& Scholtz, C. H., 2012. A revision and key to the genera of Afrotropical Mantispidae (Neuropterida, Neuroptera), with the description of a new genus. ZooKeys, 184: 67-93. http:// dx.doi.org/10.3897/zookeys.184.2489.

Stange, L. A. \& Wang, H.-Y. 1998. Guide book to insects in Taiwan. 18. Neuroptera, Megaloptera, Raphidioptera. Hsu Hsin Books. Taipei. viii +278 pp.

Stitz, H., 1913. Mantispiden der Sammlung des Berliner Museums. Mitteilungen aus dem Zoologischen Museum in Berlin, 7: 1-49.

Stitz, H., 1931. Planipennia. In: P. Schultze (ed.). Biologie der Tiere Deutschlands. Lfg. 33, Teil 35. Borntraeger. Berlin: 67-304.

Tauber, C. A., 1991. Order Neuroptera. In: F. W. Stehr (ed.). Immature insects. Vol. 2. Kendall/Hunt. Dubuque: 126-143.

Tauber, C. A. \& Tauber, M. J., 1968. Lomamyia latipennis (Neuroptera, Berothidae) life history and larval descriptions. Canadian Entomologist, 100: 623-629.

Tillyard, R. J., 1925. Odonata, Neuroptera and Trichoptera from Groote Eylandt, Gulf of Carpentaria. Records of the South Australian Museum, 3: 41-44.

Tillyard, R. J., 1926. The Insects of Australia and New Zealand. Angus and Robertson. Sydney. xi +560 pp.

Tjeder, B., 1954. Genital structures and terminology in the order Neuroptera. Entomologiske Meddelelser, 27: 23-40.

Tjeder, B., 1956. Neuroptera. In: S. L. [P.] Tuxen (ed.). Taxonomist's glossary of genitalia in insects. Munksgaard. Copenhagen: 76-83.

Tjeder, B., 1959. Neuroptera-Planipennia. The Lace-wings of Southern Africa. 2. Family Berothidae. In: B. Hanström, P. Brinck \& G. Rudebec (eds.). South African Animal Life, 6. Swedish Natural Science Research Council. Stockholm: 256-314.

Tjeder, B., 1963. A new Necyla from Uganda (Neur. Mantispidae). Opuscula Entomologica, 28: 121-126. 
Tjeder, B., 1968. The genus Mucroberotha Tjed. and its systematic position (Neuroptera). Entomologisk Tidskrift, 89: 3-18.

Tjeder, B., 1970. Neuroptera. In: S. L. [P.] Tuxen (ed.). Taxonomist's glossary of genitalia in insects, 2nd edition. Munksgaard. Copenhagen: 89-99.

Tjönneland, A., 1962. Observations on nocturnal activity in a species of Mantispidae (Neuroptera). Contributions from the Faculty of Science, University College of Addis Ababa, Series C (Zoology), 3: 1-5.

Tolbert, W. W., 1976. Population dynamics of the orb weaving spiders Argiope trifasciata and Argiope aurantia (Araneae, Araneidae): density changes associated with mortality, natality and migrations. Ph.D. Dissertation. University of Tennessee. Knoxville. 186 pp.

Tuxen, S. L. P., 1970. Taxonomist's glossary of genitalia in insects. 2nd Edition. Munksgaard. Copenhagen. $359 \mathrm{pp}$.

Ulrich, H., 1965. Der Fang- und Greifapparat von Mantispa - ein Vergleich mit Mantis. Natur und Museum, 95: 499-508.

Valerio, C. E., 1971. Parasitismo en huevos de araña Archaearanea tepidariorum (Koch) (Aranea: Theridiidae) en Costa Rica. Revista de Biología Tropical, 18: 99-106.

Viets, D., 1941. A biological note on the Mantispidae (Neuroptera). Journal of the Kansas Entomological Society, 14: 70-71.

Weber, N. A., 1942. A neuropterous myrmecophile, Nadiva valida Erichs. Psyche, 49: 1-3.

Wedmann, S. \& Makarkin, V. N., 2007. A new genus of Mantispidae (Insecta: Neuroptera) from the Eocene of Germany, with a review of the fossil record and palaeobiogeography of the family. Zoological Journal of the Linnean Society, 149: 701-716. http://dx.doi. org/10.1111/j.1096-3642.2007.00273.x.

Werner, F. G., 1962. [abstract] 189. Bulletin of the Entomological Society of America, 8: 161.

Werner, F. G. \& Butler, G. D., 1965. Some notes on the life history of Plega banksi (Neuroptera: Mantispidae). Annals of the Entomological Society of America, 58: 66-68.

Westwood, J. O., 1852. On the genus Mantispa, with descriptions of various new species. Transactions of the Royal Entomological Society of London, 6: 252-270. http://dx.doi.org/10.1111/j.1365-2311.1852.tb02505.x.

Westwood, J. O., 1867. Descriptions of new species of Mantispidae in the Oxford and British Museums. Transactions of the Royal Entomological Society of London, 15: 501-508.

Whalley, P. E. S., 1980. Neuroptera (Insecta) in amber from the Lower Cretaceous of Lebanon. Bulletin of the British Museum of Natural History, Geology, 33:157-164.
Whalley, P. E. S., 1983. Fera venatrix gen. and sp. n. (Mantispidae) from amber in Britain. Neuroptera International, 2(4): 229-233.

White, A. D., 1841. Description of a South American wasp which collects honey. Annals and Magazine of Natural History, (1), 7: 315-322. http://dx.doi. org/10.1080/03745484109442703.

White, A. D., 1861. Notes on the development of a Mantispa. Transactions of the Royal Entomological Society of London, (N.S.), 5: 29.

Willmann, R., 1990. The phylogenetic position of the Rhachiberothinae and the basal sister-group relationships within the Mantispidae (Neuroptera). Systematic Entomology, 15: 253-265. http://dx.doi. org/10.1111/j.1365-3113.1994.tb00587.x.

Willmann, R., 1994. Die phylogenetische Position ursprünglicher Mantispidae (Insecta, Planipennia) aus dem Mesozoikum und Alt-Tertiär. Verhandlungen des Naturwissenschaftlichen Vereins in Hamburg (N.F.), 34: 177-203.

Winterton, S. L., Hardy, N. B. \& Wiegmann, B. M., 2010. On wings of lace: phylogeny and Bayesian divergence time estimates of Neuropterida (Insecta) based on morphological and molecular data. Systematic Entomology, 35: 349-378. http://dx.doi. org/10.1111/j.1365-3113.2010.00521.x.

Withycombe, C. L., 1925. Some aspects of the biology and morphology of the Neuroptera. With special reference to the immature stages and their possible phylogenetic significance. Transactions of the Royal Entomological Society of London, [1924], 72: 303-411. http://dx.doi. org/10.1111/j.1365-2311.1925.tb03362.x.

Woglum, R. S., 1935. Symphrasis signata Hagen. PanPacific Entomologist, 11: 119.

Woglum, R. S. \& Lewis, H. C., 1935. Notes on citrus pests new or seldom injurious in California. Journal of Economic Entomology, 28: 1018-1021.

Yang, C.-K., 1999. [Mantispidae.] In: B.-K. Huang (ed.). Fauna of Insects Fujian Province of China. Vol. 3. Fujian Science and Technology Press. Fuzhou: 132-140, 163-164 (en chino).

Yang, C.-K. \& Peng, Y.-Z., 1998. [A new species of genus Sagittalata from Mt. Funiu (Neuroptera: Mantispidae). In: X.-c. Sheng (chief ed.). Fauna and taxonomy of insects in Henan. Vol. 2. Insects of Funiushan. China Agricultural Science and Technology Press. Beijing: 62-63.

Zakharenko, A. V., 1987. [Neuroptera of the Fauna of the USSR. I. Family Mantispidae.] Entomologicheskoe Obozrenie, 66: 621-626, 678 (abstract) (en ruso).

Zelený, J., 2005. Neuroptera (Lacewings). In: J. Farkač, D. Králd \& M. Škopik (eds.). Red list of threatened species in the Czech Republic. Invertebrates. Agentura ochrany př́rody a krajiny ČR. Praha: 163-165. 